\title{
WestVirginiaUniversity
}

THE RESEARCH REPOSITORY @ WVU

Graduate Theses, Dissertations, and Problem Reports

2001

\section{Photoluminescence study of cadmium zinc telluride}

Swati Jain

West Virginia University

Follow this and additional works at: https://researchrepository.wvu.edu/etd

\section{Recommended Citation}

Jain, Swati, "Photoluminescence study of cadmium zinc telluride" (2001). Graduate Theses, Dissertations, and Problem Reports. 1252.

https://researchrepository.wvu.edu/etd/1252

This Thesis is protected by copyright and/or related rights. It has been brought to you by the The Research Repository @ WVU with permission from the rights-holder(s). You are free to use this Thesis in any way that is permitted by the copyright and related rights legislation that applies to your use. For other uses you must obtain permission from the rights-holder(s) directly, unless additional rights are indicated by a Creative Commons license in the record and/ or on the work itself. This Thesis has been accepted for inclusion in WVU Graduate Theses, Dissertations, and Problem Reports collection by an authorized administrator of The Research Repository @ WVU. For more information, please contact researchrepository@mail.wvu.edu. 


\author{
Swati Jain \\ Thesis submitted to the \\ Eberly College of Arts and Sciences \\ at West Virginia University \\ in partial fulfillment of the requirements \\ for the degree of \\ Master of Science \\ in \\ Physics
}

Nancy C. Giles, Ph.D., Chair

Larry E. Halliburton, Ph.D.

Mohindar S. Seehra, Ph.D.

Department of Physics

Morgantown, West Virginia

2001

Keywords: Photoluminescence, PL, CdZnTe, CZT, Cd ${ }_{1-x} Z_{x}$ Te 


\section{ABSTRACT \\ PHOTOLUMINESCENCE STUDY OF CADMIUM ZINC TELLURIDE SWATI JAIN}

In this thesis, I present a detailed study of $\mathrm{Cd}_{1-\mathrm{x}} \mathrm{Zn}_{\mathrm{x}} \mathrm{Te}$ crystals with $0 \leq \mathrm{x} \leq 0.14$ using photoluminescence (PL) spectroscopy. This thesis describes in particular several of the experiments performed during the course of my study with the purpose of: 1) identifying various radiative transitions that are signatures of various point defects in bulk CdZnTe (CZT) crystals, 2) determining the zinc concentration in these crystals, and 3) identifying the nature of room-temperature PL.

I took PL spectra at liquid helium temperatures for various doped and undoped CdZnTe crystals and obtained the free exciton energy and hence their bandgaps at low temperatures. Then I used the various expressions proposed in the literature to evaluate the zinc concentrations. I have performed a detailed PL study on eleven different samples having different zinc concentrations, doped and undoped, as a function of temperature to verify the origin of the room-temperature PL from CZT grown for radiation detector/IR substrate applications. The PL measurements were made in the temperature range from $5 \mathrm{~K}$ to $300 \mathrm{~K}$. The current trend in the bulk CZT growth produces material that can be slightly n-type (it is desirable to have high resistivity, or highly compensated material). In the current state-of-theart CZT grown for radiation detectors, it is common to observe 5-K PL spectra dominated by donor-bound exciton emission $\left(\mathrm{D}^{0}, \mathrm{X}\right)$. Also, a deep acceptor-bound exciton $\left(\mathrm{A}^{0}, \mathrm{X}\right)$ related to a complex associated with Cd vacancies is usually detected. Thus, it was of interest to perform a study and determine whether the "new" trend in bulk CZT growth would produce a different conclusion about the origin of the $300-\mathrm{K}$ PL. 


\section{ACKNOWLEDGEMENTS}

I would like to express my heartfelt thanks and profound gratitude to Dr. Nancy C. Giles, my advisor, for not just giving me the opportunity to work with her on various projects but introducing me to this exciting field of Photoluminescence Spectroscopy. I am indebted to her for giving me so much of her time and educating me in various aspects of lab and its operation whether it is regarding knowledge of equipment, their safety or operating them. Her willingness to help with anything at any time is greatly appreciated. Under her kind guidance, invaluable support, patience, keen interest, contributions and stimulating insight throughout the course of this study, I was able to complete this work and learned to become a better experimentalist and physicist.

I am grateful to Dr. Larry Halliburton for his kindness, patience, inspired suggestions, and encouragement over the past two years of my graduate studies in the department and in the lab and for serving on my committee.

I am thankful to Dr. Mohindar S. Seehra for his invaluable and stimulating lectures on various aspects of theoretical and experimental Solid State Physics throughout the course of this study and for being my guardian away from home. I also thank him for serving on my committee.

I am thankful to the technical staff: Carl Weber, Doug Mathess, Tom Milam, and Chuck Sicina for their help in fixing and making equipment whenever needed. I would also like to thank all members of the department, faculty and staff, especially Sherry Puskar and Siobhan Byrne for helping me with the administrative details. 
Special thanks are extended to my friends and colleagues especially Madalina, Lijun, Lihua, Nelson and Hong Wei for their assistance in the lab; it was fun to learn Chinese and Romanian with Physics.

Finally I am deeply indebted to my parents and brother for their support, wishes and constant encouragement from far away.

The U.S. Department of Energy supported this research through Grant DE-FG0298ER45716. 


\section{TABLE OF CONTENTS}

PAGE

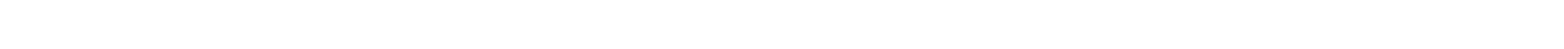

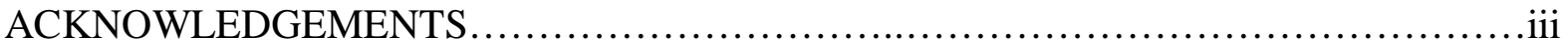

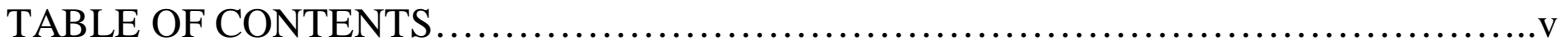

LIST OF FIGURES ......................................................................

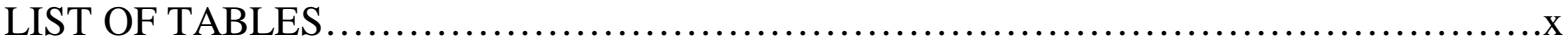

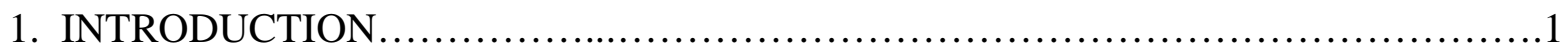

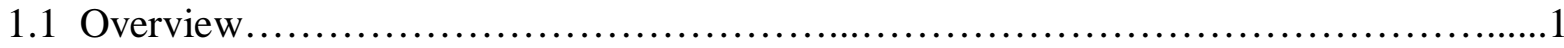

1.2 Motivation/Potential Applications of Cadmium Zinc Telluride...........................3

1.3 Usefulness of Photoluminescence Spectroscopy in the Study of CdZnTe .................6

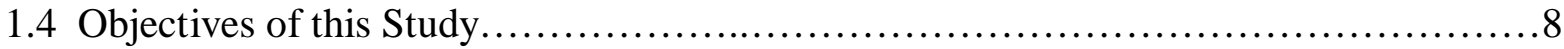

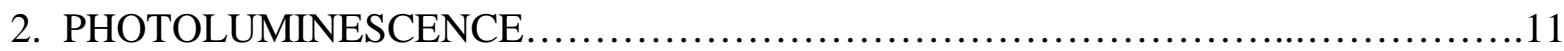

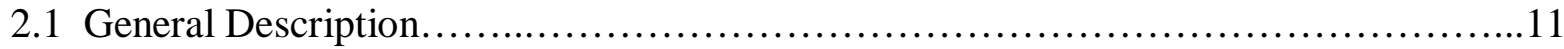

2.2 Radiative Transitions in $\mathrm{Cd}_{1-\mathrm{x}} \mathrm{Zn}_{\mathrm{x}} \mathrm{Te}$ Bulk Crystals................................. 14

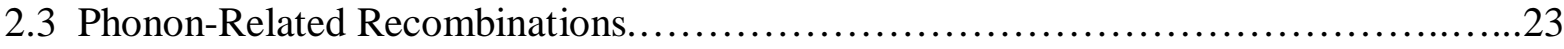

2.4 Method to Determine Free-Exciton Emission Line....................................25

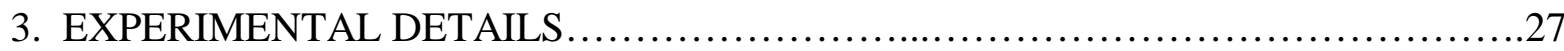

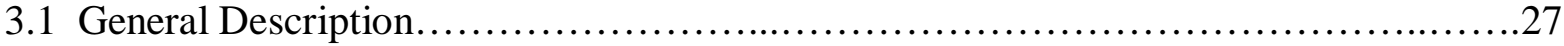

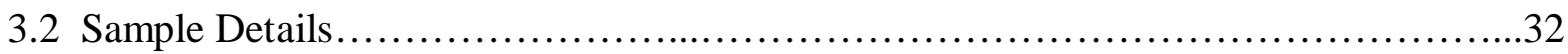

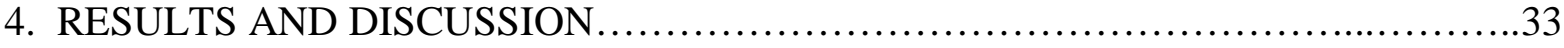

4.1 Low-Temperature PL Studies of Bulk $\mathrm{Cd}_{1-\mathrm{x}} \mathrm{Zn}_{\mathrm{x}} \mathrm{Te}(0 \leq \mathrm{x} \leq 0.14) \ldots \ldots \ldots \ldots \ldots \ldots \ldots . . . \ldots \ldots 33$ 
4.1.1 Identification of Recombination Channels from Band-Edge Emission Spectra........34

4.1.2 $\mathrm{Cd}_{1-\mathrm{x}} \mathrm{Zn}_{\mathrm{x}} \mathrm{Te}$ : Determination of Zinc Molar Concentration using PL at $4.5 \mathrm{~K} \ldots \ldots \ldots \ldots 40$

4.2 Temperature-Dependent PL Studies of $\mathrm{Cd}_{1-\mathrm{x}} \mathrm{Zn}_{\mathrm{x}} \mathrm{Te}(0 \leq \mathrm{x} \leq 0.14) \ldots \ldots \ldots \ldots \ldots \ldots \ldots . . .42$

4.2.1 Study of the PL Signal as a Function of Sample Temperature.......................42

4.2.2 Study of the Variation of Energy Band Gap with Temperature.......................55

4.3 Room-Temperature PL Studies of $\mathrm{Cd}_{1-\mathrm{x}} \mathrm{Zn}_{\mathrm{x}} \mathrm{Te}$ Bulk Crystals......................57

5. PHOTOLUMINESCENCE FROM INDIUM-DOPED CdTe.........................61

5.1 Photoluminescence Studies at Liquid-Helium Temperatures......................63

5.2 Temperature-Dependent Photoluminescence Studies.............................68

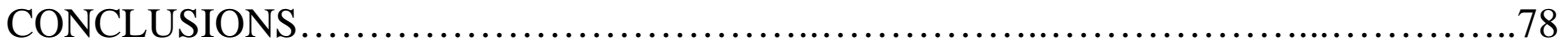

REFERENCES.............................................................. 79

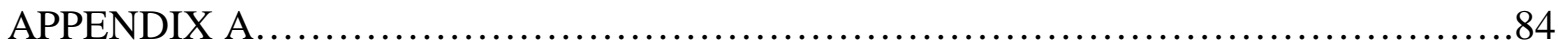




\section{LIST OF FIGURES}

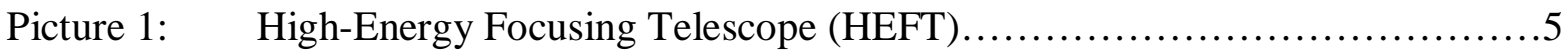

Picture 2: $\quad$ XR-100T-CZT (x-ray and gamma-ray detector, preamplifier, and cooler

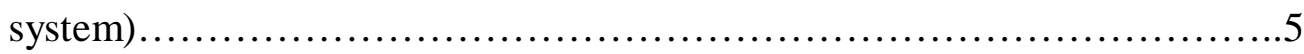

Picture 3: X-ray fluorescence analysis on the "Portland" vase from Pompeii at the

National Museum of Naples, Italy .....................................5

Figure 2.1: Energy level diagram showing various radiative transitions in

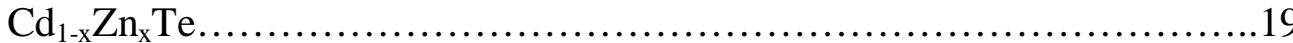

Figure 2.2: The change of the relative intensities in the different electronic-

vibrational lines with the strength of coupling, S........................24

Figure 2.3: Shifts of zero-, first-, and second-order LO phonon replica emission

lines for free exciton away from absorption lines........................26

Figure 3.1: Schematic diagram of the Photoluminescence setup.......................28

Figure 3.2: The Janis Research Products SuperVariTemp Optical Dewar................30

Figure 4.1: A representative PL spectrum of detector-grade $\mathrm{Cd}_{0.95} \mathrm{Zn}_{0.05} \mathrm{Te}$ at $4.5 \mathrm{~K} \ldots \ldots .33$

Figure 4.2.a: PL from HPB-grown CdZnTe at liquid helium temperature plotted on a

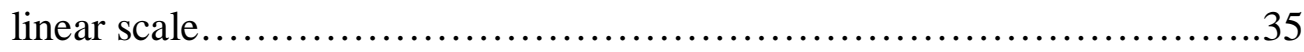

Figure 4.2.b: PL from HPB-grown CdZnTe at liquid helium temperature plotted on a logarithmic scale .36

Figure 4.3: A comparison of PL spectra from three bulk and unintentionally doped

CZT samples with different zinc concentrations, showing that higher zinc concentration shifts the spectrum to higher energies....................37 
Figure 4.4: Comparison of relative intensities of PL bands from six samples with

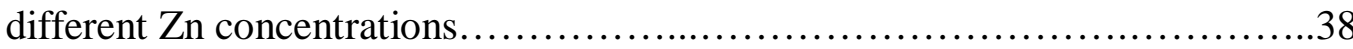

Figure 4.5: Temperature-dependence plot from $5 \mathrm{~K}$ to $15 \mathrm{~K}$ for $\mathrm{Cd}_{0.97} \mathrm{Zn}_{0.03} \mathrm{Te} . \ldots \ldots \ldots . .45$

Figure 4.6: Temperature-dependence plot from $20 \mathrm{~K}$ to $55 \mathrm{~K}$ for $\mathrm{Cd}_{0.97} \mathrm{Zn}_{0.03} \mathrm{Te} \ldots \ldots . . . .46$

Figure 4.7: Temperature-dependence plot from $65 \mathrm{~K}$ to $150 \mathrm{~K}$ for $\mathrm{Cd}_{0.97} \mathrm{Zn}_{0.03} \mathrm{Te} \ldots \ldots \ldots \ldots . .47$

Figure 4.8: Temperature-dependence plot from $175 \mathrm{~K}$ to $300 \mathrm{~K}$ for $\mathrm{Cd}_{0.97} \mathrm{Zn}_{0.03} \mathrm{Te} . \ldots . . . . .48$

Figure 4.9.a: Temperature-dependence of PL from $65 \mathrm{~K}$ to $150 \mathrm{~K}$ from bulk

$$
\mathrm{Cd}_{0.95} \mathrm{Zn}_{0.05} \mathrm{Te}
$$

Figure 4.9.b: Comparison of PL at $50 \mathrm{~K}$ and $125 \mathrm{~K}$ from bulk $\mathrm{Cd}_{0.89} \mathrm{Zn}_{0.11} \mathrm{Te}$ 49

Figure 4.10: Temperature-dependence plot from $5 \mathrm{~K}$ to $35 \mathrm{~K}$ from bulk CdTe.............50

Figure 4.11: Temperature-dependence plot from $40 \mathrm{~K}$ to $95 \mathrm{~K}$ from bulk CdTe.............51

Figure 4.12: Temperature-dependence plot from $105 \mathrm{~K}$ to $185 \mathrm{~K}$ from bulk CdTe ..........52

Figure 4.13: Temperature-dependence plot from $4.5 \mathrm{~K}$ to $90 \mathrm{~K}$ from $\mathrm{Cd}_{0.92} \mathrm{Zn}_{0.08} \mathrm{Te}$

sample.

Figure 4.14: Temperature-dependence plot from 120 to $300 \mathrm{~K}$ from $\mathrm{Cd}_{0.92} \mathrm{Zn}_{0.08} \mathrm{Te}$. .54

Figure 4.15.a: Longitudinal component of polariton ( free exciton energy) as a function of temperature in bulk undoped CZT $\ldots \ldots \ldots \ldots \ldots \ldots \ldots \ldots \ldots \ldots \ldots . \ldots \ldots$

Figure 4.15.b: Position of $\mathrm{X}_{\mathrm{L}}(\mathrm{eV})$ as a function of temperature for a bulk CZT sample.....57

Figure 4.16: Room-temperature spectrum from three different CZT samples..............58

Figure 5.1: PL spectrum for CdTe:In at $4.5 \mathrm{~K}$ using $514 \mathrm{~nm}$ source, power $5 \mathrm{~mW}, 200$ micron slits

Figure 5.2: Comparison of PL spectra of CdTe (undoped) and CdTe:In (doped) at $4.5 \mathrm{~K}$ showing phonon replicas .66 
Figure 5.3: PL Spectra of bulk undoped CdTe and bulk doped CdTe:In at $4.5 \mathrm{~K}$, comparing donor features..........................................67

Figure 5.4.a: Plot showing thermal quenching of the $\mathrm{W}$ line in CdTe:In using $514 \mathrm{~nm}, 5 \mathrm{~mW}$ power, 200 micron slits

Figure 5.4.b: Temperature dependence spectra taken for CdTe:In using $514 \mathrm{~nm}, 5 \mathrm{~mW}$ power, 200 micron slits, showing the thermal quenching of $\mathrm{W}$-line in the range $45 \mathrm{~K}-125 \mathrm{~K}$ .70

Figure 5.4.c: Temperature dependence data showing PL spectra of undoped CdTe as

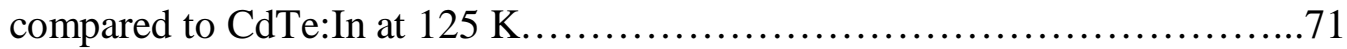

Figure 5.5: Plot showing intensity of $1.584 \mathrm{eV}$ line in bulk CdTe:In vs. 1/T..............72

Figure 5.6: Plot showing intensity of $1.580 \mathrm{eV}$ line in bulk CdTe:In vs. 1/T..............76

Figure 5.7: Plot showing FWHM of $1.584 \mathrm{eV}$ line in bulk CdTe:In vs. Temp..............77 


\section{LIST OF TABLES}

Table 2.1: $\quad$ PL energies of bound exciton recombination for donor and acceptor

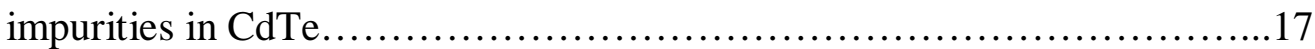

Table 4.1: Comparison of the measured zinc concentration in 10 different CZT samples cut from the same boule using the expressions proposed

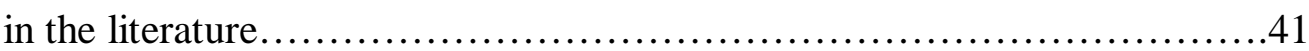

Table 4.2: $\quad$ Sample arranged in the order of first-to-freeze to last-to-freeze according to their known zinc concentrations.......................................42

Table 4.3: $\quad$ Positions of the broad PL emission below the predicted band gap at $300-\mathrm{K}$ for various samples.....................................6 60 


\section{CHAPTER 1}

\section{INTRODUCTION}

\subsection{Overview}

The ternary II-VI compound cadmium zinc telluride $\left(\mathbf{C d}_{1-\mathbf{x}} \mathbf{Z n}_{\mathbf{x}} \mathbf{T e}\right.$ or $\left.\mathbf{C Z T}\right)$ has been used as a substrate material for infrared applications for many years. Crystals of mercury cadmium telluride (HgCdTe or MCT) are used in infrared devices to detect, or sense, the thermal radiation from objects and produce visible signals or images. The effectiveness of MCT as an infrared detector depends on its orderly, crystalline structure. Manufacturers try to avoid defects in MCT crystals by solidifying the material under very controlled conditions. One method for controlling the growth of the crystal is to solidify MCT on top of another material that has a similarly ordered atomic structure. This base material is called a substrate. For $\mathrm{Hg}_{1-\mathrm{y}} \mathrm{Cd}_{\mathrm{y}} \mathrm{Te}, \mathrm{Cd}_{1-\mathrm{x}} \mathrm{Zn}_{\mathrm{x}} \mathrm{Te}$ is the "substrate of choice" among scientists and many commercial producers. CZT serves as a stabilizing influence as the MCT crystal layer forms because, during growth, the atoms between the active detector and substrate join together with a tight, interlocking match between the two lattices. This match between the two lattices reduces stress on the active detector as it grows. To achieve nominal lattice match between the materials and minimize defects due to misfit dislocation, $4.4 \%$ of zinc content is needed for $\mathrm{Hg}_{1-\mathrm{y}} \mathrm{Cd}_{\mathrm{y}} \mathrm{Te}(\mathrm{y}=0.2)$ and $4.1 \%$ for $\mathrm{y}=0.3$ (Kennedy 1988; Murphy 1986). $\mathrm{This}^{\mathrm{Hg}_{1-\mathrm{y}} \mathrm{Cd}_{\mathrm{y}} \mathrm{Te}}$ $/ \mathrm{Cd}_{1-\mathrm{x}} \mathrm{Zn}_{\mathrm{x}} \mathrm{Te}$ two-layered material can be placed in the device so that only the substrate is exposed to the air, with the $\mathrm{Hg}_{1-\mathrm{y}} \mathrm{Cd}_{\mathrm{y}} \mathrm{Te}$ crystal sealed in an inert gas or a vacuum within the device. Because $\mathrm{Cd}_{1-\mathrm{x}} \mathrm{Zn}_{\mathrm{x}} \mathrm{Te}$ is transparent to thermal radiation, it does not interfere with the transmission of heat signals to the active detector. Cadmium zinc telluride substrates are also used as a base material for the development of focal plane arrays required for the guidance 
system of anti-tank missiles (e.g. Nag, a third-generation "fire and forget" anti-tank guided missile with a range of 4 to 6 kilometers, uses Imaging Infra-Red (IIR) guidance having both day and night capability).

During the last decade, $\mathrm{Cd}_{1-\mathrm{x}} \mathrm{Zn}_{\mathrm{x}} \mathrm{Te}$ crystals with $0.05<\mathrm{x}<0.4$ have received a growing interest in the field of room-temperature $\mathrm{x}$-ray and gamma ray detectors (Doty et al. 1992, Butler 1992). Radiation may be broadly divided into two categories: uncharged radiations, which include x-rays, gamma rays and neutrons; and charged radiations, including beta particles (electrons and positrons), protons, alpha particles, and fission fragments. Gamma rays are emitted when an excited nucleus relaxes to a lower energy state or from the annihilation of electrons and positrons and x-rays are produced when fast electrons transfer their kinetic energy to photons through their interaction with the medium in which they are moving. Energies of x-ray photons are typically in the range of $1 \mathrm{keV}$ to about $100 \mathrm{keV}$, while gamma photon energy range from about $100 \mathrm{keV}$ to $10 \mathrm{MeV}$. Gamma ray emissions can serve as a signature for cancer tumors, valuable mineral deposits and radioactive waste. But until recently, detecting the rays required bulky and ultra-expensive cryogenically cooled systems. CZT emits a tiny electronic signal when hit by gamma rays. CZT detectors are already standing guard over dismantled atomic weapons and cancer detection applications could be next.

$\mathrm{Cd}_{1-\mathrm{x}} \mathrm{Zn}_{\mathrm{x}} \mathrm{Te}$ has a direct energy gap for all alloy compositions and is tunable from 1.5 to $2.3 \mathrm{eV}$ at room temperature, for $\mathrm{x}=0$ and $\mathrm{x}=1$ respectively (Olego 1985; Oettinger 1992). It possesses many of the physical properties required for detector operation, such as high atomic number $(Z)$ for efficient radiation-atomic interactions, large enough band gap for high bulk resistivity required to maintain low noise associated with leakage current in the detector, 
a large cross-section for the photoelectric absorption of gamma rays necessary for efficient conversion of the gamma-ray energy to electrical energy, high intrinsic mobility-lifetime $(\mu \tau)$ product, and reduced electronic noise.

For fabricating detectors having good charge collecting efficiency and ability to stop a large fraction of incident photons, high purity, homogeneous, defect-free material with acceptable cross-sectional area and thickness is required. Unlike silicon or gallium arsenide, it is very difficult to grow large size single crystals of CZT due to some of its inherent properties. It has the lowest thermal conductivity among all semiconductors that makes it difficult to obtain planar solid-liquid interface, which is desirable for single crystal growth. Due to its high ionicity and weak bonding, defects are easily incorporated during growth. The technology for growing device quality CZT crystals was established by developing a novel growth technique, designated as the asymmetrical Bridgman method (Zanio 1978). In this method the solid-liquid interface can be made planar during growth which helps in growing crystals of CZT with low dislocation density. With this technique, crystals up to 55-mm diameter have been successfully grown with room-temperature resistivities as high as $10^{11} \Omega$ cm. Sen et al. (1988) reported 5-cm diameter crystals of CZT in a computer controlled vertical Bridgman furnace. Other vertical Bridgman crystals were grown by Bruder et al. (Bruder 1993).

\subsection{Motivation/Potential Applications of Cadmium Zinc Telluride}

$\mathrm{Cd}_{1-\mathrm{x}} \mathrm{Zn}_{\mathrm{x}} \mathrm{Te}$ has been used in solid state devices such as solar cells, photo detectors and light emitting diodes for many years. In recent years, however, the technology of CZT detector arrays for direct detection and imaging of x-rays and gamma rays at room 
temperature has matured to the point that it is poised to impact areas far beyond those associated with basic scientific applications. A few applications are listed below.

- In nuclear medicine applications, associated with imaging techniques such as $\mathrm{x}$-ray or gamma-ray tomography, x-ray fluorescence, simultaneous dual energy radiography, i.e. to simultaneously measure the $\mathrm{x}$-ray tube peak potential $(\mathrm{kVp})$, and characterize the mammographic X-ray tube spectrum [also the technology that went to Mars on the Pathfinder Mission, www.amptek.com/medical.html];

- in national security applications, associated primarily with locating, monitoring, or identifying radioactive materials like nuclear weapons surveillance and nuclear plant monitoring for environmental remediation and safety;

- in space sciences applications such as, in the High-Energy Focusing Telescope (HEFT). HEFT (Picture 1) is a balloon-borne experiment that will use depth-graded multi-layer optics and Cadmium Zinc Telluride pixel detectors to image astrophysical sources in the hard X-ray (20-100 keV) band. Single element CZT detectors have recently been proposed in NASA's Burst Arc-Second Imager and Spectrometer (BASIS) for a next generation orbiting high-energy gamma-ray telescope and the Next Generation X-Ray Observatory (NGXO) [http://ngst.gsfc.nasa.gov]. CZT strip detectors have excellent spatial resolution (less than 100 microns), an array of more than 500,000 detectors is being built for pin-pointing the source of high energy gamma ray bursts in the galaxy. [Laboratory for Astronomy and Solar Physics; Collaboration: eV Products/II-VI Corporation, Digirad, University of Arizona, Fisk University];

- CZT detectors are being used for examination of art objects in museums and archaeological sites, e.g. commercially available XR-100T-CZT (a new high performance 


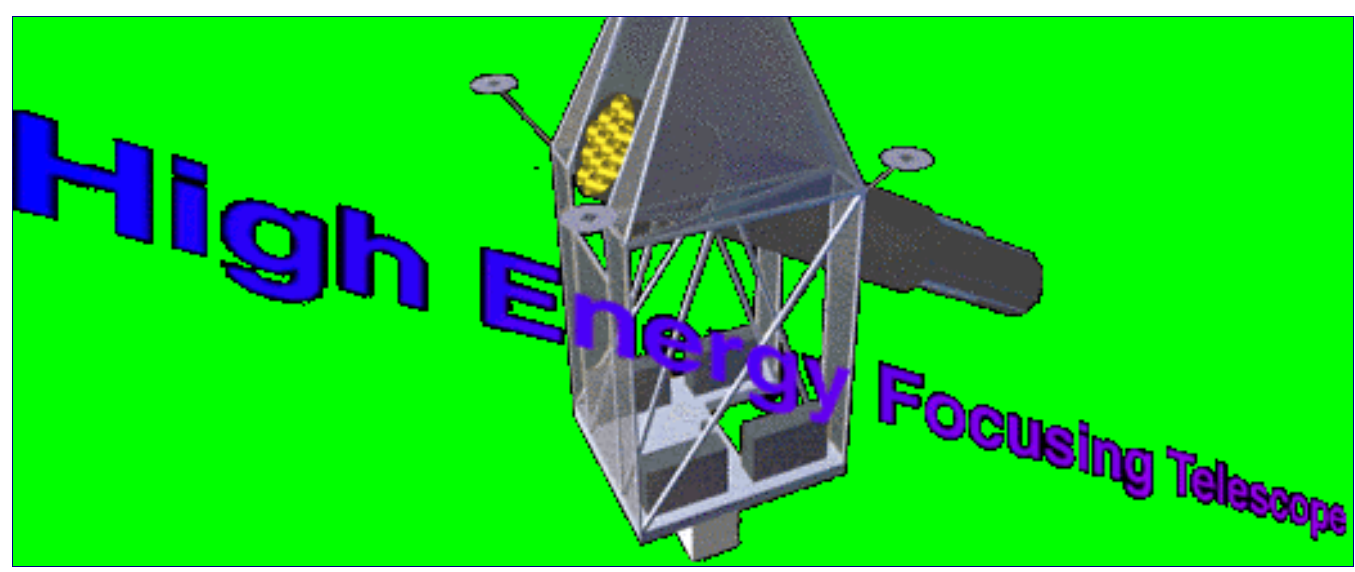

Picture 1

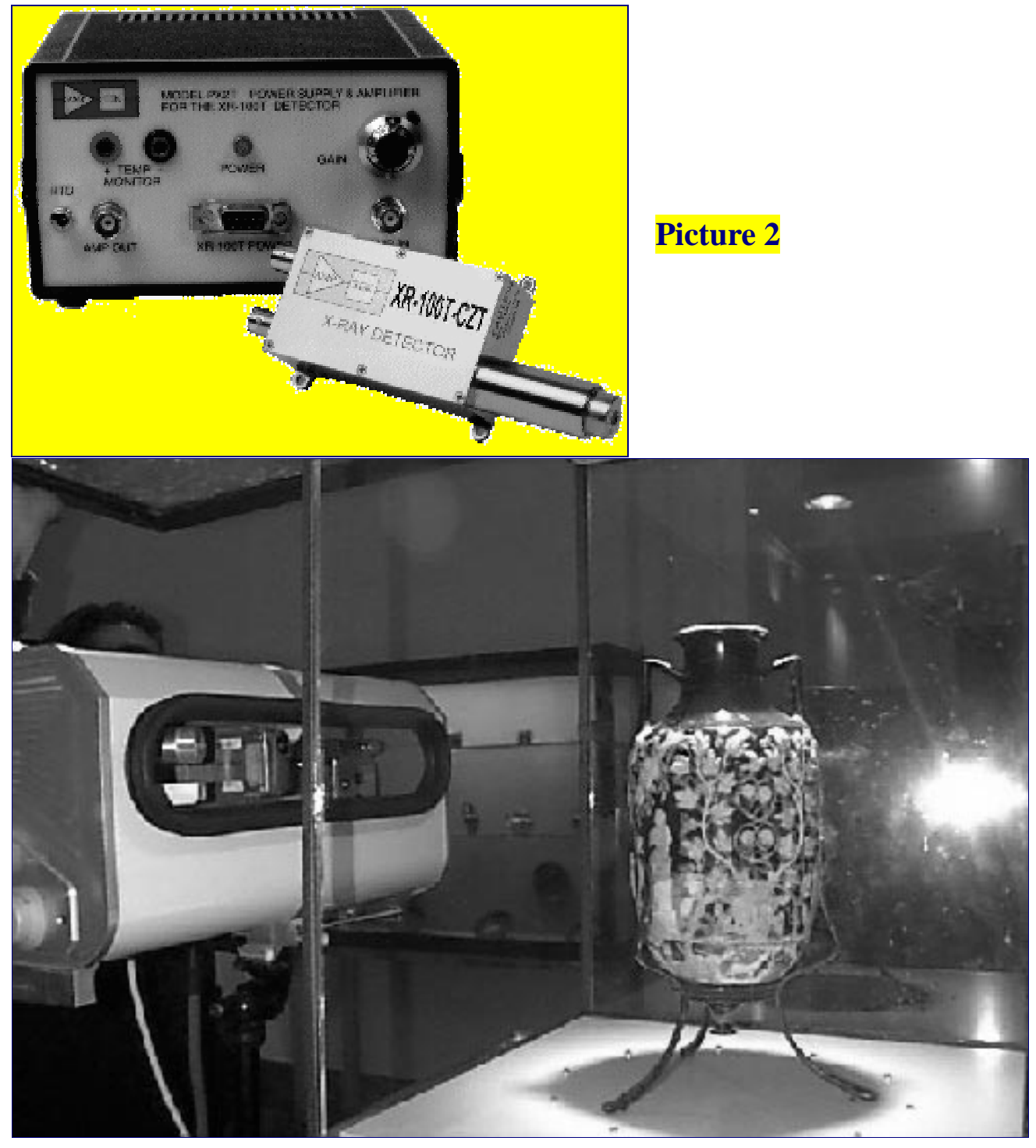

Picture 3 
X-ray and gamma-ray detector, preamplifier, and cooler system, Picture 2) is shown

performing in-situ nondestructive X-ray fluorescence analysis on the "Portland" vase from Pompeii at the National Museum of Naples, Italy (Picture 3).

\subsection{Usefulness of Photoluminescence Spectroscopy in the Study of $\mathrm{Cd}_{1-\mathrm{x}} \mathrm{Zn}_{\mathrm{x}} \mathrm{Te}$}

The identification and control of point defects in detector-grade CZT is an important research issue. For a given size of detector and a fixed applied electric field (E), the size of the current pulse is determined by the $\mu \tau \mathrm{E}$ product, with a larger $\mu \tau \mathrm{E}$ product being more desirable. Both mobility $(\mu)$ and lifetime $(\tau)$ parameters depend very much on the density of carrier traps and recombination centers within the semiconductor. Recombination centers reduce the carrier lifetimes, while carrier traps generally act as charge scattering centers and lead to a reduction in the mobility. Thus, point defects influence the carrier $\mu \tau$ product and affect the performance of nuclear radiation detectors (Schlesinger 1995). Point defects such as impurities may be introduced into the CZT from the source material, growth vessel, or handling during processing. Other point defects, such as vacancies and vacancy-impurity complexes, are produced during growth. In order to achieve high-resistivity material, intentional introduction of charge compensators has also been utilized.

Standard Photoluminescence (PL) spectroscopy is a sensitive, non-contact and non-destructive tool, best suited to characterize point defects, such as substitutional impurities (donors, acceptors) and native, or intrinsic, defects in CZT crystals. A PL emission spectrum provides information concerning the point defect nature of the crystal by determining not only the presence, but also the type of vacancies, interstitials, and impurities in the lattice. By focussing the exciting laser light to a small spot, PL mapping can be used as 
a sensitive probe of lateral variations in structural quality, impurity concentration, and stoichiometry and hence in measuring the homogeneity of composition and doping. Observation of near-band-edge emission provides approximate determination of the bandgap energy $\left(E_{g}\right)$ and thus the composition. The energy gap can be calculated from the photon energy of bound or free exciton peaks in the luminescence spectra and from the exciton binding energy. Common values of binding energy for $\mathrm{x}<0.1$ are $16-17 \mathrm{meV}$ for acceptorbound excitons, 12-13 meV for donor-bound excitons, and 10.3-10.8 meV for free-excitons (See Chapter 2, Section 2.2).

The information gained from PL data has been found to complement other semiconductor characterization techniques such as x-ray diffraction, transmission electron microscopy, and etching studies. The main advantages of this technique are that it (1) is a non-destructive technique where only small quantities of material are needed; (2) provides information mainly on minority carrier properties and, thus, it is complementary to electrical characterization techniques; (3) does not require particular sample handling and preparation; (4) is sensitive to the chemical species of impurities which can be detected even at very low densities; and (5) is an optical spectroscopic technique, i.e., it gives energetically resolved information. However, photoluminescence also has some disadvantages because it (1) is difficult to obtain quantitative information on the doping density or on the trap concentration by photoluminescence alone; (2) provides information only on radiative transitions; and (3) is not a bulk characterization technique, since only a thin near surface region is investigated if above-band-gap excitation is used. 


\subsection{Objectives of this Study}

Photoluminescence has been widely used in studying the properties of CdTe. However, the CZT is much less investigated, mainly due to the lack of high-quality samples. There are only few reports on the PL study of the HPB-grown CZT crystals (Tobin 1995, Hjelt 1997, Rablau 1998). I have tried to present a detailed study of this ternary alloy CZT in this thesis.

Determination of zinc concentration in CZT alloys is an important issue. Monitoring and controlling the substrate alloy composition is required to achieve a lattice matching with epitaxial layers. In addition, composition contours reflect the history of the melt-solid interface and thus provide insight into the crystal growth process. Previous workers have used a variety of techniques to characterize the alloy composition of CdZnTe boules and substrates. The lattice parameter from x-ray diffraction has been widely used. For example, Duncan et al. (Duncan 1990) applied the low-temperature photoluminescence technique to CdZnTe substrate composition measurements. The position of the acceptor-bound-exciton peak was correlated to precision lattice parameter measurements of alloy composition. Compositions were calculated using the Magnea et al. (Magnea 1987) calibration of PL bandgap to alloy composition measured by $\mathrm{x}$-ray fluorescence. The $77-\mathrm{K}$ photoreflectance technique was used by Kennedy et al. (Kennedy 1988) to measure alloy composition by correlating 77-K bandgap to lattice parameter and atomic absorption composition. NIR (near infrared) absorption spectra measured at room temperature (Johnson 1991) in the spectral range of the absorption edge are particularly convenient for a simple determination of the composition. On the other hand, methods giving directly a value of energy gap $\mathrm{E}_{\mathrm{g}}$ have been developed. Low-temperature PL has been established as a method providing information on 
defects and impurities as well as composition. Determinations of the bandgap energy dependence on composition have been previously performed using PL (Tobin 1995, Olego 1985, Magnea 1987, Reno 1992, Oettinger 1992, Franc 2000) and used (Stadler 1994, Hjelt 1997, Rablau 1998). An overview and a comparison of various expressions proposed for $E_{g}$ vs. $x$ dependence is presented in Chapter 4 .

Another important issue is the temperature dependence of the bandgap for these CZT crystals. A paper by Sanchez-Almazan et al. (Sanchez 1996) describes the temperature dependence of the observed band gap energies in $\mathrm{Cd}_{1-\mathrm{x}} \mathrm{Zn}_{\mathrm{x}} \mathrm{Te}(\mathrm{x} \leq 0.3)$ alloys by the wellknown Varshni formula (Varshni 1967). However, a paper by Fonthal et al. (Fonthal 2000) reports that it is incorrect to use the Varshni formula to determine the temperature dependence of the band gap since this equation is valid only for Group IV and Group III-V semiconductors (Olego 1980). I will discuss various expressions proposed in the literature (Cody 1984, Varshni 1967) and fit these expressions to my experimental data (upper polariton branch vs. temperature) for a set of CdZnTe samples in Chapter 4 .

Room-temperature PL mapping of band-edge emission and deeper defect-related emissions is proving to be a useful technique to characterize the homogeneity of the crystalline quality of III-V and group-IV semiconductor wafers (Tajima 1990, Mori 1990, Moore 1990). An earlier examination of the usefulness of 300-K PL measurements in determining composition variations in $\mathrm{Cd}_{1-\mathrm{x}} \mathrm{Zn}_{\mathrm{x}} \mathrm{Te}$ boules with low $\mathrm{Zn}$ molar fraction reported that the measured PL emission peak energy depended on the sample conductivity as well as Zn concentration (Duncan 1990). Brunett et al. (Brunett 1999) have used room temperature photoluminescence (RTPL) to correlate radiation detector performance with 
CZT material quality. A discussion on the nature of room temperature PL from the temperature dependence data collected is also given in Chapter 4.

I conclude this chapter with an overview of the remaining chapters. A brief description of the photoluminescence process in semiconductors is provided in Chapter 2 . A description of the apparatus used in this experimental study is provided in Chapter 3. Chapter 5 discusses the low temperature and temperature-dependent PL data obtained from a highresistivity bulk CdTe:In sample, and the final chapter is assigned for conclusions of this study. 


\section{CHAPTER 2}

\section{PHOTOLUMINESCENCE}

\subsection{General Description}

The term "luminescence" (the literal translation from Latin is "weak glow") was introduced into the literature by Wiedemann (1888). There are several types of luminescence depending on the cause or duration, as described below.

The presence of vacant lattice sites and other casual impurities or activator atoms in the crystal leads to the appearance of localized energy levels in the band gap. Some of them are deep, i.e. they are located at a considerable distance from the top of valence band or from the bottom of the conduction band. Such levels are often metastable and play the role of traps for charge carriers. For the electron at the metastable level to be able to recombine with a hole, it should first be transferred to the conduction band. This process can be stimulated by an electric field, by infrared light, or by simply warming the crystal. The luminescence, in the form of light, of a pre-excited crystal phosphor stimulated by heating is termed thermoluminescence (TL). It is the release of previously absorbed radiation energy and is quite different from incandescence light emission from a substance heated at high temperatures. A large number of dielectric materials, including minerals, rocks, inorganic (amorphous, singlecrystals and polycrystalline) semiconductors and insulators, glasses and ceramics exhibit TL.

Depending on the duration of the emission, one can distinguish between two general classes of luminescence--fluorescence and phosphorescence--the line of demarcation being about $10^{-8} \mathrm{sec}$, which is the lifetime of the excited atoms in the gaseous state. Phosphorescence and thermoluminescence are due to one and the same process, the only 
difference being the fixed and the rising temperature, respectively, of the emitting material during the time the emission is observed.

In phosphorescence, the presence of vacant lattice sites or other impurities, lattice defects, and/or irregularities in the host lattice, provide unoccupied states (traps) and delay the luminescence by detaining (trapping) the charge carriers (electrons/holes) before their radiative recombination with the luminescent centers.

When we use X-rays as a source of excitation, the phenomenon is called X-ray induced luminescence and when we use high-energy electrons (cathode rays) as the means of excitation; the phenomenon is called cathodoluminescence (CL). On the other hand, electroluminescence (EL) is a direct, non-thermal emission of light due to recombination of minority and majority carriers across the bandgap of crystals resulting from the application of an electric field to a material. In EL, the source of energy is the electric field and the conversion of electric energy to light is unlike that in cathodoluminescence, where there is a multistage process with acceleration of electrons in a vacuum and the generation of secondary electrons. High-field EL consists of excitation of luminescence centers by majority charge carriers accelerated under the action of strong electric fields of the order of 1 to 2 $\mathrm{MeV} / \mathrm{cm}$. The field may be either ac or dc.

Emission of energy in the form of visible light during chemical or biochemical processes is called chemiluminescence or bioluminescence. There are numerous organisms, both terrestrial and aquatic, that emit light (Hastings 1983). Chemiluminescence appears during oxidation reactions or free-radical recombination.

Photoluminescence in solids is the phenomenon in which electronic states of solids are excited by light of particular energy and the excitation energy is released as light. Stokes 
(1852) formulated the first law in the history of luminescence (Stoke's rule), which states that the wavelength of emitted light generally is equal to or longer than that of the exciting light (i.e., of equal or less energy). This difference in wavelength is caused by a transformation of the exciting light, to a greater or lesser extent, to non-radiating vibration energy of atoms or ions. In rare instances--e.g. when intense irradiation by laser beams is used or when sufficient thermal energy contributes to the electron excitation process--the emitted light can be of shorter wavelength than the exciting light (anti-Stokes radiation). A general introduction on the photoluminescence spectroscopic technique can be found in the classic work of Bebb and Williams (Bebb 1972), in the book by Pankove (Pankove 1975), and in the review article by P. J. Dean (Dean 1982).

In photoluminescence spectroscopy, photons with energy greater than the bandgap of the material studied are directed onto the surface of the semiconductor material, the incident monochromatic photon beam is partially reflected, absorbed, and transmitted by the material being probed. The absorbed photons create electron-hole pairs in the semiconductor. The electrons are excited to the conduction band, or to the energy states within the gap. In addition, electrons can lose part of their energy and transfer from the conduction band to energy levels within the gap. Photons produced as a result of the various recombinations of electrons and holes are emitted from the sample surface and it is the resulting photon emission spectrum that is studied in photoluminescence (PL). The photon energies reflect the variety of energy states that are present in the semiconductor. Different energy states are produced by different defects, and by the many different ways impurities are incorporated into the lattice. As a consequence, a PL emission spectrum provides information concerning the point defect nature of a material by determining not only the presence, but also the type, 
of vacancies, interstitials, and impurities in the lattice. A direct conduction band-to-valence band recombination is rarely observed in PL spectra. Even if direct band-to-band recombinations occur, the crystal will strongly reabsorb the photons emitted. Therefore, in PL spectra, recombination processes are observed with emission energies less than $\mathrm{E}_{\mathrm{g}}$. These processes include excitonic recombinations and indirect transitions, which involve the trapping of electrons (or holes) by impurities. Recombination processes in semiconductors are described with great care in the recent book by Landsberg (Landsberg, 1991). These various recombination channels are discussed next, where I will focus the discussion on the recombinations most important to my thesis work.

\subsection{Radiative Transitions in $\mathrm{Cd}_{1-\mathrm{x}} \mathrm{Zn}_{\mathrm{x}}$ Te Bulk Crystals}

\section{Free excitons}

A free hole in the valence band and a free electron in the conduction band experience a Coulomb force as a pair of opposite charges and form a composite particle called an "exciton". The electron and the hole are weakly bound to each other by their attractive electrostatic interaction and the electron can orbit about the hole as in the hydrogen atom. When the exciton is not trapped by a defect or impurity, it is called a free exciton. The energy states of the free exciton can be described by the hydrogen model as follows

$$
E_{x}=E_{g}-2 \pi^{2} m_{r}^{*} q^{4} / h^{2} \varepsilon^{2}
$$

where $\mathrm{E}_{\mathrm{g}}$ is the band gap energy, $\mathrm{h}$ is the Plank's constant, $\varepsilon$ is the dielectric constant, and $\mathrm{m}_{\mathrm{r}}^{*}$ is the reduced effective mass of the electron-hole pair. The reduced mass is given by

$$
1 / \mathrm{m}_{\mathrm{r}}^{*}=1 / \mathrm{m}_{\mathrm{e}}^{*}+1 / \mathrm{m}_{\mathrm{h}}^{*}
$$

where $m_{e}{ }^{*}$ is the electron effective mass and $m_{h}{ }^{*}$ is the effective mass of the hole. 
In Eq. 2.1, $\mathrm{n}$ is an integer indicating the various allowed states of the free exciton. The ground state of the free exciton corresponds to $\mathrm{n}=1, \mathrm{n}=2$ corresponds to the first excited state of the free exciton, and $n=3$ to the second excited state, and so on. In CdTe, the binding energy of the free exciton energy is about $10 \mathrm{meV}$. The ground state energy level of the free exciton is thus $10 \mathrm{meV}$ lower than the conduction band edge. The energy gap of CdTe at liquid helium temperatures is well established as $1.6064 \mathrm{eV}$ (Madelung 1987). Therefore, the free exciton ground state has absorption energy of $1.5964 \mathrm{eV}$. The first excited state of the free exciton $(\mathrm{n}=2)$ will give rise to PL emission at $1.6039 \mathrm{eV}$ and the second excited state $(\mathrm{n}=3)$ appears close to the band edge at $1.6063 \mathrm{eV}$. In some high quality CdZnTe samples, I could observe the second excited state of the free excitons. Higher order excited states merge into the conduction band due to the free exciton kinetic energy.

In the ternary compound $\mathrm{Cd}_{1-\mathrm{x}} \mathrm{Zn}_{\mathrm{x}} \mathrm{Te}$, the band gap and free exciton binding energies depend on the zinc molar concentration $\mathrm{x}$. The binding energy of the free exciton varies linearly between about $10 \mathrm{meV}$ for CdTe and $13 \mathrm{meV}$ for ZnTe (Vegard's law) and is chosen to be $10.8 \mathrm{meV}$ (Franc 2000) in my thesis work. Several expressions for band gap energy as a function of zinc molar concentration have been proposed based on experimental data and these relations will be discussed in Chapter 4 .

When the exciton-photon interaction is strong, the propagation of electromagnetic waves through the crystal is regarded as a mixture of electronic polarization and electromagnetic waves. This new energy packet mixture is called a polariton. This excitonphoton interaction may lift the degeneracy of the exciton energy states. The splitting between the lower (transverse) and higher (longitudinal) energy states can often be resolved at low temperature (Bebb 1972). In my experiments, I could observe the transverse and longitudinal 
polariton branches of the free exciton for several undoped bulk CdZnTe samples at low temperatures. The transverse polariton branch could be observed up to $30 \mathrm{~K}$, whereas the longitudinal polariton branch could be observed up to $125 \mathrm{~K}$ for some high quality $\mathrm{CdZnTe}$ samples. The splitting in CdZnTe between these branches is typically of the order of $2 \mathrm{meV}$.

\section{Bound Excitons}

In a real material, there exist many kinds of impurities or defects. When excitons are near defects, the defects can either increase or decrease the binding energy of the exciton. When the defects reduce the total system energy of the exciton, excitons will be trapped about the defects, which leads to the formation of bound excitons. When the total system energy of the exciton is increased by a particular defect, the exciton will remain free. Bound excitons give rise to PL emission at lower energy than that of free excitons. These emission lines exhibit narrower line widths than free exciton emissions due to increased localization. Since most semiconducting materials contain significant amounts of impurities and/or defects which can trap excitons, the identification of the bound exciton states provides an important characterization of impurities, which control the electro-optic properties of semiconductors.

Neutral and ionized donors and acceptors can trap excitons and form bound excitons.

Excitons bound to ionized donors $\left(\mathrm{D}^{+}, \mathrm{X}\right)$, excitons bound to neutral donors $\left(\mathrm{D}^{0}, \mathrm{X}\right)$, excitons bound to ionized acceptors $\left(\mathrm{A}^{-}, \mathrm{X}\right)$, and excitons bound to neutral acceptors $\left(\mathrm{A}^{0}, \mathrm{X}\right)$ are the various types found in many semiconductor systems. The $\left(\mathrm{D}^{+}, \mathrm{X}\right)$ complex is regarded as consisting of a donor ion, an electron and a hole. The $\left(\mathrm{D}^{0}, \mathrm{X}\right)$ bound exciton consists of a donor ion, two electrons, and a hole. The $\left(\mathrm{A}^{0}, \mathrm{X}\right)$ bound exciton consists of an acceptor ion, an electron, and two holes (Bebb 1972). 
Table 2.1 PL energies of bound exciton recombination for donor and acceptor inpurities in CdTe [Francou 1990, Molva 1984].

\begin{tabular}{|c|c|c|c|}
\hline Donors & $\left(\mathrm{D}^{0}, \mathrm{X}\right)(\mathrm{eV})$ & $\varepsilon_{\mathrm{B}}(\mathrm{meV})$ & $\varepsilon_{D}(\mathrm{meV})$ \\
\hline $\mathrm{F}$ & 1.59314 & 3.36 & 13.67 \\
\hline $\mathrm{Ga}$ & 1.59309 & 3.41 & 13.88 \\
\hline $\mathrm{Al}$ & 1.59305 & 3.46 & 14.05 \\
\hline In & 1.59302 & 3.48 & 14.15 \\
\hline $\mathrm{Cl}$ & 1.59296 & 3.54 & 14.48 \\
\hline-- & 1.59284 & 3.66 & 14.60 \\
\hline 1 & 1.5927 & 3.8 & $\sim 15.1$ \\
\hline Acceptors & $\left(\mathrm{A}^{0}, \mathrm{X}\right)(\mathrm{eV})$ & $\varepsilon_{B}(\mathrm{meV})$ & $\varepsilon_{\mathrm{A}}(\mathrm{meV})$ \\
\hline $\mathrm{O}$ & --- & -- & 46 \\
\hline$N$ & 1.5892 & 7.2 & 56.0 \\
\hline $\mathrm{Li}$ & 1.58923 & 7.17 & 58.0 \\
\hline $\mathrm{Na}$ & 1.58916 & 7.24 & 58.7 \\
\hline $\mathrm{Sb}$ & 1.5895 & 6.8 & 65 \\
\hline $\mathrm{P}$ & 1.58897 & 7.43 & 68.2 \\
\hline As & 1.58970 & 6.70 & 92.0 \\
\hline $\mathrm{Ag}$ & 1.58848 & 7.92 & 107.5 \\
\hline $\mathrm{Cu}$ & 1.58956 & 6.84 & 146.0 \\
\hline $\mathrm{Au}$ & 1.57606 & 20.34 & 263 \\
\hline
\end{tabular}

In CdZnTe, $\left(\mathrm{D}^{+}, \mathrm{X}\right),\left(\mathrm{D}^{0}, \mathrm{X}\right)$, and $\left(\mathrm{A}^{0}, \mathrm{X}\right) \mathrm{PL}$ emission bands are observed. However, $\left(\mathrm{A}^{-}, \mathrm{X}\right) \mathrm{PL}$ emission band is not detected in this material. The observation of $\left(\mathrm{D}^{+}, \mathrm{X}\right)$ emission or $\left(\mathrm{A}^{-}, \mathrm{X}\right)$ PL emission bands in a particular material will depend on the ratio of 
electron and hole effective masses $m_{e}$ and $m_{h}$ (Sharma 1967, Hopfield 1964, Bebb 1972). An exciton can be bound to an ionized donor if $\mathrm{m}_{\mathrm{h}} / \mathrm{m}_{\mathrm{e}}>1$.4. Similarly, an exciton can be bound to an ionized acceptor if $\mathrm{m}_{\mathrm{e}} / \mathrm{m}_{\mathrm{h}}>1.4$. Therefore, it is not expected that $\left(\mathrm{D}^{+}, \mathrm{X}\right)$ and $\left(\mathrm{A}^{-}, \mathrm{X}\right)$ PL emission bands coexist in the same material. In CdZnTe, $\mathrm{m}_{\mathrm{h}} / \mathrm{m}_{\mathrm{e}}$ is about 3 , thus only $\left(\mathrm{D}^{+}, \mathrm{X}\right)$ emission bands are observed, as has been verified by many experimental studies.

In CZT, excitons bound to donors and acceptors exhibit PL emission peaks just below the free exciton PL emission line. Fig. 2.1 shows the placement of various energy levels in $\mathrm{Cd}_{1-\mathrm{x}} \mathrm{Zn}_{\mathrm{x}} \mathrm{Te}$ relative to the valence and conduction band. In $\mathrm{CdTe},\left(\mathrm{D}^{0}, \mathrm{X}\right)$ recombinations give rise to the PL peaks in the range from 1.592 to $1.595 \mathrm{eV}$ and $\left(\mathrm{D}^{+}, \mathrm{X}\right)$ emission bands appear at $1.590-1.592 \mathrm{eV}$, so this can be used as a guide for finding similar features in CdZnTe with low zinc. In CdTe, since the binding energies of shallow donor impurities are in the range from 13.5 to $15 \mathrm{meV}$ (Francou 1990), the PL emission for transitions from shallow donors to valence band $\left(D^{0}, h\right)$, occurs at almost the same energies of that due to $\left(D^{+}\right.$, $\mathrm{X})$ recombinations. Emission bands at $1.5910-1.5920 \mathrm{eV}$ are thus the superposition of $\left(\mathrm{D}^{+}\right.$, $\mathrm{X})$ and $\left(\mathrm{D}^{0}, \mathrm{~h}\right)$ recombinations. $\left(\mathrm{A}^{0}, \mathrm{X}\right)$ recombinations give rise to $\mathrm{PL}$ emissions in the range from 1.5890-1.588 eV (Molva 1984). The binding energies and emission peaks for several different donor- and acceptor-bound excitons and the ionization energies of several donor and acceptor impurities are listed in Table 2.1. Ionization energies for donors are much smaller as compared to that of acceptors (shallow acceptors have ionization energies in the range from 56 to $263 \mathrm{meV}$ in $\mathrm{CdTe}$ ) even though both donor- and acceptor-bound exciton PL lines appear just below the free exciton emission because $m_{h}{ }^{*}$ is 3 times larger than $m_{e}{ }^{*}$ in $\operatorname{CdTe}\left(\mathrm{m}_{\mathrm{e}}{ }^{*}=0.11\right.$ and $\left.\mathrm{m}_{\mathrm{h}}{ }^{*}=0.35\right)$. The binding energies of neutral impurity-bound excitons 


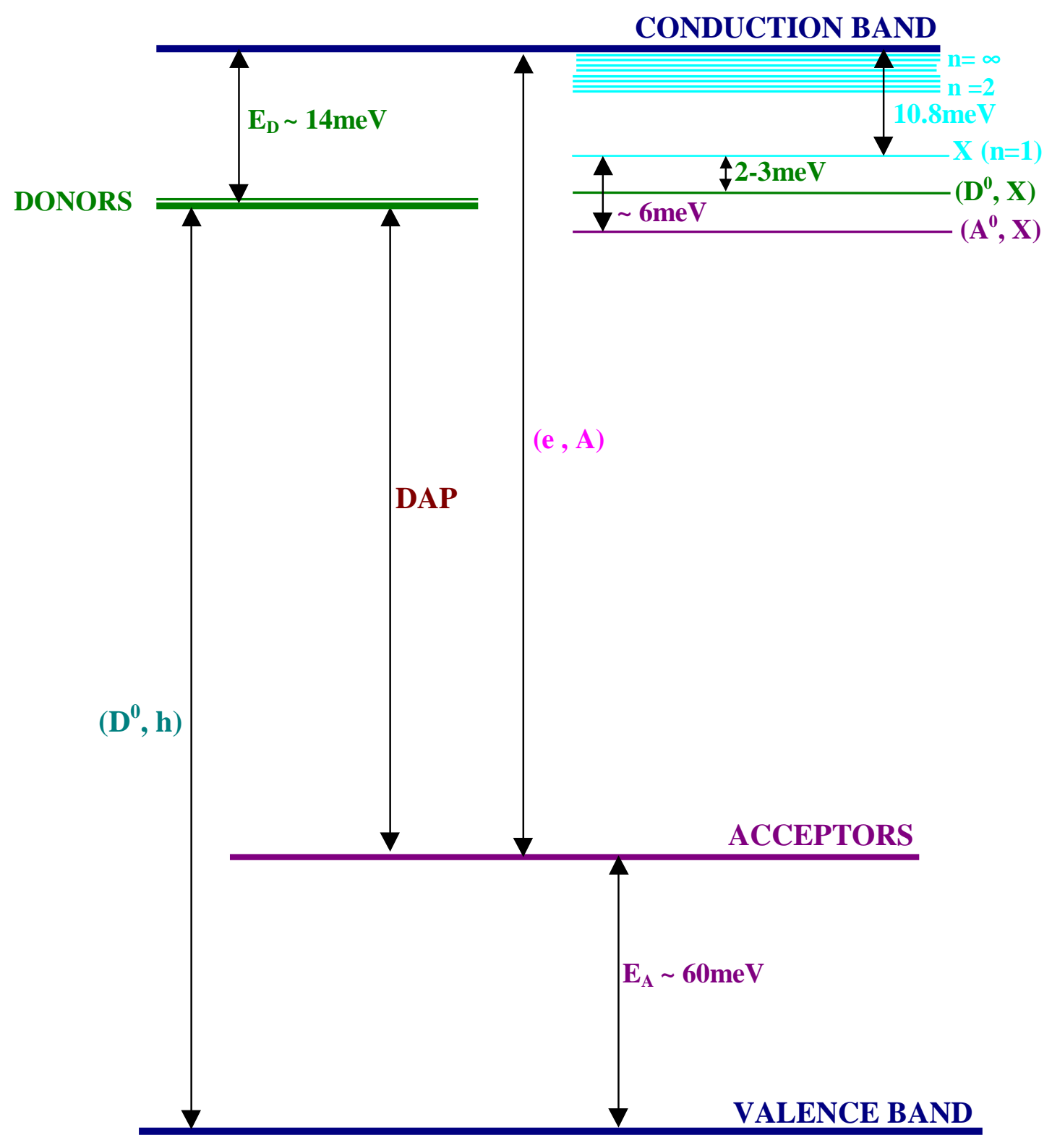

FIGURE 2.1: Energy level diagram showing various radiative transitions in $\mathrm{Cd}_{1-\mathrm{x}} \mathrm{Zn}_{\mathrm{x}} \mathrm{Te}$. (DAP stands for donor-acceptor pair). 
excitons often exhibit a linear dependence on impurity ionization energy, as was first observed in silicon (Haynes 1960). This linear dependence is often referred to as Haynes' rule. In silicon, the exciton binding energies for both neutral donors and acceptors were shown by Haynes' to be about 0.1 of the impurity ionization energies. In $\mathrm{CdZnTe}$, however, neutral donors and neutral acceptors behave differently. Donor bound excitons follow

$$
\varepsilon_{\mathrm{DB}} / \varepsilon_{\mathrm{D}}=0.2
$$

and many acceptor-bound excitons follow

$$
\varepsilon_{\mathrm{AB}} / \varepsilon_{\mathrm{A}}=0.1
$$

where $\varepsilon_{\mathrm{DB}}$ and $\varepsilon_{\mathrm{AB}}$ are the binding energies of donor- and acceptor-bound excitons, respectively, and $\varepsilon_{\mathrm{D}}$ and $\varepsilon_{\mathrm{A}}$ are the ionization energies of donor and acceptor impurities (Halstead 1965). Although these relations may not hold for all donor- and acceptor-bound excitons, they have been found to give good agreement with experimental data when the impurities are hydrogenic (Noblanc 1970). Temperature dependence behaviors of these features are discussed in Chapter 4.

\section{Band to Impurity Level Recombinations}

This recombination process includes electron transitions from neutral donor levels to the valence band $\left(\mathrm{D}^{0}, \mathrm{~h}\right)$ and electron transitions from the conduction band to neutral acceptor levels $\left(\mathrm{e}, \mathrm{A}^{0}\right)$. Donor impurity level to valence band recombination will emit photons having energy of

$$
\mathrm{E}_{\mathrm{PL}}=\mathrm{E}_{\mathrm{g}}-\mathrm{E}_{\mathrm{D}}
$$


where $E_{P L}$ is the PL peak energy of the $\left(D^{0}, h\right)$ emission, $E_{g}$ is the band-gap energy and $E_{D}$ is the ionization energy of the donor impurity. The PL emission peak energy related to transitions between the conduction band and acceptor impurities is described by

$$
E_{P L}=E_{g}-E_{A}+(1 / 2) k T_{e}
$$

where $E_{P L}$ is the PL peak energy of $\left(e, A^{0}\right)$ emission, $E_{g}$ is the band gap energy, $E_{A}$ is the ionization energy of acceptor impurities, $k$ is Boltzmann's constant and $T_{e}$ is the effective temperature of electrons in the conduction band. This effective temperature can be obtained from the high-energy side of the exponential tail of the emission band. The binding energies of various acceptor impurities can be determined from analysis of PL emission spectra using Equation 2.6. The $\left(\mathrm{e}, \mathrm{A}^{0}\right)$ emission exhibits a shift of the PL peak position to higher energies with an increase in excitation power (Espinosa 1983) and temperature (Kim 1984) due to band filling. The shift in energy due to increasing temperature can be offset by the band gap narrowing with increase of temperature.

\section{Donor-Acceptor Pair Recombination}

$\mathrm{Cd}_{1-\mathrm{x}} \mathrm{Zn}_{\mathrm{x}} \mathrm{Te}$ bulk crystals may contain both donor and acceptor impurities, and is referred to as n-type or p-type, according to which impurity is dominant. These donors and acceptors can form pairs and act as stationary molecules imbedded in the host crystal. The Coulomb interaction between donor and acceptor impurities will have an influence on the binding energies of the isolated impurities. The recombination energy of a donor-acceptor pair (DAP) is given by

$$
E_{P L}=E_{g}-\left(E_{A}+E_{D}\right)+e^{2} / \varepsilon R
$$


where $E_{P L}$ is the peak energy of the DAP emission, $E_{g}$ is the energy of the band gap, $E_{A}$ is the acceptor ionization energy, $E_{D}$ is the donor ionization energy, e is the electron charge, $\varepsilon$ is the dielectric constant, and $\mathrm{R}$ is the distance between the donor and acceptor in the pair. When $\mathrm{R}$ is large (much greater than the internal dimension or effective Bohr radii of either the neutral donor or neutral acceptor), the emission lines will overlap and form a broad band which is commonly observed in CdZnTe. A shift of emission band to higher energies up to the temperature of $30 \mathrm{~K}$ and a rapid decrease in PL intensity of shallow donor related-emissions in the temperature range from $25 \mathrm{~K}$ to $35 \mathrm{~K}$ gives indirect evidence of DAP emission in PL spectra from CdTe. The reason for these characteristics is that as the temperature is increased, the electrons on the donor are ionized and excited to the conduction band. These excited electrons contribute to the $\left(\mathrm{e}, \mathrm{A}^{0}\right)$ recombination process, which occur at higher energy than DAP recombination. The transition of an electron from the conduction band to the acceptor level $\left(\mathrm{e}, \mathrm{A}^{0}\right)$ contributes more as the temperature is increased. The relative change of DAP and (e, $\left.\mathrm{A}^{0}\right)$ amplitudes cause the emission peak of DAP recombination to shift to the higher energy side. However, the shallow-donor-acceptor-pair-emission band disappears about $30 \mathrm{~K}$, and band gap shrinkage due to the temperature increase causes (e, $\mathrm{A}^{0}$ ) to move to lower energies above $30 \mathrm{~K}$. In CdTe, DAP recombination between shallow donors and the shallow substitutional acceptors $\mathrm{Li}_{\mathrm{Cd}}$ and/or $\mathrm{Na}_{\mathrm{Cd}}$ produces an emission band about $1.538 \mathrm{eV}$ at liquid helium temperature. Donor-acceptor pair emission between shallow donors and $\mathrm{Ag}_{\mathrm{Cd}}$ and $\mathrm{Cu}_{\mathrm{Cd}}$ acceptors give rise to PL peaks at about $1.49 \mathrm{eV}$ and $1.45 \mathrm{eV}$, respectively (Dean 1984). In addition to the acceptor states produced by substitutional impurities like $\mathrm{Ag}$ and $\mathrm{Cu}$, it is also common to observe PL emission due to acceptor-like point defect complexes, such as the cation-vacancy-donor center commonly referred to as an 
A center in II-VI semiconductors. DAP recombination in CdTe due to shallow donors and Acenter acceptors has been often observed in the $1.4 \mathrm{eV}$ to $1.5 \mathrm{eV}$ region. Similar behavior is expected for CdZnTe, especially when the zinc molar composition is low.

\subsection{Phonon-Related Recombinations}

When an electron and hole recombine, the energy can be transformed into photons and/or phonons (phonons are collective vibrational modes of the atoms forming the crystal). The electron-phonon interaction can lead to the simultaneous emission of one or more phonons, giving replicas or satellites of the main recombination peak in the PL spectrum displaced by the energies of the relevant phonons. Strong phonon coupling can lead to the observation of multiple orders of phonon replicas. At temperature $\mathrm{T}=0 \mathrm{~K}$, the shape of the emission band due to the phonon replicas is:

$$
I_{e m}(E)=I_{0} \sum_{n} \frac{\exp (-S) S^{n}}{n !} \delta\left(E_{0}-n \hbar \omega-E\right)
$$

where $E_{0}$ is the energy of the zero-phonon transition and $S$ is the Huang-Rhys coupling factor representing the average number of phonons involved (Dean 1979, Henderson 1989). At T >

$0 \mathrm{~K}$, the term $\exp (-\mathrm{S})$ becomes $\exp (-\mathrm{S}(1+2 \mathrm{n}))$ where $\mathrm{n}=[\exp (\hbar \omega / \mathrm{kT})-1]^{-1}$ is the mean thermal occupancy in the vibrational mode. The intensity in the zero-phonon line then becomes $\mathrm{I}_{0}$ $\exp (-\mathrm{S}$ coth $\hbar \omega / 2 \mathrm{kT})$ which decreases with increasing temperature. When $\mathrm{S}$ is much less than unity, the zero-phonon line intensity becomes $\mathrm{I}_{0}(1-\mathrm{S}$ coth $(\hbar \omega / 2 \mathrm{kT}))$, showing that the sideband intensity increases with temperature as $\mathrm{I}_{0} \mathrm{~S}$ coth $(\hbar \omega / 2 \mathrm{kT})$.

In $\mathrm{Cd}_{1-\mathrm{x}} \mathrm{Zn}_{\mathrm{x}} \mathrm{Te}$, the direct electron-phonon interaction is dominated by the longitudinal optical (LO) mode because of the associated polarization fields. Transverse optical (TO) 

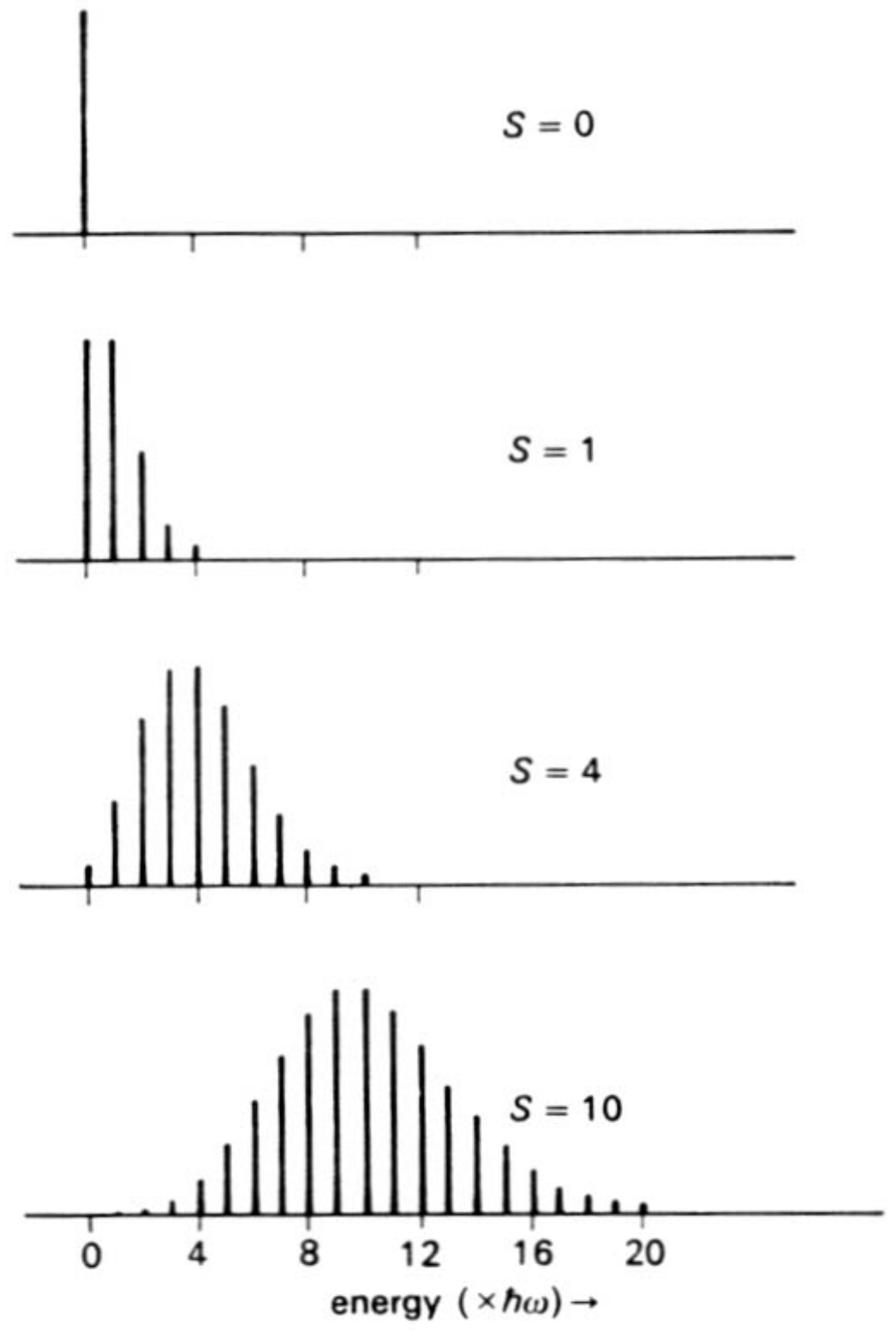

Fig. 2.2: The change of the relative intensities in the different electronic-vibrational lines with the strength of coupling, S. The envelope of the individual intensities give the predicted band shapes (from Henderson 1989). 
phonons are normally not observed in PL spectra. The coupling interaction strength for electron-TO phonons is small. The LO phonon energy in CZT is about $21 \mathrm{meV}$ (same as the LO phonon energy in CdTe). Phonon replicas of $\left(e, A^{0}\right),\left(A^{0}, X\right), D A P$ bands, and excitonic transitions are often seen in $\mathrm{Cd}_{1-\mathrm{x}} \mathrm{Zn}_{\mathrm{x}}$ Te. The appearance of multiple phonon replicas may be an indication of long-range crystalline order in the crystal, and certainly indicates a strength of the coupling between the localized electrons (or holes) and the lattice. Normally, the coupling is small to moderate strength for excitonic and impurity level to band recombinations, and is stronger for DAP emission. The strength of the $\mathrm{S}$ factor in DAP recombination is due to the acceptor-hole localization strength. For example, $\mathrm{S} \sim 3.1$ in CdTe:Au for which $\varepsilon_{\mathrm{A}}=263 \mathrm{meV}$ (Molva 1984), S 1.5 for CdTe:Cu for which $\varepsilon_{\mathrm{A}}=146 \mathrm{meV}$ (Chamonal 1982), and $\mathrm{S} \sim 0.9$ for CdTe:Ag for which $\varepsilon_{\mathrm{A}}=108 \mathrm{meV}$ (Chamonal 1982). When the $\mathrm{S}$ factor is large, the zero-phonon emission peak will be low in amplitude in comparison with higher order peaks. The predicted band shapes for different values of S (Eq. 2.8) are plotted in Fig. 2.2 (Henderson 1989). The curves are scaled to have the same maximum intensity. The zero-phonon line is a transition between purely electronic states and should appear as a sharp line. The side band transitions occurring at increasingly lower energies involve the creation of $\mathrm{n}$ phonons in the excited state. Since there is a wide spectrum of lattice vibrational frequencies we expect that in practice the side band features above the zero-phonon line will appear as broad bands.

\subsection{Method to Determine Free-Exciton Emission Line}

In the PL analysis of CZT, in order to determine which emission line corresponds to the ground state of the free exciton among the several edge emission peaks at liquid-helium 


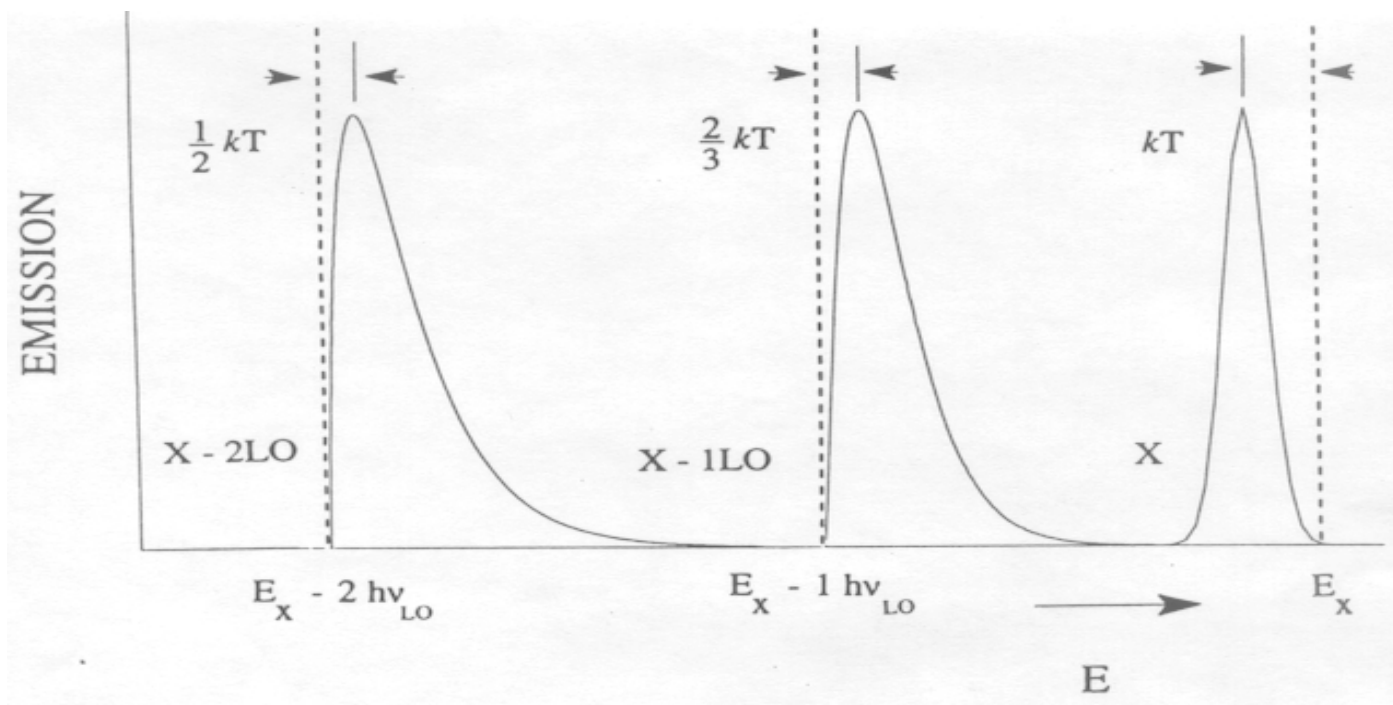

Figure 2.3. Shifts of zero-, first-, and second-order LO phonon replica emission lines for free exciton away from absorption lines. The vertical lines are absorption energies. The curves stand for emissions. The zero-phonon line is simply shifted by the Boltzmann factor to the lower energy. The first-LO phonon line is shifted to higher energies by kinetic energy distribution of the excitons.

temperature, I first determined the energy of the first-order LO phonon replica of the free exciton, and then added $20.7 \mathrm{meV}$ to it. The energy of $20.7 \mathrm{meV}$ corresponds to the $\mathrm{LO}$ phonon energy $(21.3 \mathrm{meV}$ ) minus $(5 / 3) \mathrm{kT}$ (which gives about $0.6 \mathrm{meV}$ at $5 \mathrm{~K}$ ), since the ground state transition of the free exciton will shift the PL emission peak (zero phonon line) by $\sim \mathrm{kT}$ to the lower energy side and the first and second order phonon replicas shift to the higher energy side by (2/3) kT and (1/2)kT at low temperatures, respectively (see Fig. 2.3). The emission line intensities of first- and second- order LO phonon replicas for free exciton as shown in Fig. 2.3 are normalized to the zero order phonon emission intensity and so they appear equal. In reality, the intensity of the phonon replicas follow the Poisson intensity distribution function $I(n)=I_{0} e^{-S} S^{n} / n$ ! and hence decrease as one goes to higher orders. 


\section{CHAPTER 3}

\section{EXPERIMENTAL DETAILS}

\subsection{General Description}

The experimental set-up needed to conduct low-temperature photoluminescence experiments, consists of three main parts: (1) an excitation light source providing a beam of photons with energy greater than the band gap of the material studied; (2) a dewar maintaining the samples at cryogenic temperatures while allowing the source light to reach the surface of the sample, such as through a window; and (3) a detection system to disperse and analyze the photons which are emitted from the sample. A description of the equipment systems that I used to conduct temperature dependent PL studies is given below and a schematic diagram of the PL equipment and setup is shown in Figure 3.1.

The single-line output from a Uniphase model no. $1136 \mathrm{He}-\mathrm{Ne}$ gas laser $(632.8 \mathrm{~nm})$, or the single-line visible output $(457.9,487.9$ and $514.5 \mathrm{~nm})$ from a Innova 400-10 argon ion laser from Coherent, Inc. or a tunable Ti: Sapphire laser $(755 \mathrm{~nm}$ to $910 \mathrm{~nm}$ with MW output coupler and 710 to $795 \mathrm{~nm}$ with SW output coupler) pumped by the argon ion laser is used as the optical excitation source in the PL experiments. In a particular experiment, the choice of laser wavelength is made so as to provide incident photons with energies greater than the band gap of the material studied. For example, to study the CdTe crystal, the He-Ne laser is a suitable light source since the output photon energy $(1.9588 \mathrm{eV})$ is greater than the band gap of CdTe at $4.2 \mathrm{~K}\left(\mathrm{E}_{\mathrm{g}}=1.6064 \mathrm{eV}\right)$. In the conversion from wavelength to energy, the index of refraction of air for a wavelength of $\lambda=0.8 \mu \mathrm{m}$ was taken to be $\mathrm{n}=1.00026140$ at $30^{\circ} \mathrm{C}$, therefore, $\mathrm{E}(\mathrm{eV})=\mathrm{hc} / \mathrm{n} \lambda=[12398.4244 / 1.00026140 * \lambda] \mathrm{eV}=12395.2 / \lambda(\AA)$. 


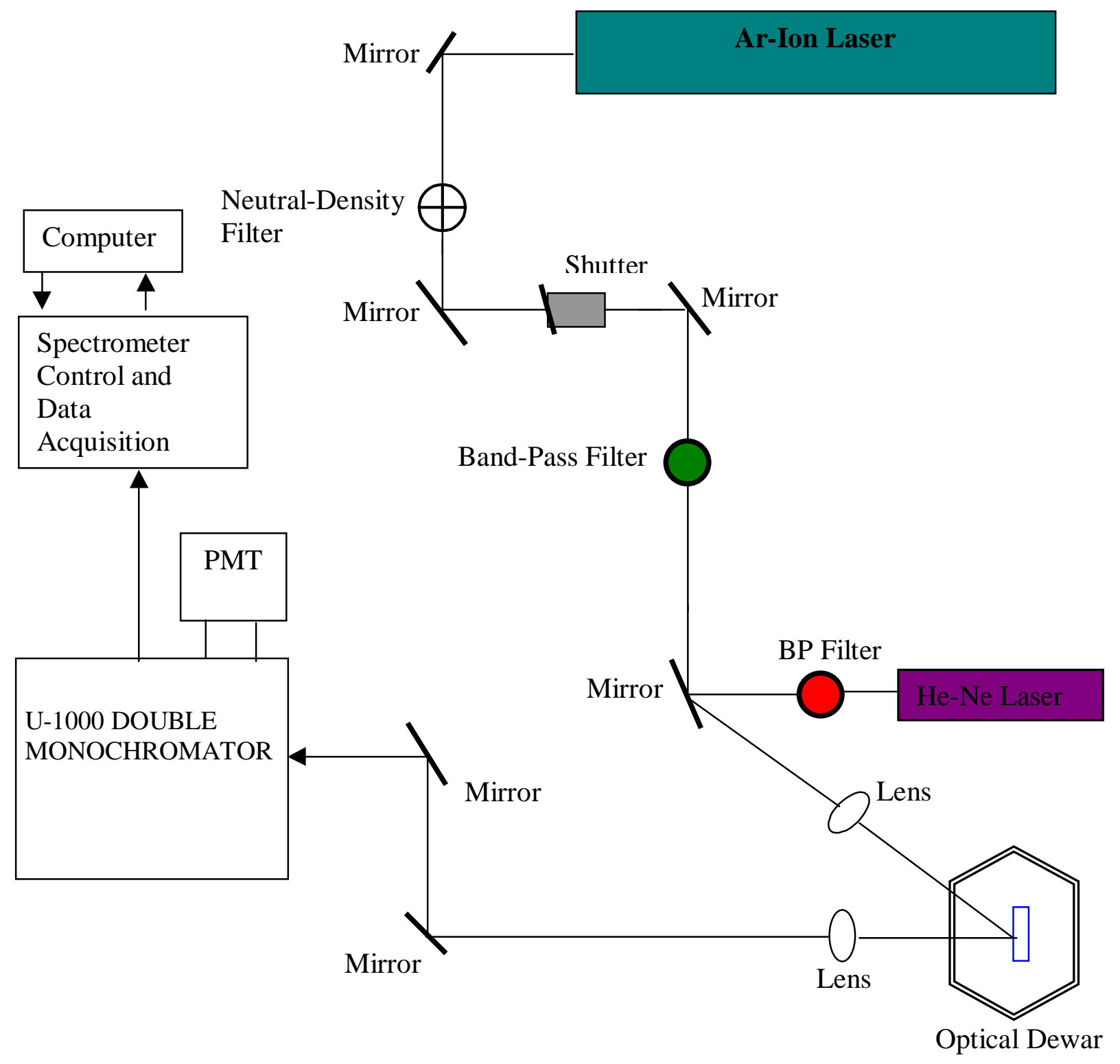

Fig. 3.1: Schematic diagram of the Photoluminescence setup. Not drawn to scale. Positions represented are approximate. 
The output beam from the He-Ne laser or Ar ion laser, after passing through a bandpass filter (that removes all the other laser frequencies) and a neutral density filter is directed to the sample surface by a set of mirrors (Al coated front surface mirrors with $\mathrm{SiO}$ overcoat) and is focussed with a glass convergent lens. The beam spot diameter on the sample surface is approximately $0.5 \mathrm{~mm}$. The sample is enclosed in a Janis Research Products Super Varitemp Optical Dewar (Figure 3.2), designed to offer the user control of sample temperature from liquid helium (about $4 \mathrm{~K}$ ) to room temperature about $(300 \mathrm{~K})$ and is composed of an inner helium reservoir and a sample chamber connected with each other by a capillary tube. The adjustment of the needle valve opening of the capillary tube allows the flow of the liquid helium or liquid nitrogen from the inner reservoir of the dewar into the central sample chamber and the control of its level. The samples are mounted on a molybdenum plate and attached to a copper block with copper vacuum grease to allow thermal contact with the cryogen, i.e., liquid nitrogen or liquid helium. The dewar contains two heaters: one is on the helium vaporizer and diffuser, the other is on the sample holder. The sample surface is cooled by flowing vapor, and the temperature inside the dewar is monitored on the copper sample holder by a silicon diode. The sensor outputs are fed to a Lake Shore Cryotronics, Inc. Model 805 temperature controller which displays the temperature or voltage corresponding to the standard curve of the silicon diode sensor. The dewar tail has four quartz windows, which transmit photon wavelengths out to $3 \mu \mathrm{m}$, so they can be used in studies of visible and near-IR PL emissions. The emitted luminescence is focussed by a plano-convex glass lens (diameter $25 \mathrm{~mm}$, and $\mathrm{f} / \# \sim 2$ to match the dewar optical access) onto the entrance slit of a Jobin-Yvon Ramanor U-1000 double monochromator. The spectral range of the U-1000 with two $1800 \mathrm{~g} / \mathrm{mm}$ diffraction gratings 


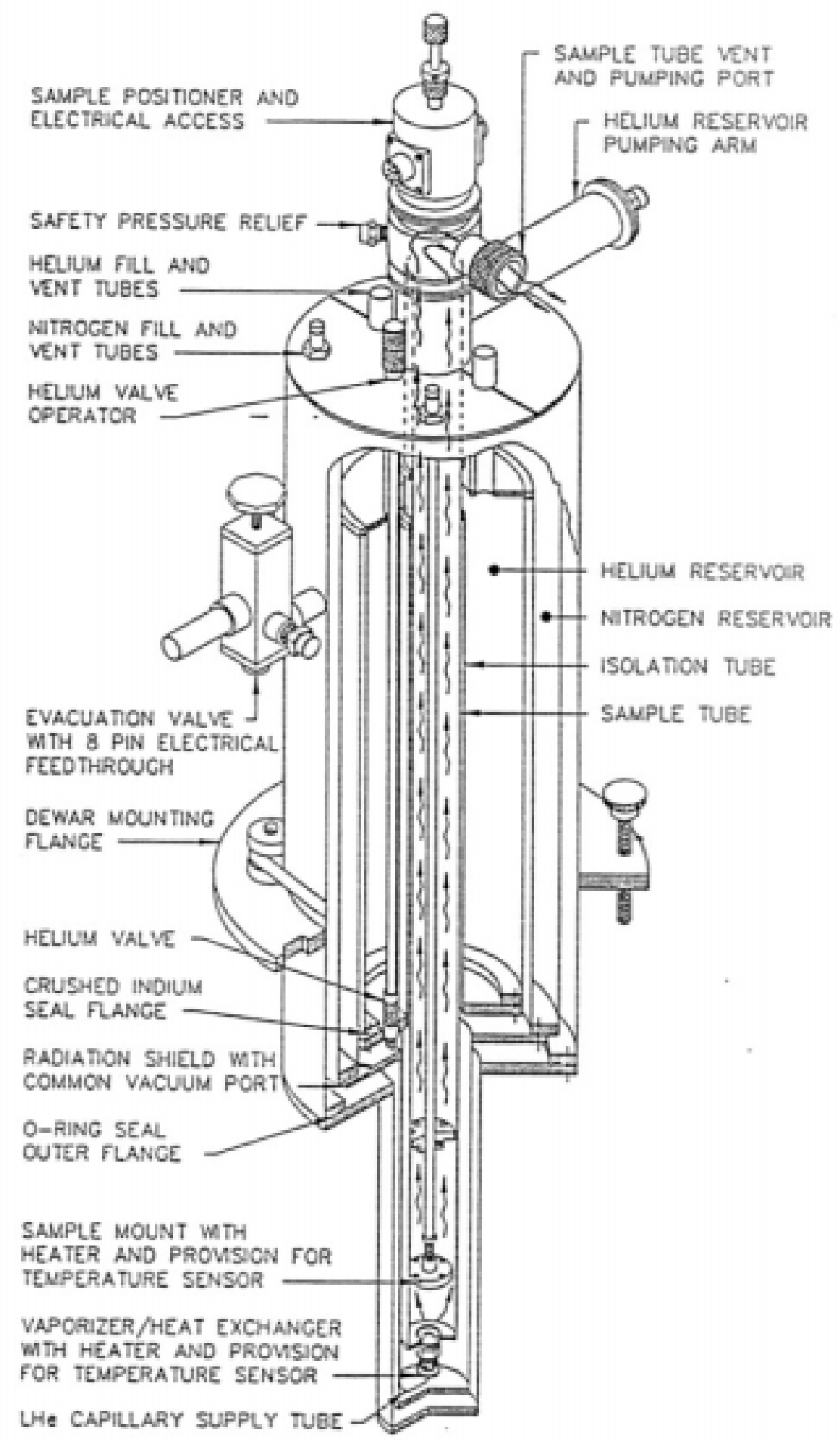

Fig. 3.2: The Janis Research Products SuperVariTemp Optical Dewar. 
and f/8 aperture is from $322.5 \mathrm{~nm}$ to $910 \mathrm{~nm}$. The exit slit is connected to a GaAs-cathode photomultiplier tube (Hamamatsu R943-02) which has a cut-off wavelength of $880 \mathrm{~nm}$. Photon-counting electronics were used to detect the luminescence signals. In the case of photon-counting acquisitions, all the light that enters the spectrometer is amplified (so the room lights are kept off). The output from the PMT goes into a Spectra Link system that controls the spectrometer and is commanded by computer software (PRISM). Instruments S.A., Inc. produces both the Spectra Link and the PRISM software. All data reported in this thesis have been corrected for spectral intensity response of the system using a broad band Quartz Tungsten Halogen lamp and the spectral wavelength calibration of U-1000 was done using the emission lines from a $\mathrm{Hg}$ lamp to within $\pm 0.1 \mathrm{meV}$. Photoluminescence reports usually quote the incident power density instead of incident power. So, a calculation of power density, from the incident power measured, for this particular system is summarized in Appendix A. The reflective losses caused by optical filters, lenses and dewar windows have been accounted for in determining the incident power densities. The incident laser power was varied by either changing the current through the laser tube when using CW Ar ion laser or by using a neutral density filter. For most of my experiments using a He-Ne laser as an excitation source, a power of $8 \mathrm{~mW}$ before the dewar was chosen corresponding to a power density of $3.45 \mathrm{~W} / \mathrm{cm}^{2}$. The power was measured with a silicon detector in a power meter from Coherent, Inc., whose response is dependent on the wavelength of the radiation measured. The manufacturer provided us with a correction curve as a function of wavelength, and I did correct accordingly the power measured for each wavelength used. All experiments were done on a vibration reducing optical table. 


\subsection{Sample Details}

A variety of $\mathrm{Cd}_{1-\mathrm{x}} \mathrm{Zn}_{\mathrm{x}} \mathrm{Te}$ samples (zinc concentration varying from 2 to $14 \%$ as determined from low-temperature PL studies) from various sources in U.S and abroad were investigated in my study. Most of them were grown by the High-Pressure Bridgman technique. The undoped bulk crystals were provided by companies like Digirad Corporation (San Diego, CA), Chemicon (Pittsburgh, PA), and by II-VI, Inc./eV products (Saxonburg, PA). One of the bulk CdTe (0\% Zn, undoped) samples provided by II-VI, Inc. has been used as a PL standard in our laboratory for many years. One bulk CdZnTe:In sample was grown by horizontal Bridgman and was grown at IMARAD (Israel). This particular sample contained about $6.3 \mathrm{ppm}$ of indium by weight, or about $1.9 \times 10^{17} \mathrm{~cm}^{-3}$, as determined form glow-discharge mass spectroscopy at Sandia. All of the samples had chemically polished surfaces to yield bright PL signals at low temperatures.

The bulk CdTe:In sample discussed in Chapter 5 was chemically polished and etched by me with a $2 \% \mathrm{Br} /$ methanol solution prior to PL measurements. Several intentionally doped (Cd,Zn)Te samples provided by Albert-Ludwigs-University Freiburg, Germany, and grown by a vapor-phase method with oriented seeds and polished on both sides with a bromine (2 Vol.-\%)-ethylene-glycol-solution were also included in the study. All samples were around $5 \times 2 \times 2 \mathrm{~mm}^{3}$ in dimension. 


\section{CHAPTER 4}

\section{RESULTS AND DISCUSSION}

\subsection{Low-Temperature PL Studies of Bulk $\mathrm{Cd}_{1-\mathrm{x}} \mathrm{Zn}_{\mathrm{x}} \mathrm{Te}(0 \leq \mathrm{x} \leq 0.14)$}

Low-temperature photoluminescence spectroscopy was performed on a set of eleven bulk $\mathrm{Cd}_{1-\mathrm{x}} \mathrm{Zn}_{\mathrm{x}} \mathrm{Te}(0 \leq \mathrm{x} \leq 0.14)$ samples in the emission region near the band-gap energy. $\mathrm{A}$ representative low temperature PL spectrum displaying detected recombination features in the near-edge emission range $1.4-1.65 \mathrm{eV}$ from the bulk $\mathrm{Cd}_{0.95} \mathrm{Zn}_{0.05} \mathrm{Te}$ (not intentionally doped) is shown in Fig. 4.1.

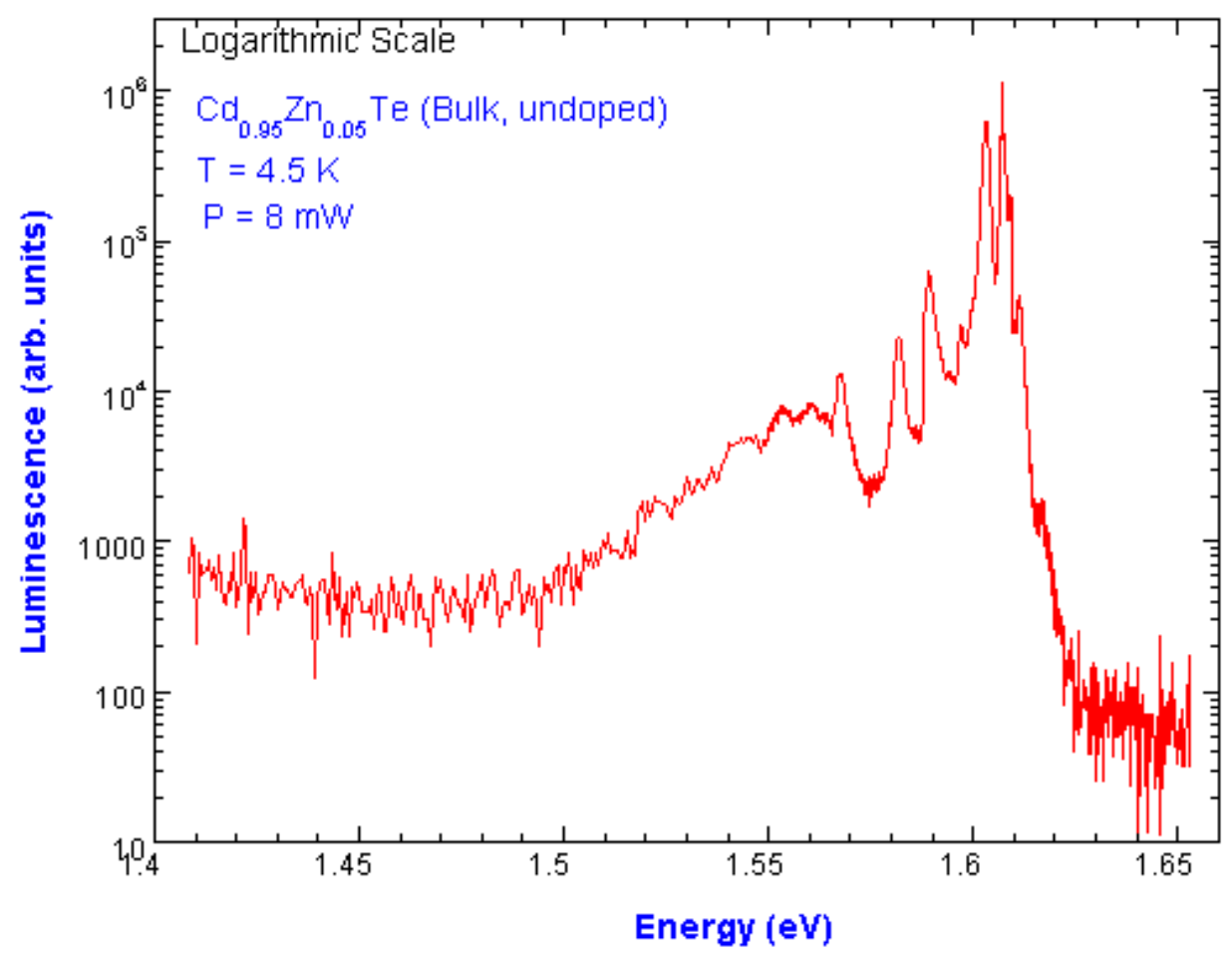

Figure 4.1: A representative PL spectrum of detector-grade $\mathrm{Cd}_{0.95} \mathrm{Zn}_{0.05} \mathrm{Te}$ at $4.5 \mathrm{~K}$. 


\subsubsection{Identification of Recombination Channels from Band-Edge Emission Spectra}

Most of the samples investigated exhibited a sharp, bright $\left(\mathrm{D}^{0}, \mathrm{X}\right)$ emission at $5 \mathrm{~K}$, as shown for sample $\mathrm{Cd}_{0.97} \mathrm{Zn}_{0.03} \mathrm{Te}$ in Figure 4.2. The excitation power density was 3.45 W/ $/ \mathrm{cm}^{2}$. Fig. 4.2.a (on next page) shows the PL data on a linear scale, and the same data is plotted on a logarithmic scale in Fig. 4.2.b. From Fig. 4.2.b, we see that the dominant ( $\left.\mathrm{D}^{0}, \mathrm{X}\right)$ line is at $1.606 \mathrm{eV}$. The PL feature at $1.588 \mathrm{eV}$ is identified from its asymmetric line shape as the $\mathrm{X}-1 \mathrm{LO}$ emission. The $\mathrm{LO}$ phonon energy in $\mathrm{Cd}_{1-\mathrm{x}} \mathrm{Zn}_{\mathrm{x}} \mathrm{Te}$ is essentially that of CdTe (21.3 $\mathrm{meV}$ ) for small $\mathrm{x}$ values, thus, adding $20.7 \mathrm{meV}$ to the $\mathrm{X}-1 \mathrm{LO}$ emission energy yields a freeexciton emission energy of about $1.609 \mathrm{eV}$. The predicted energy value for the free-exciton PL from the $\mathrm{Cd}_{0.97} \mathrm{Zn}_{0.03} \mathrm{Te}$ sample falls between the $1.608 \mathrm{eV}$ and $1.610 \mathrm{eV}$ features shown in Fig. 4.2.b. These two emissions are identified as the transverse (lower energy) and longitudinal (higher energy) components of the polariton (i.e., exciton-photon interaction). The energy difference of $2 \mathrm{meV}$ is the splitting of the exciton energy states due to the strong exciton-photon interaction. The polariton splitting observed in PL spectra from bulk CdTe is typically $0.4-0.5 \mathrm{meV}$, however energy splitting of about $1 \mathrm{meV}$ have been observed in CdTe epilayers (Giles 1987). Using a free-exciton energy of $1.609 \mathrm{eV}$ and then adding the free exciton binding energy of $10.8 \mathrm{meV}$, we get the bandgap $\mathrm{E}_{\mathrm{g}}$ for this sample to be 1.62 $\mathrm{eV}$ and the zinc molar concentration $\mathrm{x}$ equal to 0.027, using an expression by Franc (Franc 2000) as will be discussed in detail in the next section. The weak feature at $1.616 \mathrm{eV}$

corresponds to the $n=2$ excited state of the free exciton. At lower energies, we see the $\left(\mathrm{A}^{0}, \mathrm{X}\right)$ recombinations at $1.602 \mathrm{eV}$ and its first phonon replica appears at $1.581 \mathrm{eV}$. The peak at $1.593 \mathrm{eV}$, which appears $\sim 23 \mathrm{meV}$ below the $\mathrm{X}_{2}$ emission band, is a phonon replica $\left(\mathrm{X}_{2}\right.$ - 
1LO) of the excited-state of the free exciton. Detection of the $X_{2}$ and $\left(X_{2}-1 L O\right)$ emissions is unusual and gives evidence that this sample is of high quality (detector-grade).

The deep $\left(\mathrm{A}^{0}, \mathrm{X}\right)$ at $\sim 25 \mathrm{meV}$ below the bandgap is attributed to defects, or complexes, involving cadmium vacancies (Hjelt 1997). We note that a PL emission has been detected 22 meV below the band gap in high-resistivity CdTe:In (Zimmerman 1994, Worschech 1995) and attributed to an isoelectronic defect complex involving two indium atoms and a Cd vacancy as will be discussed in detail in Chapter 5.

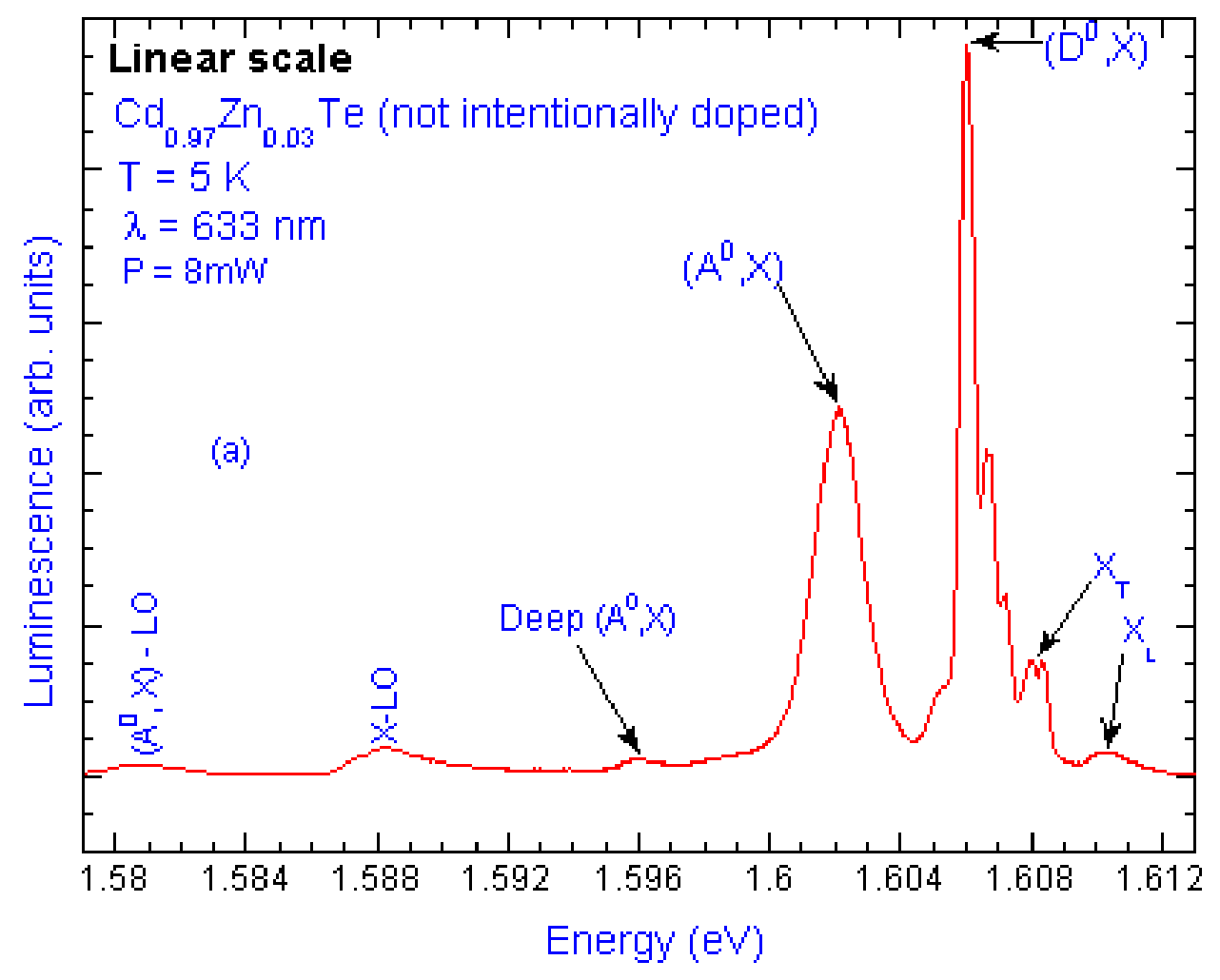

Figure 4.2.a: PL from HPB-grown CdZnTe at liquid helium temperature plotted on a linear scale. 


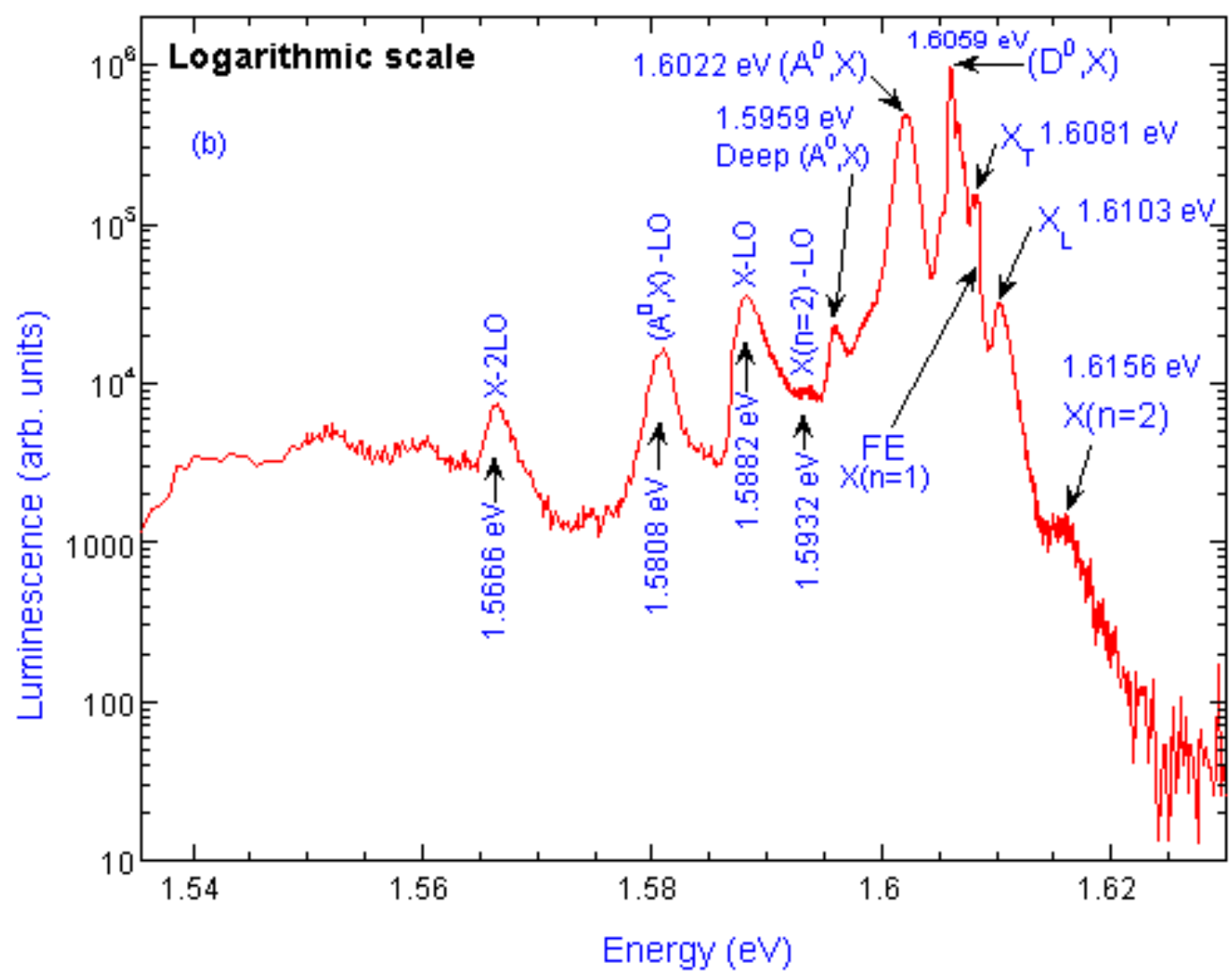

Figure 4.2.b: PL from HPB-grown CdZnTe at liquid-helium temperature plotted on a logarithmic scale.

Typical PL spectra of three different detector grade CZT samples with different zinc concentrations are shown in Figure 4.3. We see that in all the three samples, the spectra is dominated by a sharp donor bound exciton emission line $\left(\mathrm{D}^{0}, \mathrm{X}\right)$ and it is at a higher energy value for higher zinc concentration, i.e., an increase in zinc concentration shifts the PL spectra to higher energy. 


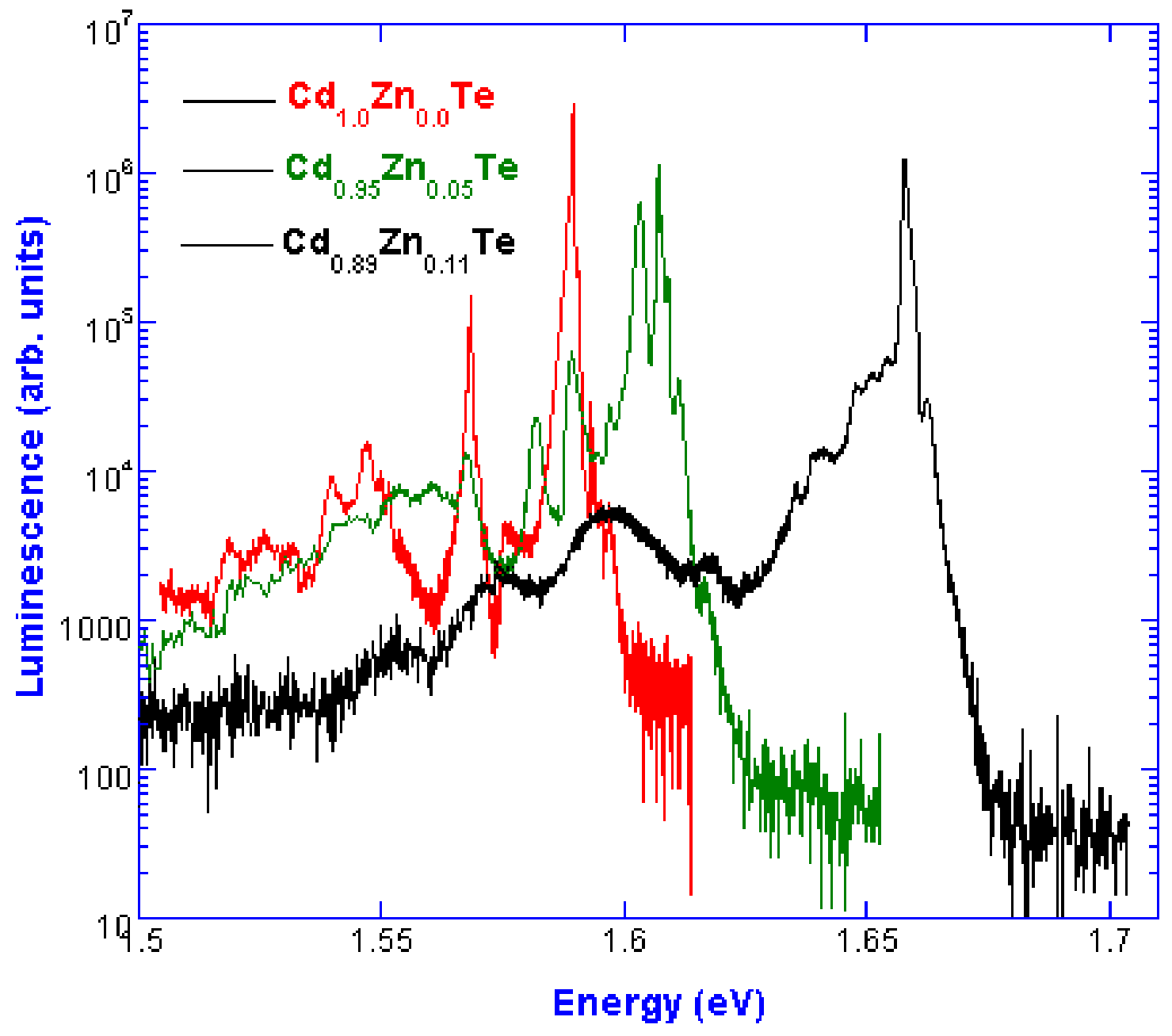

Figure 4.3: A comparison of PL spectra from three bulk and unintentionally doped CZT samples with different zinc concentrations, showing that higher zinc concen-tration shifts the spectrum to higher energies. 


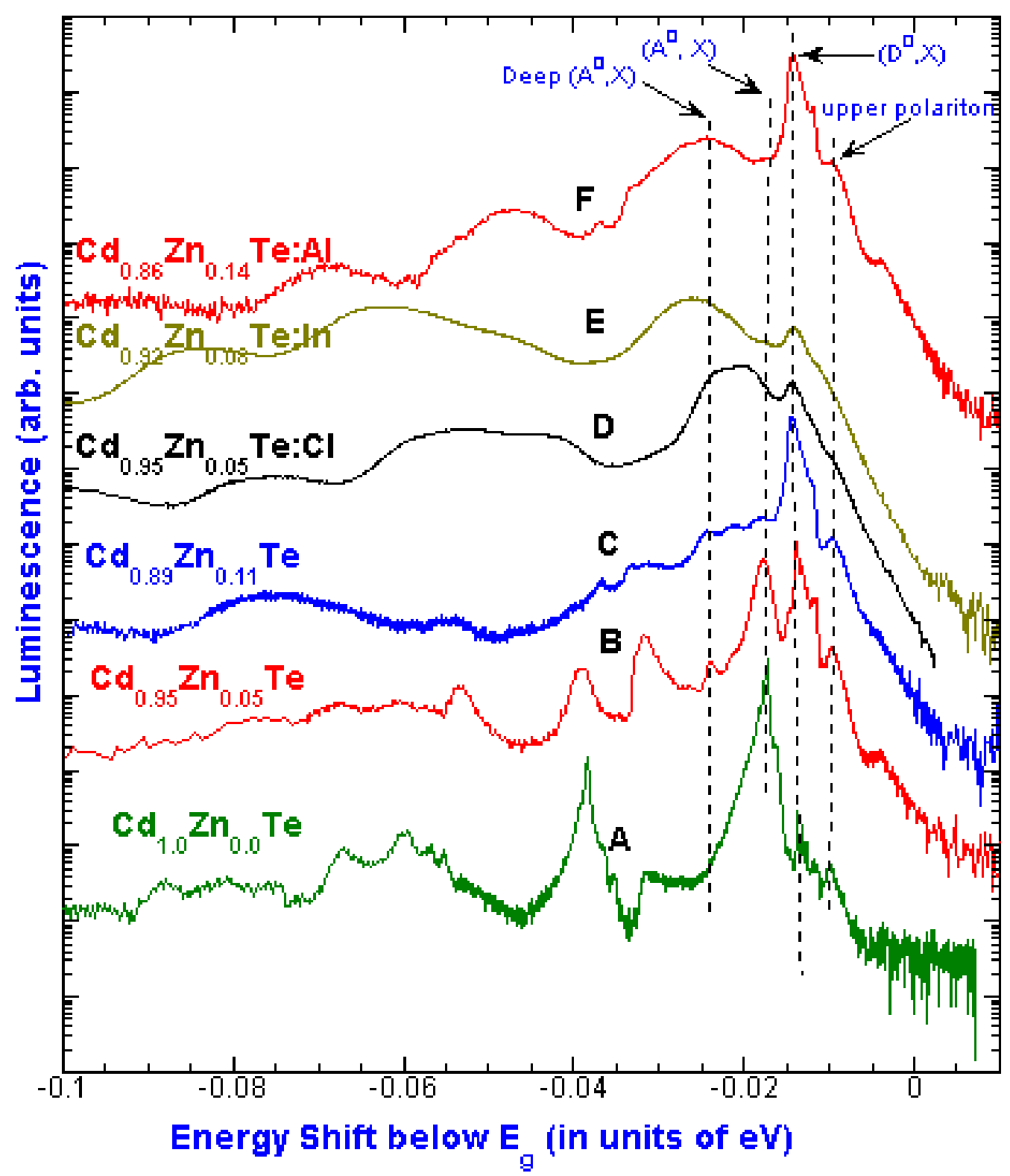

Figure 4.4: Comparison of relative intensities of PL bands from six samples with different Zn concentrations. The horizontal axis is normalized to show the energy shift relative to the band gap for each sample. Spectra are displaced vertically for clarity. 
The samples in my study exhibit PL spectra at $5 \mathrm{~K}$, which are similar to Fig. 4.2, but there are small differences in the radiative recombination spectra which provide useful information. To compare relative intensities of PL bands from samples with different $\mathrm{Zn}$ concentrations, I have chosen six different samples, three undoped and three intentionally doped and their emission energies relative to the band gap energy are used for clarity. Results are shown in Figure 4.4, where the horizontal axis is normalized to show the energy shift (in eV) relative to the band gap for each sample. The logarithm of the PL intensity is plotted vs. energy, with the six curves displaced vertically for ease of comparison. First, consider the deep $\left(\mathrm{A}^{0}, \mathrm{X}\right)$ band at about 23 to $24 \mathrm{meV}$ below the bandgap. This PL, denoted by the left vertical dashed line in Fig. 4.4, is prominent in Samples D, E, and F, and shows up weakly in Sample C. The feature in Sample B at this location is believed to be the $X(n=2)-1 L O$ band (note Sample B shows clearly the excited-state emission above the upper polariton). We attribute the deep $\left(\mathrm{A}^{0}, \mathrm{X}\right)$ band to acceptor complexes involving donor impurities. Thus, based on the data presented in Fig. 4.4, the Imarad sample E is expected to have maximum donor impurities $\left(1.7 \times 10^{17} \mathrm{~cm}^{-3}\right)$ as indicated by the relative intensities of the deep $\left(\mathrm{A}^{0}, \mathrm{X}\right)$ emission. From Figure 4.4, we notice that though samples B through F are all bulk CZT, their PL spectra at $5 \mathrm{~K}$ look very different. The neutral acceptor bound exciton feature $\left(\mathrm{A}^{0}, \mathrm{X}\right)$ due to shallow acceptors is very prominent in Sample B and is weak or entirely absent in the other CZT samples. Also, we can see the upper polariton branch in the undoped samples very clearly but not so clearly in the Cl- and In-doped samples. The PL from Sample F shows clearly the upper polariton branch, thus indicating that the donor concentration is less than that in Samples D and E. 


\subsection{2 $\mathrm{Cd}_{1-\mathrm{x}} \mathrm{Zn}_{\mathrm{x}}$ Te: Determination of Zinc Molar Concentration using PL at 4.5 K}

In the ternary compound $\mathrm{Cd}_{1-\mathrm{x}} \mathrm{Zn}_{\mathrm{x}} \mathrm{Te}$, the band gap and free-exciton energies depend on zinc molar concentration (x). As $\mathrm{x}$ increases from 0 to 1 , the lattice parameter decreases. This reduction in the inter-atomic spacing increases the repulsive interaction between core electrons and thus increases the band gap. The $\mathrm{Zn}$ molar fraction ( $\mathrm{x}$ ) is determined from PL using expressions in the literature that predict band-gap energy $\left(\mathrm{E}_{\mathrm{g}}\right)$ vs $\mathrm{x}$. Low-temperature PL was done at $4.5 \mathrm{~K}$ on a set of 8 high quality undoped bulk CZT crystals cut from the same boule using the $633-\mathrm{nm}$ He-Ne laser, $\sim 2 \mathrm{~mW}$ power, and spectrometer slits set to $200 \mu \mathrm{m}$. The band-gap energy for each sample was determined using liquid-helium PL data. In most samples, the upper and lower polariton branches can be observed directly in PL spectra. The $\mathrm{E}_{\mathrm{g}}$ value is determined by adding $10.8 \mathrm{meV}$ (free exciton binding energy) to the average value of the upper and lower polariton energies. Room temperature PL is not used to determine $\mathrm{E}_{\mathrm{g}}$ (or $\mathrm{x}$ values) since the PL emission band is composed of several overlapping bands related to excitonic transitions. Phonon-associated exciton recombinations can also occur, and shallow donor emission may still be present in n-type doped samples as discussed in the next section. Thus, PL data at $4.5 \mathrm{~K}$ is found to be the most reliable way to determine $\mathrm{E}_{\mathrm{g}}$.

Expressions in the literature (used in Table 4.1):

1. $\mathrm{E}_{\mathrm{g}}(12 \mathrm{~K})=1.598+0.614 \mathrm{x}+0.166 \mathrm{x}^{2}(\mathrm{eV})[$ Olego 1985] $(0<\mathrm{x}<1)$

2. $\mathrm{E}_{\mathrm{g}}(9 \mathrm{~K})=1.604+0.42 \mathrm{x}+0.33 \mathrm{x}^{2} \quad(\mathrm{eV})[$ Chen 1991] $(0<\mathrm{x}<0.1)$

3. $\mathrm{E}_{\mathrm{g}}(4.2 \mathrm{~K})=1.606+0.322 \mathrm{x}+0.463 \mathrm{x}^{2} \quad(\mathrm{eV})[$ Reno and Jones 1992] $(0<\mathrm{x}<1)$

4. $\mathrm{E}_{\mathrm{g}}(4.2 \mathrm{~K})=1.6058+0.546 \mathrm{x} \quad(\mathrm{eV})[$ Tobin 1995] $(0.03<\mathrm{x}<0.06)$

5. $\mathrm{E}_{\mathrm{g}}(2 \mathrm{~K})=1.606+0.522 \mathrm{x}+0.26 \mathrm{x}^{2} \quad(\mathrm{eV})[$ Magnea 1994] $(0<\mathrm{x}<1)$

6. $\mathrm{E}_{\mathrm{g}}(\mathrm{x})=1.606+0.520 \mathrm{x}+0.254 \mathrm{x}^{2} \quad(\mathrm{eV})[$ Franc, 2000] $(0<\mathrm{x}<0.06)$ 
Table 4.1: Comparison of the measured zinc concentration in 10 different CZT samples cut from the same boule using the expressions proposed in the literature.

\begin{tabular}{cccccccc} 
Sample & Energy & $\boldsymbol{X}$ & $\boldsymbol{X}$ & $\boldsymbol{X}$ & $\boldsymbol{X}$ & $\boldsymbol{X}$ & $\boldsymbol{X}$ \\
$\#$ & bandgap & [Olego] & [Chen] & [Jones] & [Tobin] & [Magnea] & [Franc] \\
\hline $\boldsymbol{1}$ & $1.6622 \mathrm{eV}$ & 0.102 & 0.126 & 0.144 & 0.103 & 0.102 & 0.103 \\
$\mathbf{2}$ & $1.6585 \mathrm{eV}$ & 0.096 & 0.119 & 0.136 & 0.096 & 0.096 & 0.096 \\
$\mathbf{4}$ & $1.6500 \mathrm{eV}$ & 0.083 & 0.101 & 0.117 & 0.081 & 0.081 & 0.081 \\
$\mathbf{5}$ & $1.6752 \mathrm{eV}$ & 0.122 & 0.151 & 0.172 & 0.127 & 0.125 & 0.125 \\
$\mathbf{6}$ & $1.6742 \mathrm{eV}$ & 0.120 & 0.149 & 0.170 & 0.125 & 0.123 & 0.124 \\
$\mathbf{8}$ & $1.6696 \mathrm{eV}$ & 0.113 & 0.141 & 0.160 & 0.117 & 0.115 & 0.116 \\
$\mathbf{9}$ & $1.6638 \mathrm{eV}$ & 0.104 & 0.129 & 0.148 & 0.106 & 0.105 & 0.106 \\
$\mathbf{1 0}$ & $1.6638 \mathrm{eV}$ & 0.104 & 0.129 & 0.148 & 0.106 & 0.105 & 0.106 \\
\hline
\end{tabular}

\section{Comments:}

We see that the bandgap varies by about $25 \mathrm{meV}$. The minimum concentration of $\mathrm{Zn}$ found was 0.08 in Sample \#4 and the max. concentration of Zn found was 0.13 in Sample \#5. We see that the results from the expressions by Olego, Magnea, Tobin and Franc are in good agreement. Values obtained from Chen and Jones expressions are high. Tobin and Franc expressions are in good agreement even though the Tobin expression was determined for a narrow range of $0.03<x<0.06$. Magnea's expression yields $\mathrm{x}$ values between Olego and Tobin. The samples are arranged in the order of first-to-freeze to last-to-freeze in Table 4.2. 
Table 4.2: Samples arranged in the order of first-to-freeze to last-to-freeze according to their known zinc concentrations.

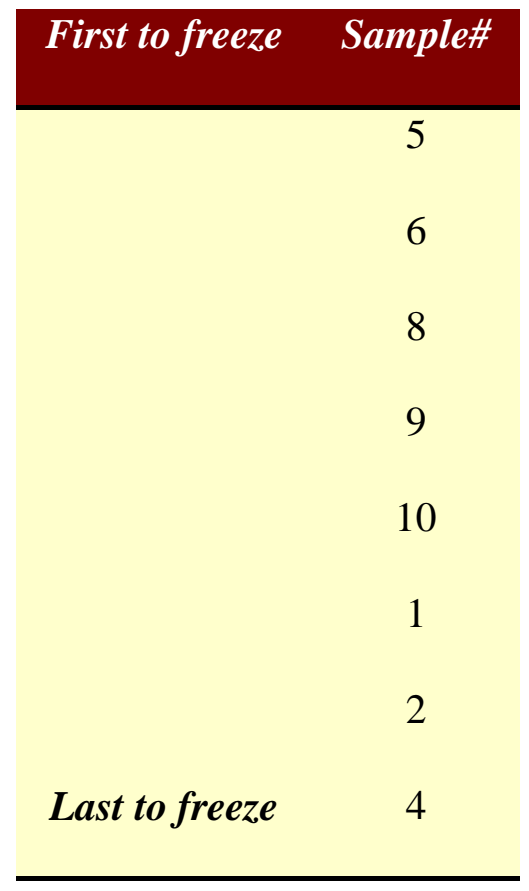

Because the segregation coefficient of zinc in CdZnTe is greater than one, the zinc content of the crystal decreases as solidification proceeds. The composition decreases in the growth direction by 0.05 over a distance of a few centimeters.

\subsection{Temperature-Dependent PL Studies of $\mathrm{Cd}_{1-\mathrm{x}} \mathrm{Zn}_{\mathrm{x}} \mathrm{Te}$ crystals $(0 \leq \mathrm{x} \leq 0.14)$}

\subsubsection{Study of the PL Signal as a Function of Sample Temperature}

I have performed a detailed PL study on eleven different samples, doped and undoped having different zinc concentrations, as a function of temperature to verify the origin of the room-temperature PL from CZT grown for radiation-detector/IR-substrate applications. PL measurements were made in the range from $5 \mathrm{~K}$ to $300 \mathrm{~K}$. Figures 4.5 through 4.8 show the temperature dependence behavior of the PL from a bulk $\mathrm{Cd}_{0.967} \mathrm{Zn}_{0.033} \mathrm{Te}$ sample (nominally 
undoped) from $5 \mathrm{~K}$ to $300 \mathrm{~K}$. At $5 \mathrm{~K},\left(\mathrm{D}^{0}, \mathrm{X}\right)$ and $\left(\mathrm{A}^{0}, \mathrm{X}\right)$ recombinations are dominant. Over the range of temperature from $20 \mathrm{~K}$ to $60 \mathrm{~K}$, most of the shallow-donor related PL is thermally quenched. The $\left(\mathrm{A}^{0}, \mathrm{X}\right)$ peak quenches rather rapidly when the temperature is raised merging with other transitions at about $30 \mathrm{~K}$. The $\left(\mathrm{D}^{0}, \mathrm{X}\right)$ peak possibly evolves to a donor-to-valence band transition with increasing temperature. The first-order phonon replica of the "free exciton" (upper polariton branch can be resolved from most samples up to 125 K) can be seen at about 21-22 meV below the exciton emission band. This 1LO phonon replica merges and superimposes with the decaying shallow-donor related band as sample temperature is raised. The phonon replica of band-band recombination can also contribute and a single broad emission band can be tracked from $150 \mathrm{~K}$ to room temperature. The exciton contribution appears as a high-energy tail merging with the band-band recombination at $300 \mathrm{~K}$.

Figure 4.9 shows additional temperature dependence data taken from unintentionally doped CZT. Figure 4.9.a shows the PL data taken from $65 \mathrm{~K}$ to $150 \mathrm{~K}$ for another $\mathrm{Cd}_{0.95} \mathrm{Zn}_{0.05} \mathrm{Te}$ (not intentionally doped) sample. The temperature dependence behavior of the PL is very similar to that shown in Fig. 4.8. The 5-K PL from this sample was also dominated by $\left(\mathrm{D}^{0}, \mathrm{X}\right)$ and $\left(\mathrm{A}^{0}, \mathrm{X}\right)$ features which quenched above $35 \mathrm{~K}$. From $65 \mathrm{~K}$ to 150 $\mathrm{K}$, we see clearly that the donor-related PL quenches and merges with the phonon replica of the polariton as the sample temperature is raised. Figure 4.9.b shows a comparison of PL spectra at $50 \mathrm{~K}$ and $125 \mathrm{~K}$ from a $\mathrm{Cd}_{0.89} \mathrm{Zn}_{0.11}$ Te bulk sample, which is not intentionally doped. The separation between the upper polariton branch and the other remaining emission peak at $50 \mathrm{~K}$ is only about $6 \mathrm{meV}$ (indicating that the peak has a donor contribution). At 125 $\mathrm{K}$, however, the energy separation has increased to $11 \mathrm{meV}$ indicating clearly that the 
intensity of the donor-related peak decreases with temperature and is not a dominant factor in the PL at higher temperatures. The donor-related emission superimposes with another feature at lower energy causing a net broadening in the band and hence an increased separation. This lower-energy PL band that overlaps and merges with the donor-related feature, and is comparable in intensity, is the phonon replica of the upper polariton $\left(\mathrm{X}_{\mathrm{U}}-1 \mathrm{LO}\right)$.

To explore the temperature dependence further, a sample of CdTe was studied. Figures 4.10 through 4.12 show the PL spectra from undoped bulk CdTe from $5 \mathrm{~K}$ to $185 \mathrm{~K}$. The temperature dependence behavior from 200 to $300 \mathrm{~K}$ is not shown for this sample as it is similar to the one shown in Fig. 4.8 (one broad peak shifting to lower energies with increasing temperature). From $40 \mathrm{~K}$ to $60 \mathrm{~K}$, the merging of the $\left(\mathrm{D}^{0}, \mathrm{~h}\right)$ and $\mathrm{X}-1 \mathrm{LO}$ features into one broad band is observed.

Figures 4.13 and 4.14 show the PL spectra from $4.5 \mathrm{~K}$ to $300 \mathrm{~K}$ for a doped bulk $\mathrm{Cd}_{0.92} \mathrm{Zn}_{0.08}$ Te:In sample (from IMARAD). The 4.5-K PL spectrum shows a bright deep-level band peaking near $1.45 \mathrm{eV}$, attributed to DAP recombination related to shallow indium donor centers and the indium A-center acceptor (i.e., $\mathrm{V}_{\mathrm{Cd}}-\mathrm{In}_{\mathrm{Cd}}$ ). The features are broader in this sample and the upper polariton branch is not clearly resolved. The deep DAP emission quenches and is not observed at $300 \mathrm{~K}$. There is one emission at room temperature, similar to the undoped samples. Because the upper polariton branch is not resolved from donorrelated PL, it is difficult to comment on the radiative transition that is remaining at higher temperatures in this sample. We note that this n-type material has been reported to have good detector efficiencies and measurements of the internal electric field have indicated uniformity. So, even though there are a significant number of shallow donors and compensating acceptors present in this sample, these do not appear to hinder device performance! 


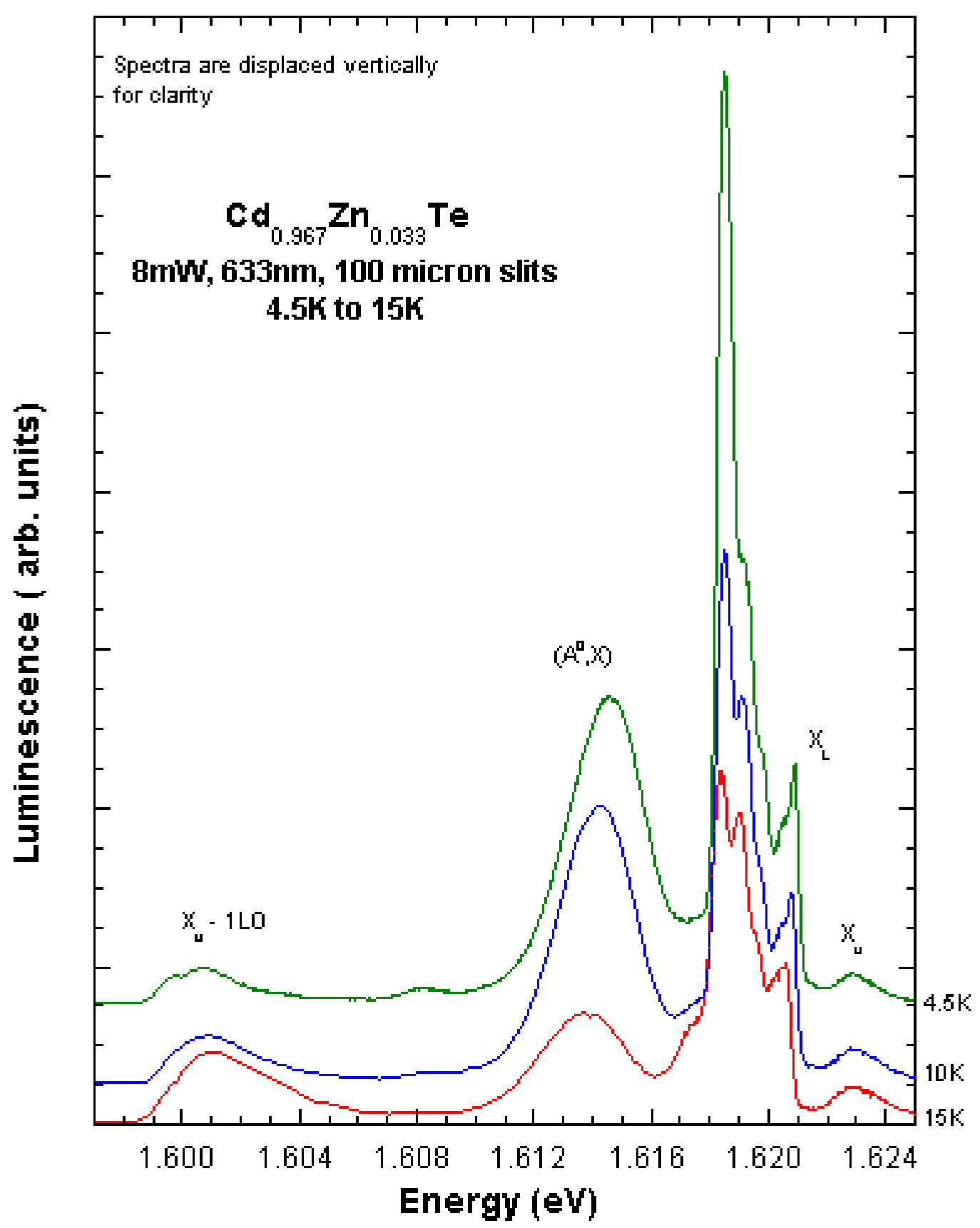

Figure 4.5: Temperature-dependence plot from $5 \mathrm{~K}$ to $15 \mathrm{~K}$ for $\mathrm{Cd}_{0.97} \mathrm{Zn}_{0.03} \mathrm{Te}$. 


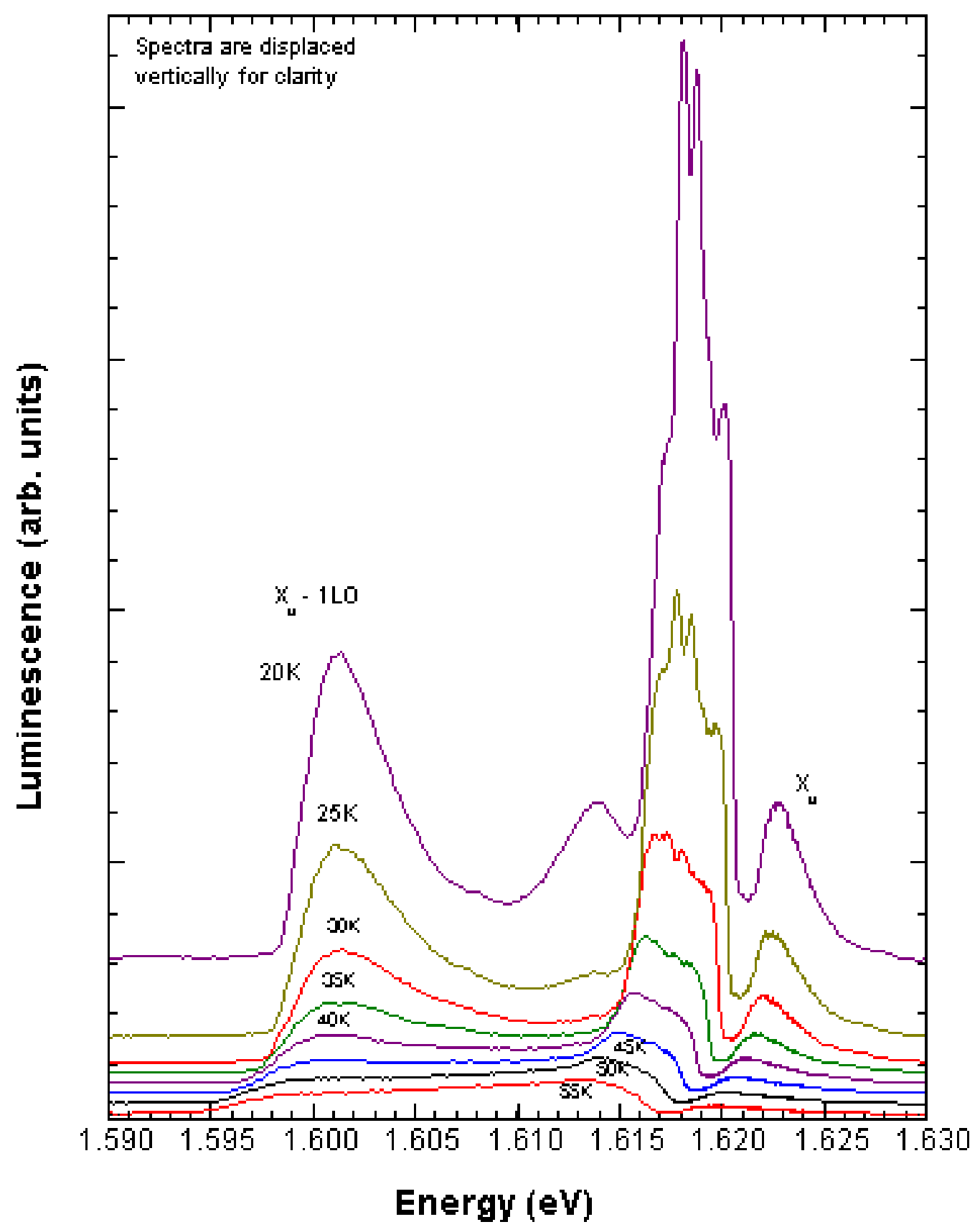

Figure 4.6: Temperature-dependence plot from $20 \mathrm{~K}$ to $55 \mathrm{~K}$ for $\mathrm{Cd}_{0.97} \mathrm{Zn}_{0.03} \mathrm{Te}$. 


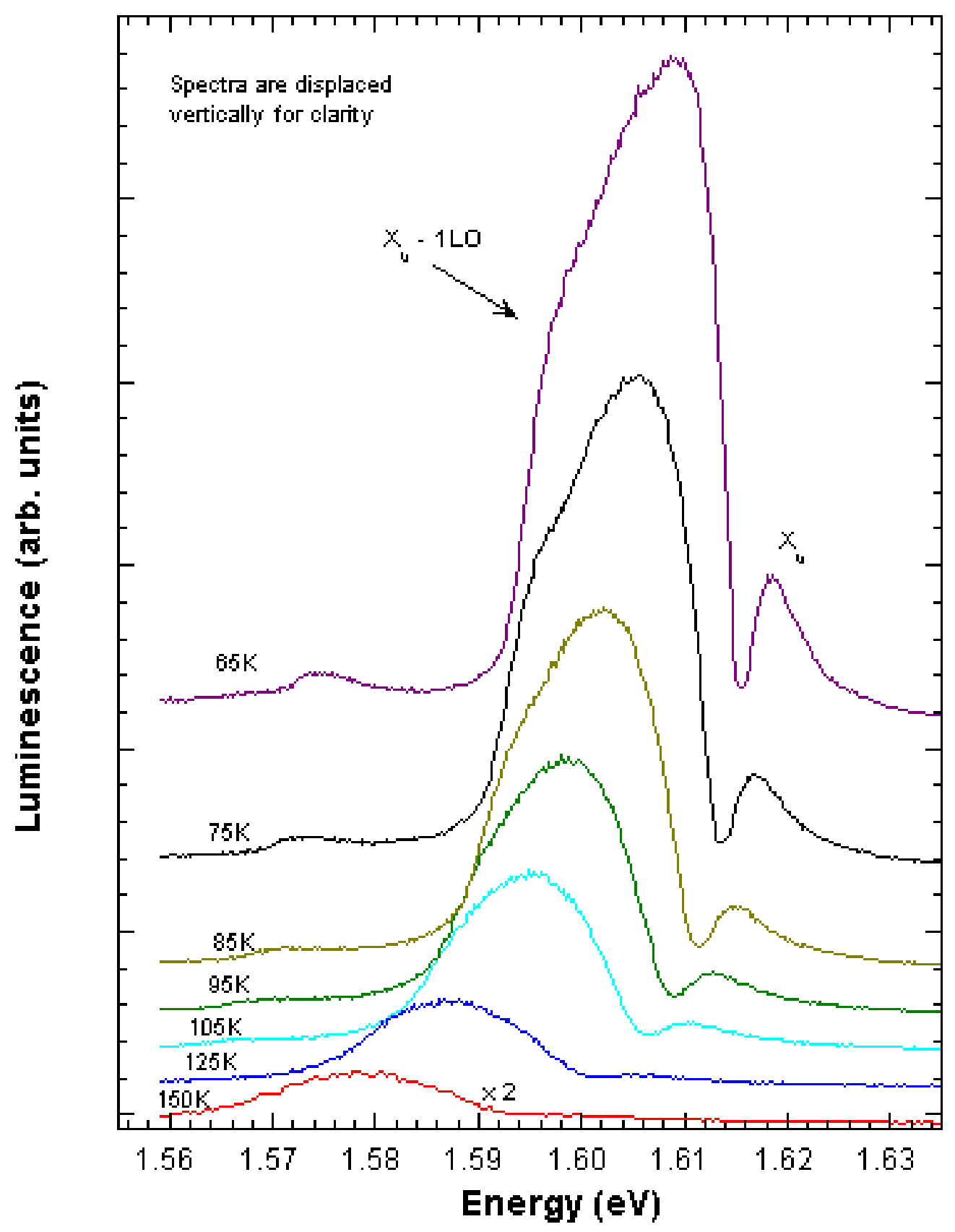

Figure 4.7: Temperature-dependence plot from $65 \mathrm{~K}$ to $150 \mathrm{~K}$ for $\mathrm{Cd}_{0.97} \mathrm{Zn}_{0.03} \mathrm{Te}$. 


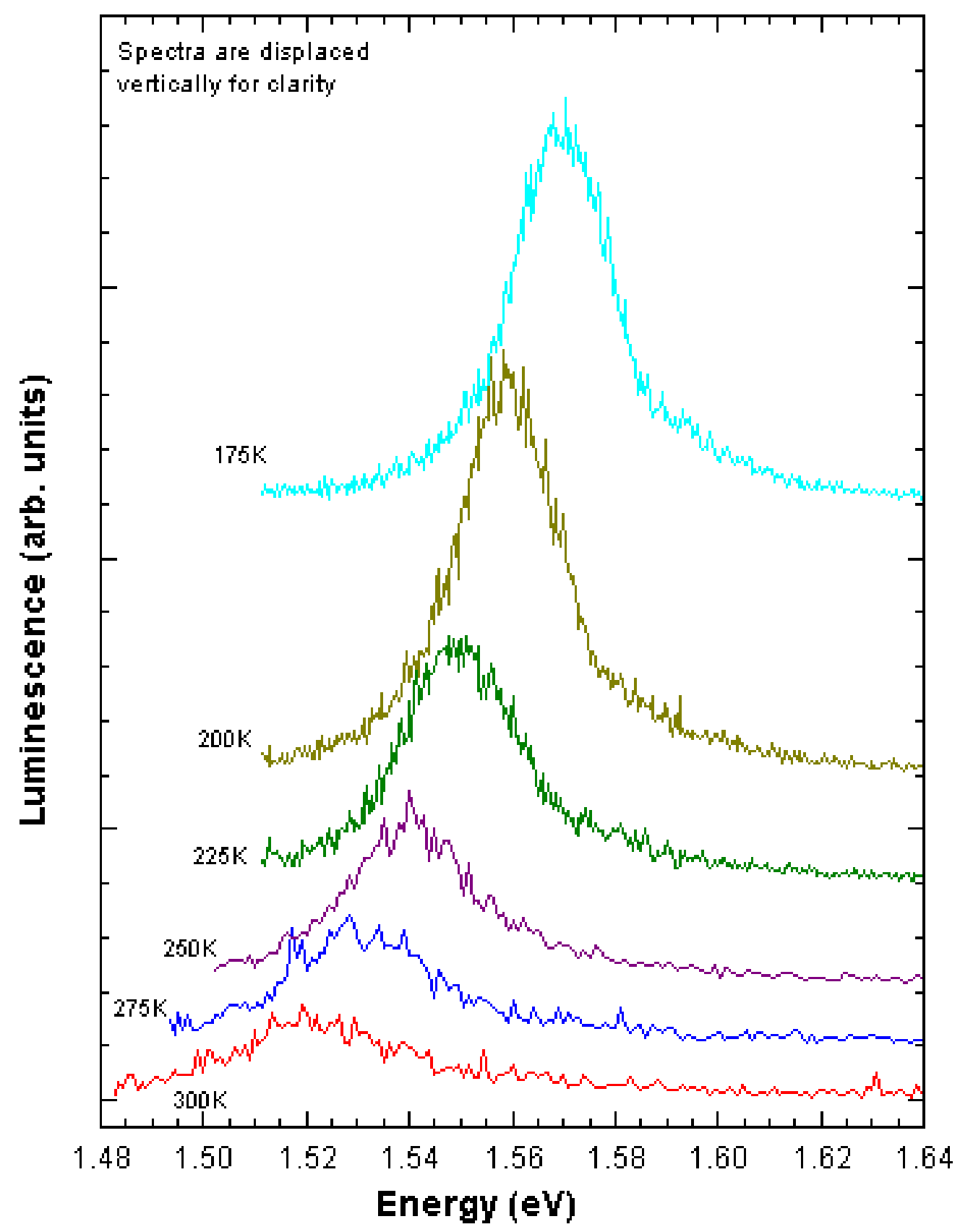

Figure 4.8: Temperature-dependence plot from $175 \mathrm{~K}$ to $300 \mathrm{~K}$ for $\mathrm{Cd}_{0.97} \mathrm{Zn}_{0.03} \mathrm{Te}$. 


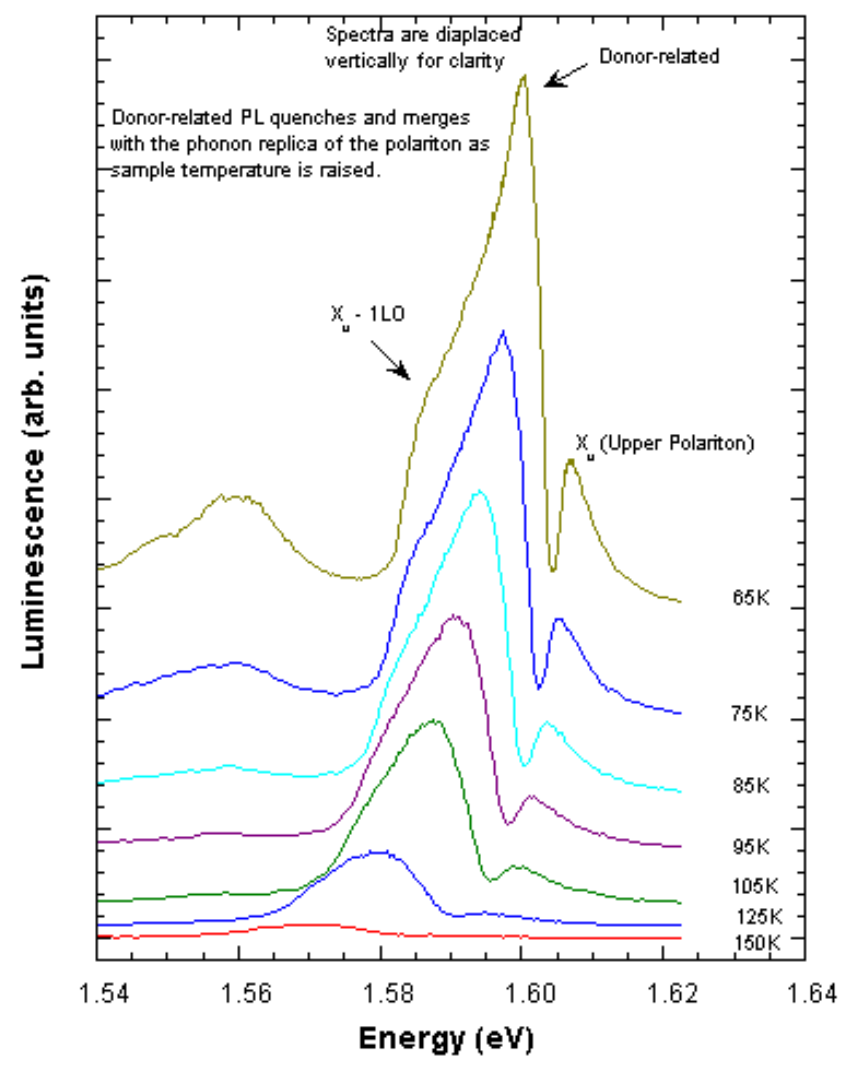

Figure4.9.a: Temperature-dependence of PL from $65 \mathrm{~K}$ to $150 \mathrm{~K}$ from bulk $\mathrm{Cd}_{0.95} \mathrm{Zn}_{0.05} \mathrm{Te}$.

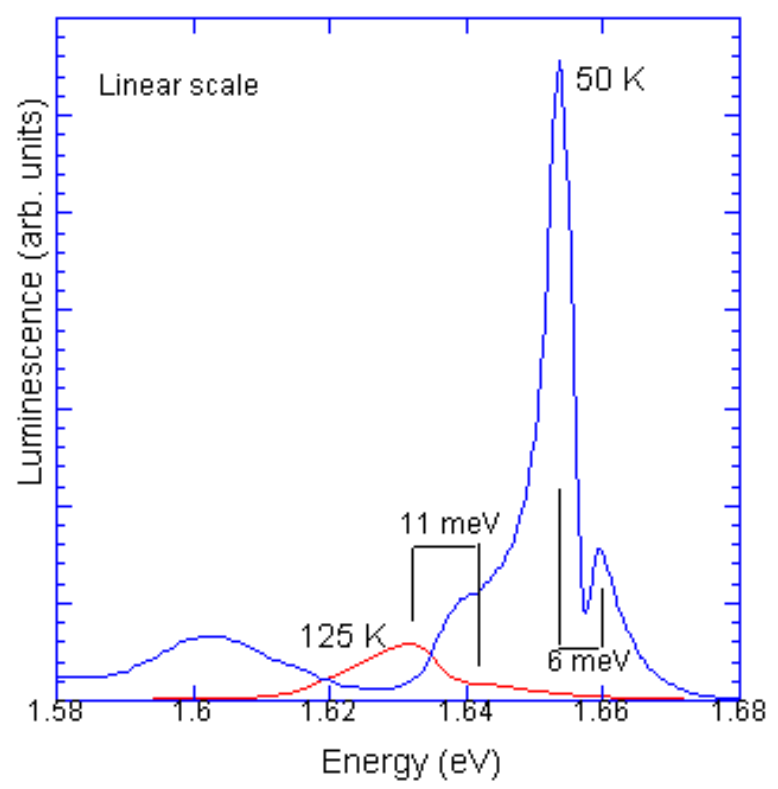

Figure 4.9.b: Comparison of $\mathrm{PL}$ at $50 \mathrm{~K}$ and $125 \mathrm{~K}$ from bulk $\mathrm{Cd}_{0.89} \mathrm{Zn}{ }_{0.11} \mathrm{Te}$. 


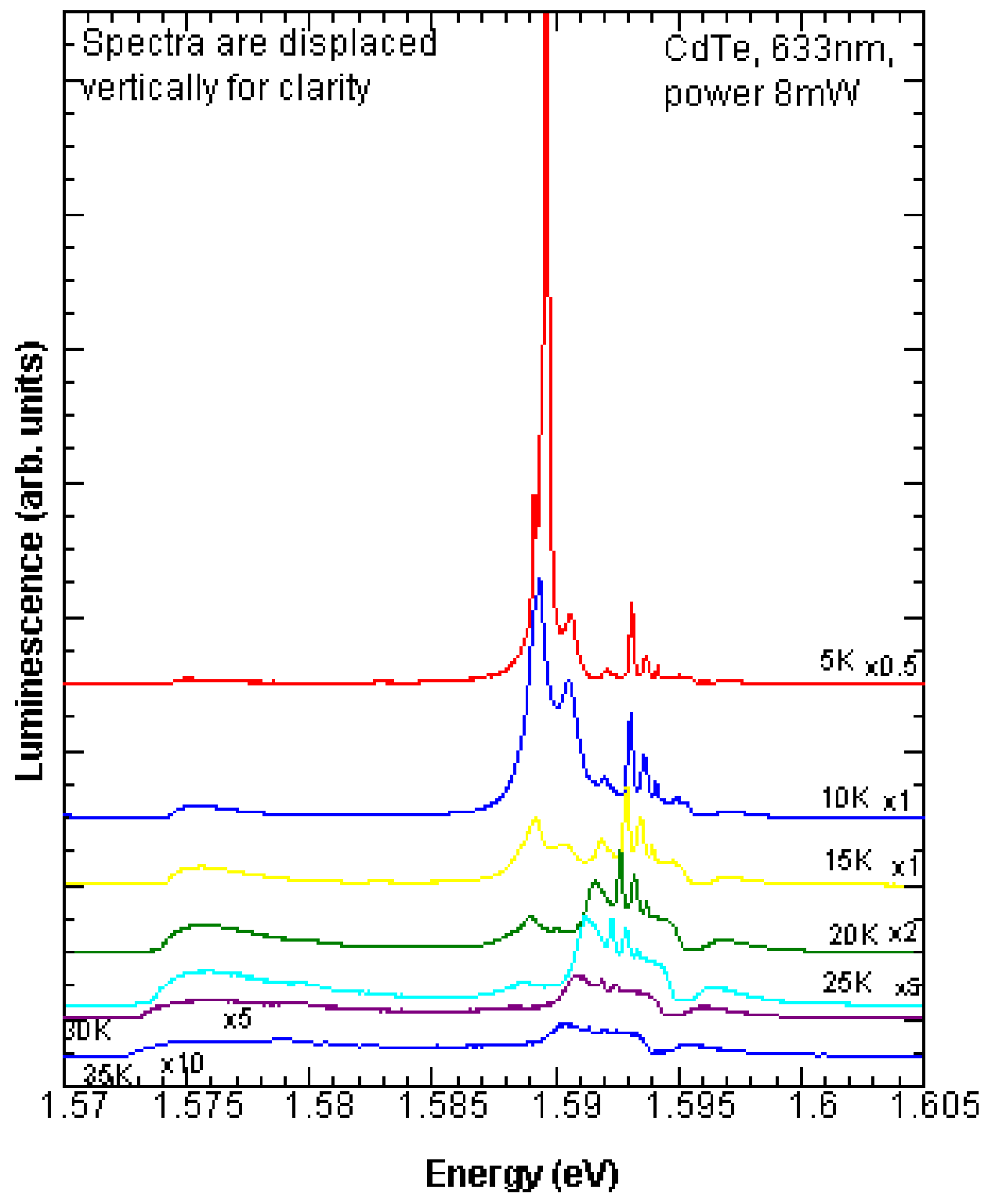

Figure 4.10: Temperature-dependence plot from $5 \mathrm{~K}$ to $35 \mathrm{~K}$ from bulk CdTe. 


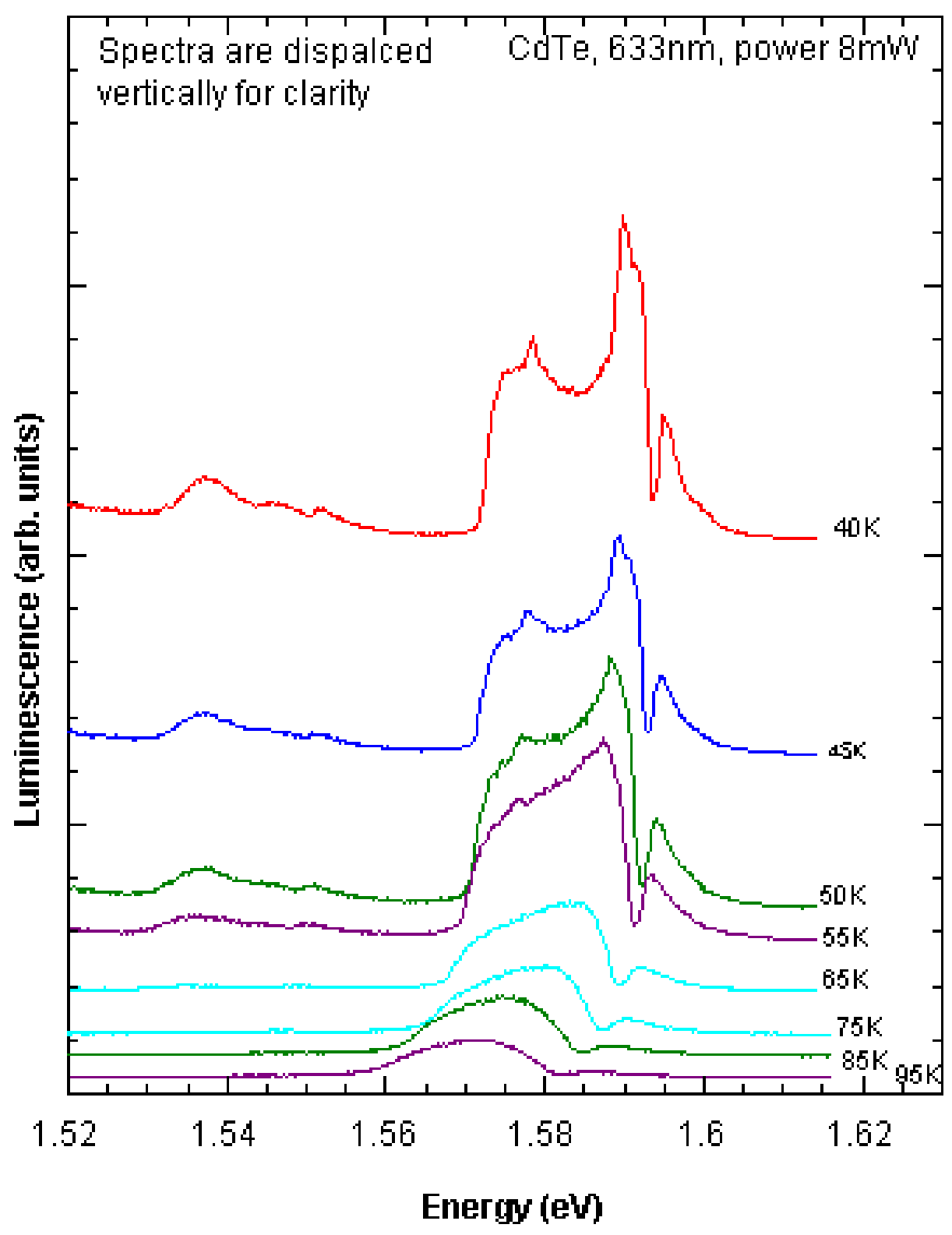

Figure 4.11: Temperature-dependence plot from $40 \mathrm{~K}$ to $95 \mathrm{~K}$ from undoped CdTe. 


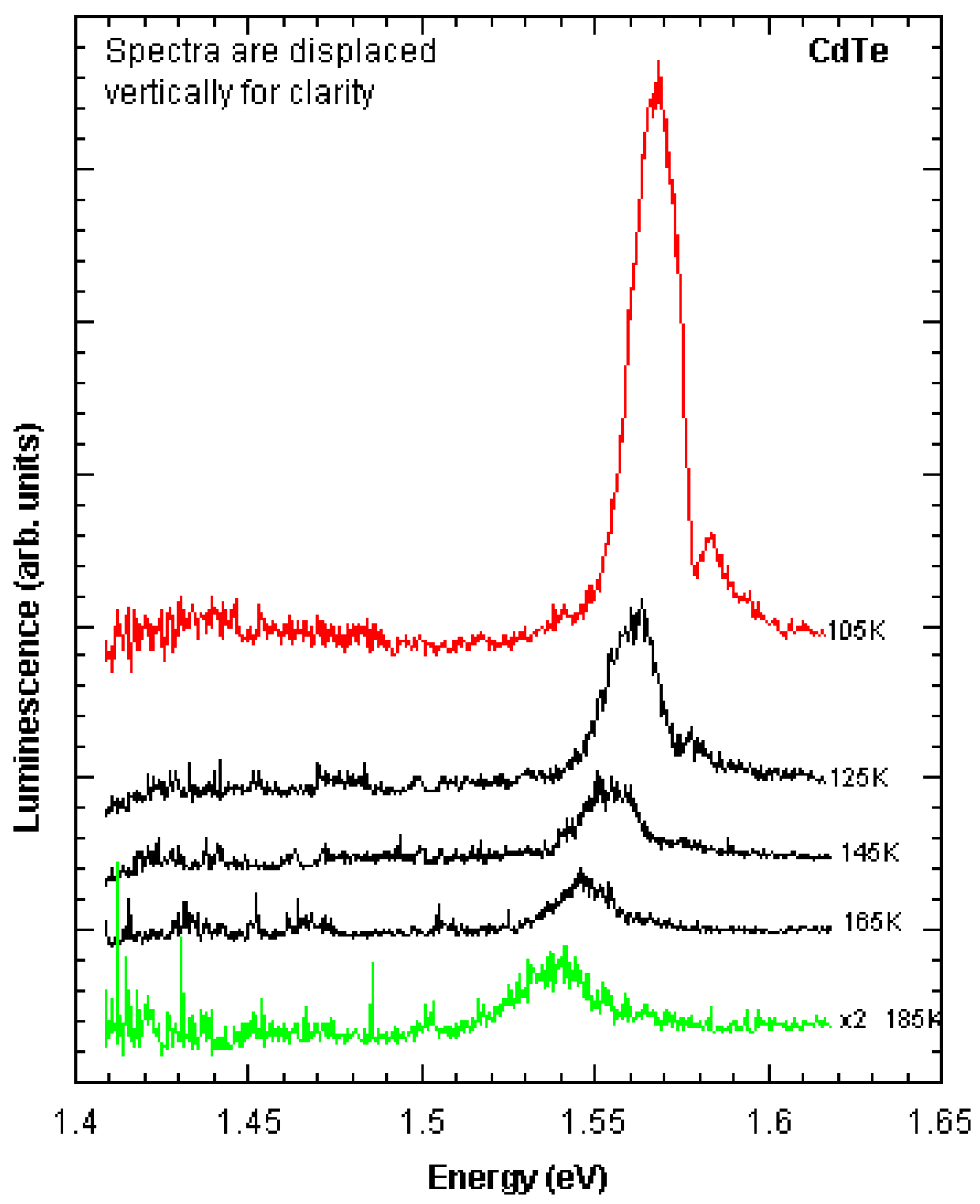

Figure 4.12: Temperature-dependence plot from $105 \mathrm{~K}$ to $185 \mathrm{~K}$ from undoped CdTe. 


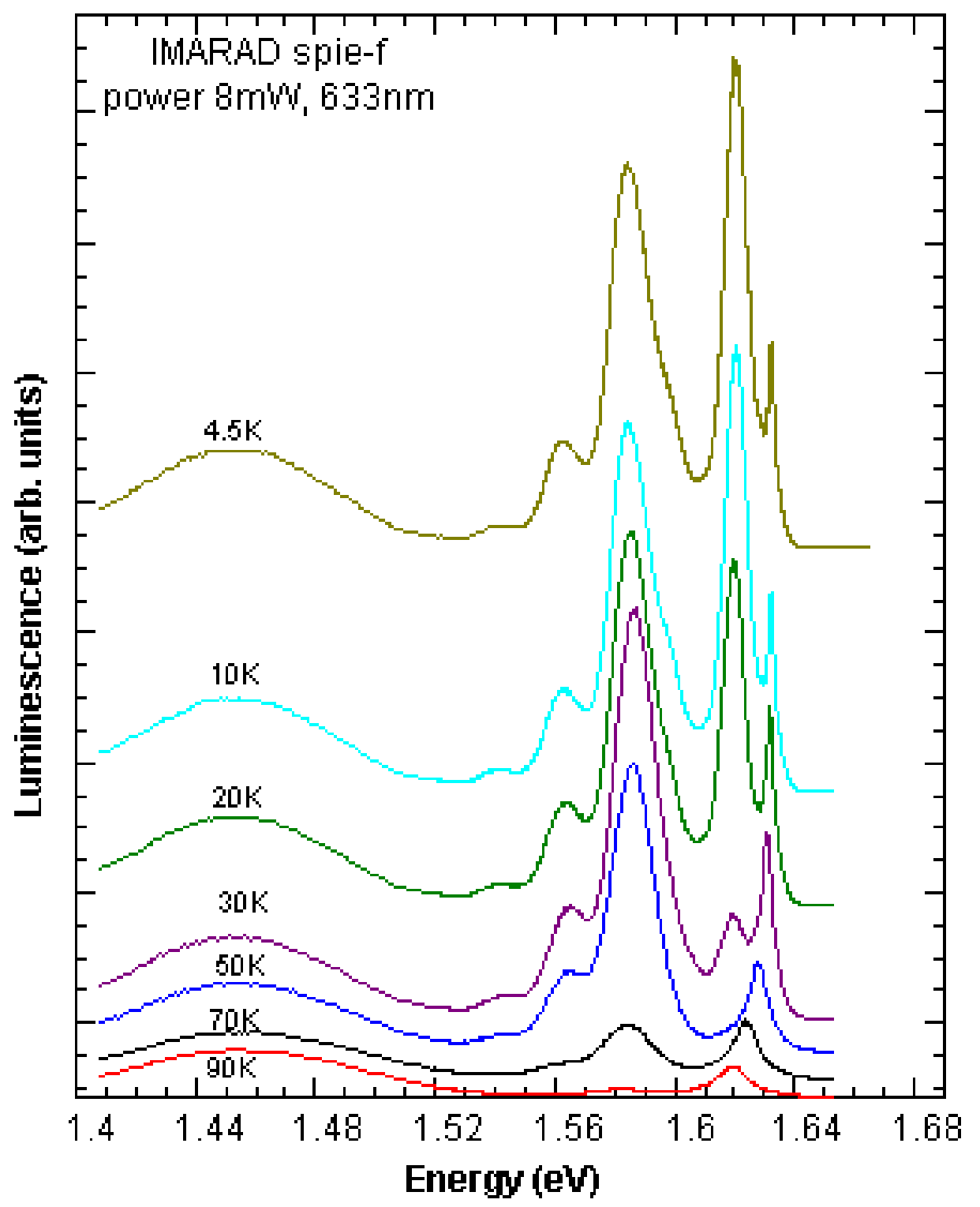

Figure 4.13: Temperature-dependence plot from $4.5 \mathrm{~K}$ to $90 \mathrm{~K}$ from $\mathrm{Cd}_{0.92} \mathrm{Zn}_{0.08} \mathrm{Te}$ :In. 

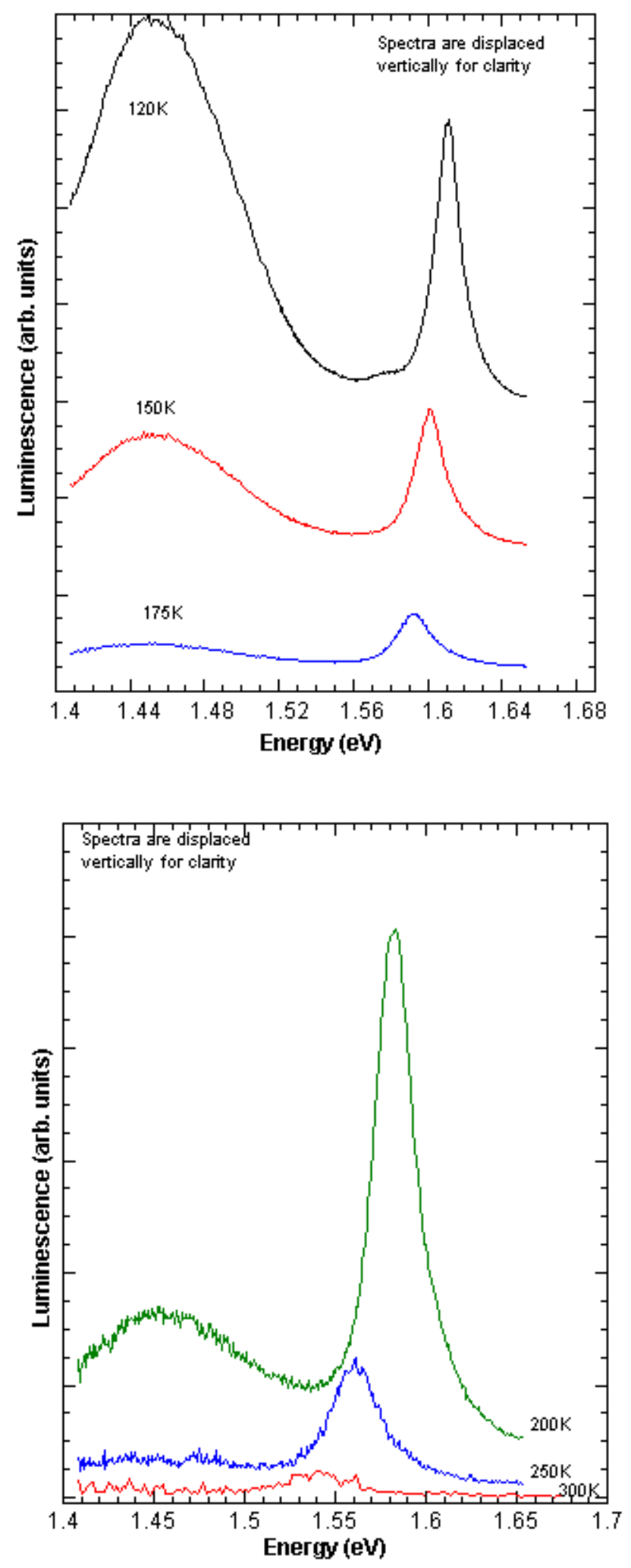

Figure 4.14: Temperature-dependence plot from 120 to $300 \mathrm{~K}$ from $\mathrm{Cd}_{0.92} \mathrm{Zn}_{0.08} \mathrm{Te}: \mathrm{In}$. 


\subsubsection{Study of the Variation of Energy Band Gap with Temperature}

Three relations for the variation of the energy gap $\left(E_{g}\right)$ with temperature in semiconductors have been proposed:

$$
\begin{aligned}
& \mathbf{E}_{\mathrm{g}}=\mathbf{E}_{\mathbf{0}}-\alpha \mathbf{T}^{2} /(\mathbf{T}+\beta) \quad \text { where } \alpha \text { and } \beta \text { are constants (Varshni 1967) } \\
& \mathbf{E}_{\mathbf{g}}=\mathbf{E}_{\mathbf{0}}-\left(\alpha \mathbf{T}^{2}+v\right) /(\mathbf{T}+\beta)
\end{aligned}
$$

where $\alpha, \beta$ and $\nu$ are constants [Y.P. Varshni's modification] (Varshni 1967).

$$
\mathbf{E}_{\mathrm{g}}=\mathbf{E}_{\mathbf{0}}-\alpha /\left[\exp \left(\theta_{\mathrm{E}} / \mathbf{T}\right)-1\right]
$$

The last relation, equation 4.3 was applied to $\mathrm{h}-\mathrm{GaN}$ where $\mathrm{E}_{0}=3.488 \mathrm{eV}, \alpha=0.144$ and $\theta_{\mathrm{E}}$ $=349 \mathrm{~K}($ Cody 1984) .

On a bulk $\mathrm{Cd}_{0.89} \mathrm{Zn}_{0.11} \mathrm{Te}$ undoped crystal, I conducted a temperature dependence experiment with $633-\mathrm{nm}$ source, $6.4 \mathrm{~mW}$, and $600 \mu \mathrm{m}$ spectrometer slits. Figure 4.15.a shows the upper polariton branch of the free exciton ( bandgap) vs. temperature and the curve fits using the 3 proposed expressions given above. The room-temperature $\mathrm{E}_{\mathrm{g}}$ values predicted by these curves differ by almost $20 \mathrm{meV}$. From the upper polariton $\mathrm{X}_{\mathrm{L}}$ energy at 5 $\mathrm{K}$ for this CZT sample, I could determine the approximate 5-K bandgap $\left(\mathrm{E}_{\mathrm{g}}=\mathrm{X}_{\mathrm{L}}+9.3 \mathrm{meV}\right)$ to be equal to $1.664 \mathrm{eV}$ and it is about $58 \mathrm{meV}$ higher than the known $5-\mathrm{K}$ bandgap of $\mathrm{CdTe}$ $(1.606 \mathrm{eV})$. Assuming this energy difference stays fairly constant with temperature, I could then predict the position of $X_{\mathrm{L}}$ at $300 \mathrm{~K}$ for this sample to be at $1.562 \mathrm{eV}\left(\mathrm{X}_{\mathrm{L}}=1.513 \mathrm{eV}+\right.$ $58 \mathrm{meV}-9.3 \mathrm{meV}$ ). Figure 4.15.b shows the plot using this predicted value of $\mathrm{X}_{\mathrm{L}}$ at $300-\mathrm{K}$ and then fitting the upper polariton branch vs. temperature using the 3 expressions proposed. It has been shown (Chichibu 1997) that in polar semiconductors that have optical phonon branches energetically next to the acoustic ones, fitting of the temperature variation of a bandgap using the empirical equation that assumes Einstein phonons (Fan 1951), is better 
than using the Varshni fitting, which assumes Debye phonons. My results are in agreement with this statement. The bandgap variation with temperature can then be predicted over the entire range from $5 \mathrm{~K}$ to $300 \mathrm{~K}$. The curve fitting gave a value of $\theta_{\mathrm{E}}=250 \mathrm{meV}$.

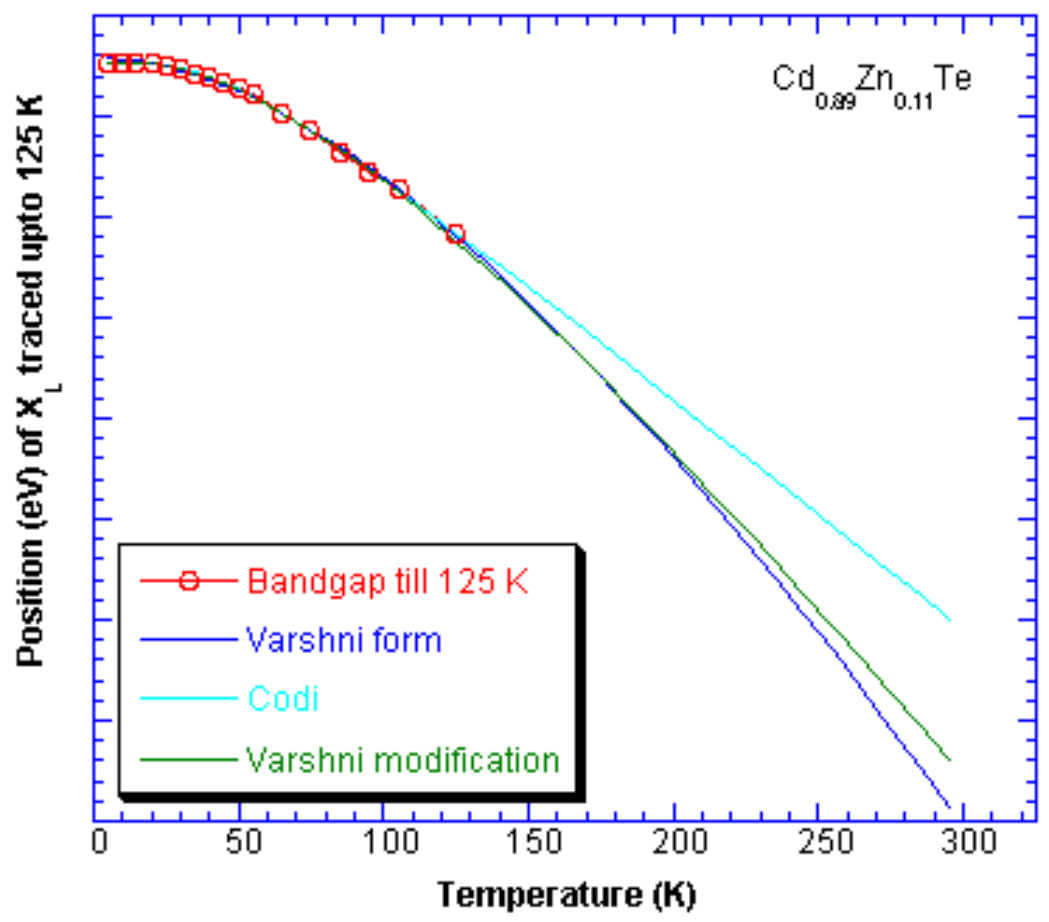

Figure 4.15.a: Longitudinal component of polariton ( free exciton energy) as a function of temperature in bulk undoped CZT. The open circles are experimental data taken by me and solid lines are the curve fits using Varshni, Codi \& Varshni's modification expressions for band gap variation with temperature. 


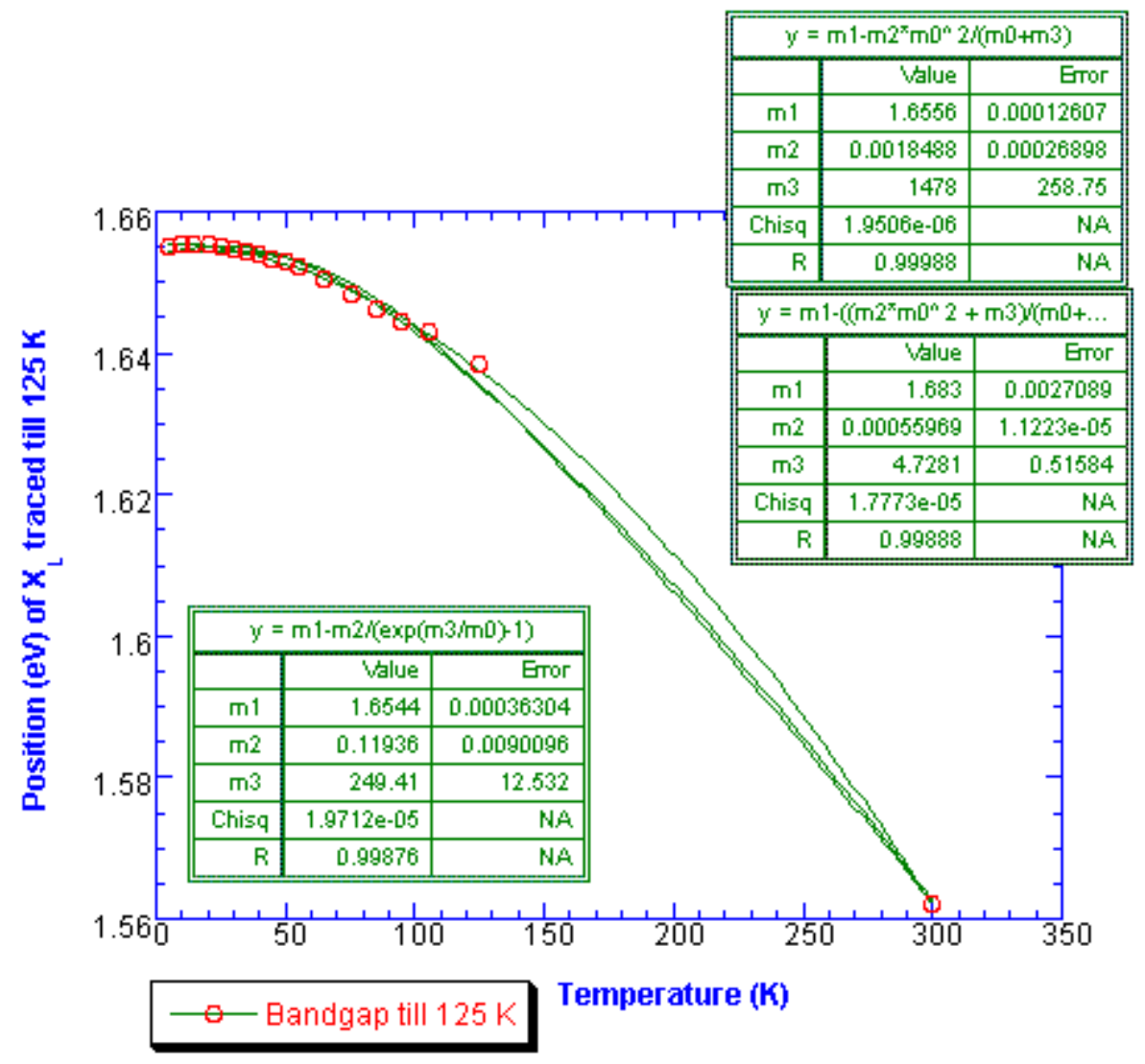

Figure 4.15.b: Position of $\mathrm{X}_{\mathrm{L}}(\mathrm{eV})$ as a function of temperature for a bulk CZT sample.

The open circles are experimental data. Also is included the predicted value of $\mathrm{X}_{\mathrm{L}}$ for this sample at $300-\mathrm{K}$. The solid lines are the curve fits using the Varshni, Codi and Varshni's modification expressions.

\subsection{Room-Temperature PL Studies of $\mathrm{Cd}_{1-\mathrm{x}} \mathrm{Zn}_{\mathrm{x}}$ Te Bulk Crystals}

Figure 4.16 shows the representative PL spectra at $300 \mathrm{~K}$ from three samples; one is a bulk CdTe (0\% zinc) which is not intentionally doped, the second is a bulk CZT (5\% zinc) intentionally doped with chlorine, and the third is a bulk CZT sample $(11 \%$ zinc, not intentionally doped). We see that the PL spectrum from CZT at room temperature is composed of a single broad band peaking at an energy close to the band-gap energy. We also 
see that the PL signal is bright at room temperature and exhibits an asymmetric line shape.

Higher zinc concentration shifts the spectrum to higher energies.

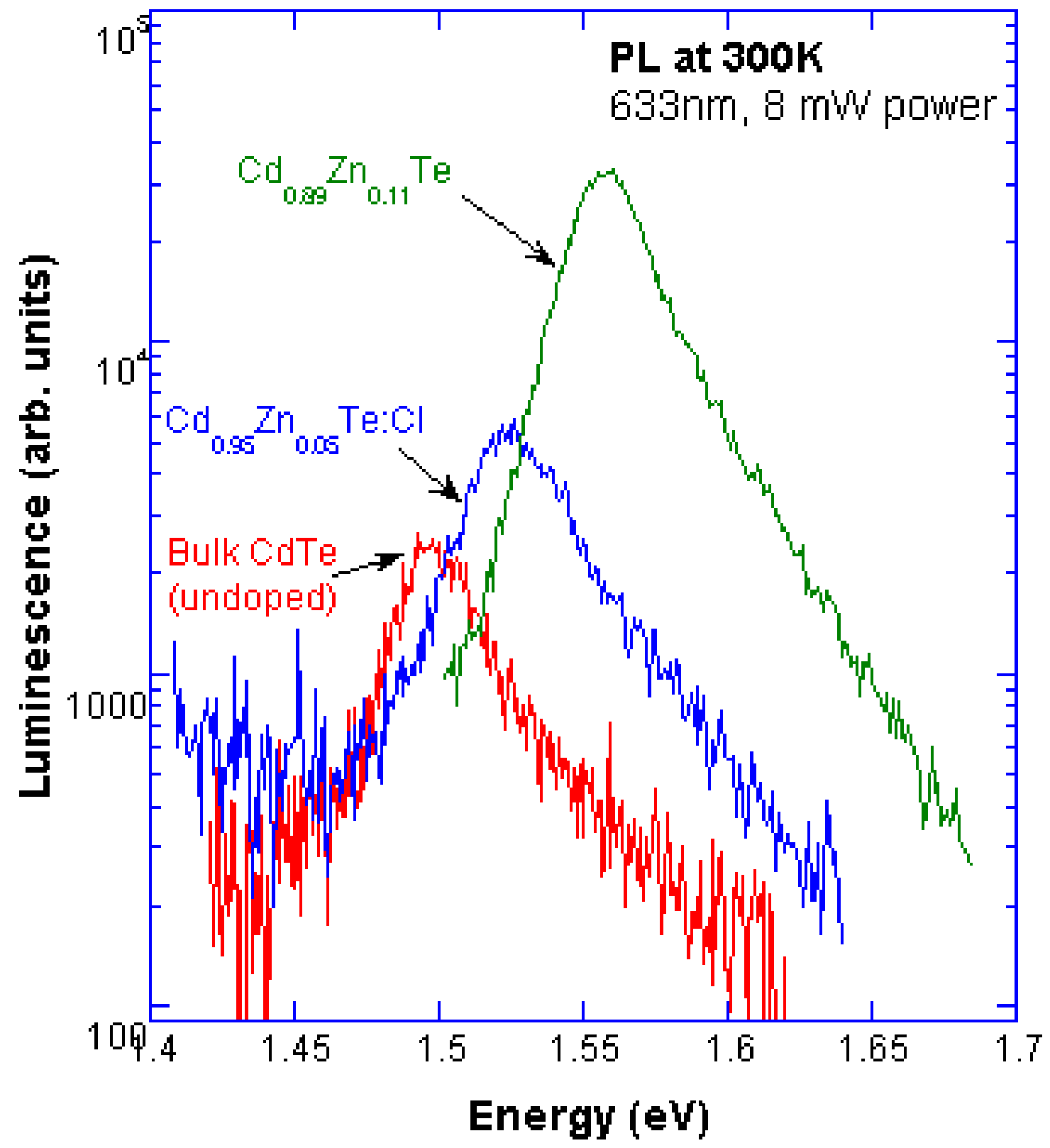

Figure 4.16: Room-temperature spectrum from three different CZT samples. 
Several physical emission processes dominate the room temperature PL (RTPL) emission including band-to-band emission, excitonic emission, and phonon-assisted excitonic emission. Free-exciton recombination is typically dominant in RTPL due to the large number of free carriers populating the valence and conduction bands. Brunett et al. (Brunett 1999) have used nonlinear curve fitting on the data to extract the individual contributions from separate physical processes. The approach of fitting room temperature PL spectra using the line shapes of band-to-band, exciton and phonon-assisted recombination has been applied with some success to CdTe (Lee 1994).

To understand the nature of room-temperature PL emission, I have chosen a set of 5 different bulk samples: Sample A is undoped CdTe (0\% zinc), Sample B is $\mathrm{Cd}_{0.95} \mathrm{Zn}_{0.05} \mathrm{Te}: \mathrm{Cl}$ (dopant concentration is $5 \times 10^{18} \mathrm{~cm}^{-3}$ ), Sample $\mathrm{C}$ is $\mathrm{Cd}_{0.92} \mathrm{Zn}_{0.08} \mathrm{Te}$ :In from IMARAD (dopant concentration is $1.8 \times 10^{17} \mathrm{~cm}^{-3}$ ), Sample $\mathrm{D}$ is $\mathrm{Cd}_{0.95} \mathrm{Zn}_{0.05} \mathrm{Te}$ (undoped, with bright shallow neutral $\left(\mathrm{A}^{0}, \mathrm{X}\right)$ feature at $5 \mathrm{~K}$ ), and Sample $\mathrm{E}$ is $\mathrm{Cd}_{0.89} \mathrm{Zn}_{0.11} \mathrm{Te}$ (undoped, and did not have a bright $\left(\mathrm{A}^{0}, \mathrm{X}\right)$ feature as seen in Sample D). The five samples had quite different PL features at low temperature, and the purpose of these additional measurements was to determine whether the room-temperature PL from these samples would be different. As seen in the previous section, only one broad band remains at $300 \mathrm{~K}$. In order to determine the nature of the 300-K PL from donor-doped material, the relative position of the PL from the bandgap must be considered. To predict the bandgap at $300 \mathrm{~K}$, I found the difference in the energy value of the bandgap at $5 \mathrm{~K}$ for that sample (determined from the low temperature PL spectra) from the bandgap for CdTe at $5 \mathrm{~K}$. Then, I assume that the energy difference remains fairly constant with temperature and I add that difference to the known bandgap of CdTe at $300 \mathrm{~K}$ which is $1.513 \mathrm{eV}$. Results are shown in Table 4.3. 
Table 4.3: Positions of the broad PL emission below the predicted band gap at $300 \mathrm{~K}$ for various samples.

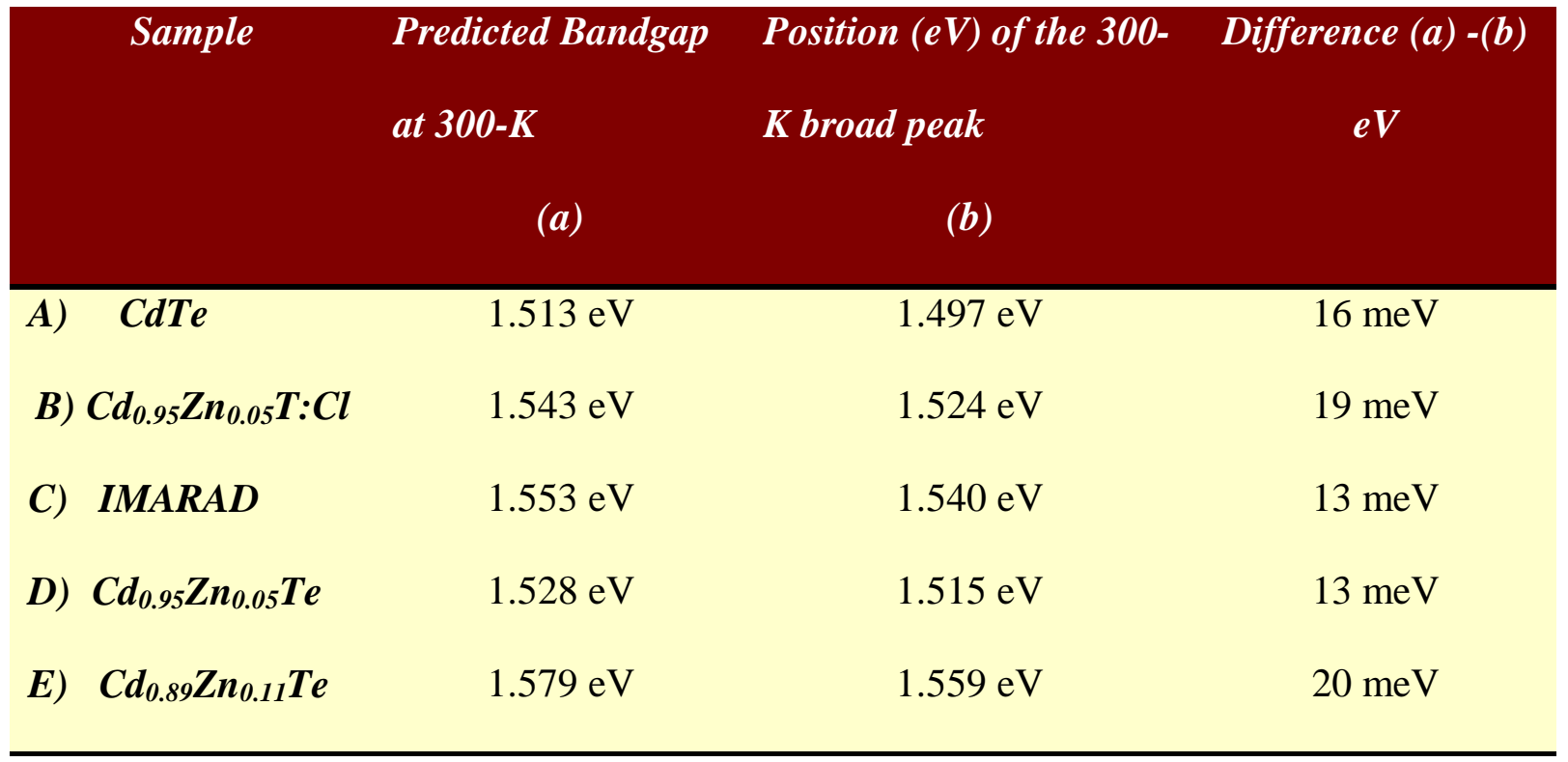

We see from Table 4.3 that the peak positions of the broad PL at $300 \mathrm{~K}$ from undoped CdTe and CZT can be in the range from 13 to $20 \mathrm{meV}$ below $\mathrm{E}_{\mathrm{g}}$. In these undoped samples, it was clear that the donor-related PL quenches and merges with the phonon replica of the polariton as the sample temperature is increased. Sample B (doped with $\mathrm{Cl}$ ) and Sample C (doped with In) fall in the same "energy-difference window" below its bandgap at roomtemperature as that for the undoped samples. Although there still remains a possibility of contributions arising from $\left(\mathrm{D}^{0}, \mathrm{~h}\right)$ transitions to the room-temperature PL in at least the donor doped materials, my experimental data supports that the nature of PL emission at $300 \mathrm{~K}$ is highly excitonic, with the main contribution arising from phonon-assisted excitonic emissions. 


\section{CHAPTER 5}

\section{PHOTOLUMINESCENCE FROM INDIUM-DOPED CdTe}

One of the principal problems that has hindered the use of II-VI compounds in device applications has been the tendency for these materials to self-compensate, yielding high resistivity as-grown material since an increase of dopants often causes a decrease of the freecarrier concentration. For example, Indium (In), a donor when sitting on a Group II site, is often intentionally introduced into cadmium telluride $(\mathrm{CdTe})$ for the purpose of compensating native defects and producing semi-insulating materials. Usually such selfcompensation effects are attributed to defect complexes consisting of chemical dopants in conjunction with vacancies.

This chapter describes a detailed near-edge PL study of bulk In-doped CdTe, which often has high resistivity as mentioned above. The sample was chemi-mechanically polished with a $2 \%$ Bromine and ethylene glycol solution as removing the surface layers restores the sharpness and intensity of the PL emission lines [An unusual property of CdTe is that its luminescence may degrade with time (Monemar 1986)]. PL spectra were taken using the 514-nm output from an argon ion laser as an excitation source and $5 \mathrm{~mW}$ of power. Measurements were done in the temperature range from $4.5 \mathrm{~K}$ to $125 \mathrm{~K}$. The low-temperature $\mathrm{PL}$ spectra from bulk CdTe:In shows a near-edge region dominated by a bound exciton line at $1.584 \mathrm{eV}$. It is believed that the appearance of the recombination peak at $1.584 \mathrm{eV}$ in the lowtemperature PL spectra is a signature of insulating CdTe:In.

Previous studies of the low temperature PL spectra from CdTe:In observed this line at about $1.584 \mathrm{eV}$ in high-resistivity bulk crystals (Barnes 1975, Giles 1988) and in MBE materials (Fong 1986, Giles 1987) and attributed it to an exciton bound to an In-related 
complex center (Barnes 1975, Fong 1986, Bassani 1991). An alternative explanation for this $1.584 \mathrm{eV}$ line was a $\left(\mathrm{D}^{0}, \mathrm{~h}\right)$ transition (Giles 1988) based on the excitation PL spectrum that showed that the free exciton energy was a competing radiative recombination channel. In order to determine the symmetry and internal structure of the defect responsible for the 1.584-eV line in CdTe:In, techniques such as magnetoluminescence spectroscopy and optically detected magnetic resonance (ODMR) would be useful. These have been applied to indium-doped CdTe, as reviewed next.

Zimmermann et al. (Zimmermann 1994) reported that the $1.584-\mathrm{eV}$ line (referred to as the $\mathrm{W}$ line) appears after a heat treatment in a Te atmosphere, accompanied by a decrease in the $\left(\mathrm{D}^{0}, \mathrm{X}\right)$ emission. They measured the Zeeman pattern of the $\mathrm{W}$ line, including its dependence on the directions of magnetic field and polarization. Their PL data showed that this line originates from the annihilation of a two-particle bound exciton localized at trigonal complexes with symmetry axes parallel to the [111] directions. By analyzing the level splitting and relative transition probabilities on the basis of a standard spin Hamiltonian, they found that the trigonal impurity potential is due to a 'tensional' lattice deformation. Together with the magnitude of the diamagnetic shift, the Zeeman spectra showed that the electron orbitals in the bound excitons are rather extended and the hole orbitals are rather localized. $\mathrm{In}_{\mathrm{i}}-\mathrm{V}_{\mathrm{Cd}}, \mathrm{In}_{\mathrm{i}}-\mathrm{A}_{\mathrm{Cd}}$, or $\mathrm{In}_{\mathrm{i}}-3 \mathrm{~A}_{\mathrm{Cd}}$ complexes (A being small-size acceptor impurities such as Li or $\mathrm{Na}$ ) were considered to be the most probable candidates for the centers giving rise to the $\mathrm{W}$ line. Worschech et al. (Worschech 1995) reported a more detailed study of the center responsible for the bound exciton line at $1.584 \mathrm{eV}$ (referred to as the $\mathrm{C}$ line). They used magnetoluminescence spectroscopy to determine Zeeman-split energy levels of the exciton and were able to resolve up to 28 magnetic subcomponents in the PL spectra of the C line. 
Anisotropy of the observed Zeeman splitting led them to propose that the $1.584 \mathrm{eV}$ line is connected with an exciton bound to an isoelectronic defect consisting of two In atoms on Cd sites and a Cd vacancy. This strain-inducing complex has a tetrahedral structure and involves three nearest neighbors in a (111) plane; that is, two In atoms at $\mathrm{Cd}$ sites and an adjacent $\mathrm{Cd}$ vacancy. The nearest $\mathrm{Cd}$ atom in the [111] direction is tilted by $2^{\circ}$. $\mathrm{A}$ consequence of this model is that the defect associated with the 1.584-eV line is not an Acenter-like $\mathrm{D}_{\mathrm{Cd}}-\mathrm{V}_{\mathrm{Cd}}$ complex ( $\mathrm{D}$ is a donor on a cadmium site like aluminum or indium). The A center leads to a tetragonal symmetry as shown by recent ODMR measurements by Stadler et al. (Stadler 1994).

\subsection{Photoluminescence Studies at Liquid-Helium Temperatures}

A representative low-temperature PL spectrum displaying detected recombination features in the near-edge emission range of 1.4 -1.6 eV from the bulk CdTe:In is shown in Fig. 5.1. The main features are: 1) a dominant emission line at $1.584 \mathrm{eV}$ (W or the $\mathrm{C}$ line) accompanied by a lower-energy side-band at $1.580 \mathrm{eV} ; 2)$ a $\left(\mathrm{D}^{0}, \mathrm{X}\right)$ recombination at 1.593 $\mathrm{eV}$; 3) the lower and upper polariton branches of the free exciton at $1.595 \mathrm{eV}$ and $1.597 \mathrm{eV}$, respectively; 4) the first, second and third LO phonon replicas of the W line (labeled as W$\mathrm{nLO} ; \mathrm{n}=1,2,3)$ and of the lower-energy side band; and 5) a DAP recombination band. We

note that the $\mathrm{W}$ line occurs in the spectral region associated with the $\left(\mathrm{A}^{0}, \mathrm{X}\right)$ emissions in CdTe. The low amplitude DAP defect band emission is seen centered at about $1.437 \mathrm{eV}$. The zero-phonon recombination occurs at about $1.478 \mathrm{eV}$. Three orders of phonon replicas are seen in Fig. 1 from $1.458 \mathrm{eV}$ to $1.417 \mathrm{eV}$. I note that the earlier PL study of a high-resistivity 


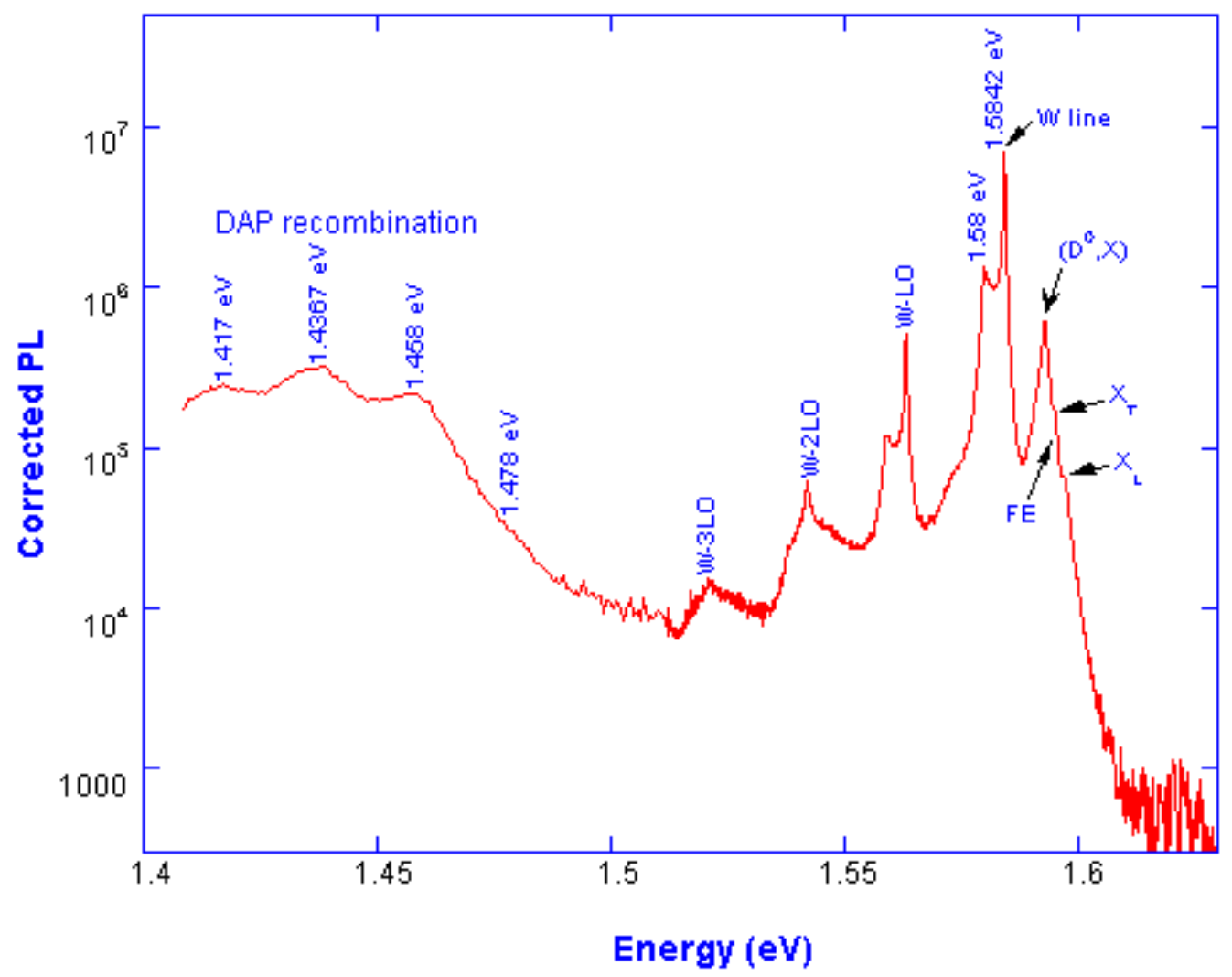

Figure 5.1: PL spectrum for CdTe:In at $4.5 \mathrm{~K}$ using $514 \mathrm{~nm}$ source, power $5 \mathrm{~mW}$, slits 200 micron slits.

bulk CdTe:In assigned the zero-phonon emission of the deep level band to be at $1.454 \mathrm{eV}$ (Barnes 1975, Giles 1988). The origin of the emission band has been speculated to involve stable complexes of In-donor atoms and $V_{C d}$ (Barnes 1975, Norris 1982, Zanio 1978) which serve to compensate the donor atoms in the material. However, a study of the effects of heat treatments on 77 K-PL spectra concluded that no supporting evidence could be offered for the $\mathrm{V}_{\mathrm{Cd}}-\mathrm{In}_{\mathrm{Cd}}$ complex being responsible for the $1.4 \mathrm{eV}$ emission band (Norris 1982). Thus, the origin of the $1.4 \mathrm{eV}$ emission band in CdTe:In is still unresolved. Fig. 5.2 shows the energy positions of the various PL emission lines observed in the spectra from bulk CdTe:In 
in comparison with undoped bulk CdTe (used as a reference sample in the lab for many years). At energies immediately above the $\mathrm{W}$ line, emissions at $1.593 \mathrm{eV}, 1.594 \mathrm{eV}, 1.595 \mathrm{eV}$ and $1.597 \mathrm{eV}$ are recorded. The nature of the line at $1.593 \mathrm{eV}$ indicated as $\mathrm{D}_{1}{ }^{1}$ in Fig. 5.3 (referred to as TET lines (Francou 1990) and labeled as $\left.\mathrm{D}^{\mathrm{n}}{ }_{2,3,4 . \ldots}\right)$ is believed to be a $\left(\mathrm{D}^{0}, \mathrm{X}\right)$ recombination (transition of the ground state of the complex $\left(\mathrm{D}^{0}, \mathrm{X}\right)$ to the ground state of the neutral donor, the donor being Indium). This identification is made from the spectral position of the emission peak from the free exciton position. The binding energy of the free exciton to this indium donor level is $\varepsilon_{\mathrm{B}}=2.6 \mathrm{meV}$. The line at $1.594 \mathrm{eV}$ indicated as $\mathrm{D}_{1}{ }^{2}$ refers to an excited initial state of the complex. The lines at $1.583 \mathrm{eV}$ and $1.581 \mathrm{eV}$ observed in the bulk undoped CdTe sample refer to the transitions from the various initial states to excited states of the neutral donor. These transitions are replica of the $\mathrm{D}_{1}{ }^{\mathrm{n}}$ transitions. The shift $D_{1}{ }^{n}-D_{2}{ }^{n}$ gives directly the $1 \mathrm{~s}-2 \mathrm{~s}$ energy difference, in this case being $10.1 \mathrm{meV}$. PL emissions at $1.595 \mathrm{eV}$ and $1.597 \mathrm{eV}$ represent the transverse $\left(\mathrm{X}_{\mathrm{T}}\right)$ and longitudinal $\left(\mathrm{X}_{\mathrm{L}}\right)$ polariton branches of the free exciton recombination. The presence of these lines indicates that the crystal is of good quality. The dip between the polariton branches in CdTe:In is not as prominent as in undoped CdTe but an average of the two polariton branch energies gives a free-exciton transition energy at $1.596 \mathrm{eV}$ which agrees very well with the predicted theoretical value for undoped CdTe. Also Fig. 5.2 clearly shows the LO phonon replicas of the $\mathrm{W}$ line in CdTe:In and of the $\left(\mathrm{A}^{0}, \mathrm{X}\right)$ and $\mathrm{X}_{\mathrm{L}}$ branch of the free exciton in undoped bulk CdTe. 


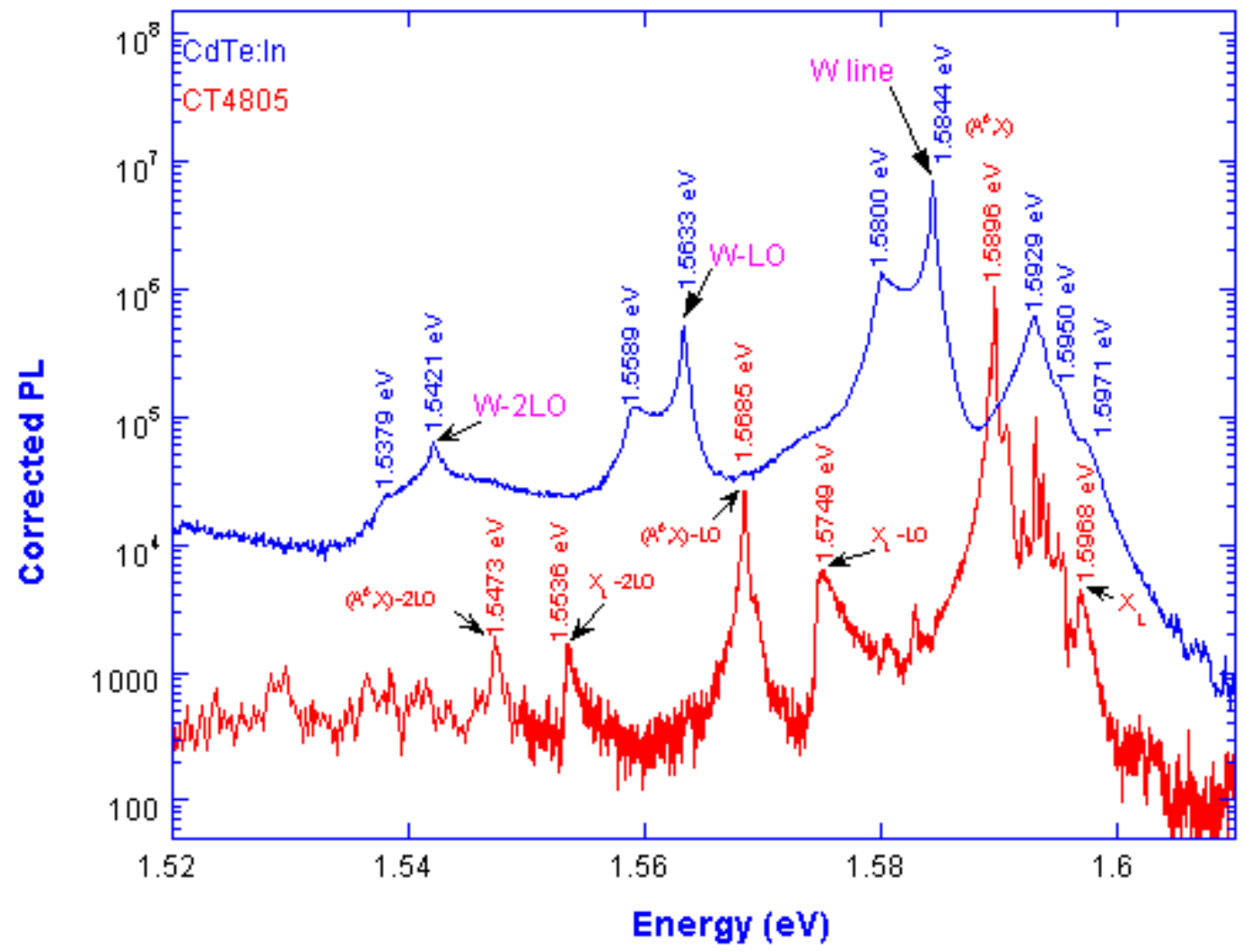

Figure 5.2: Comparison of PL Spectra of CdTe (undoped) and CdTe:In (doped) at $4.5 \mathrm{~K}$ showing phonon replicas.

We get the first LO phonon sideband of an emission line when part of the electronic energy is absorbed by one phonon. The emitted photon is displaced to lower energy by the 21.3-meV LO phonon energy. Higher-order LO phonon replicas occur when more than one phonon is involved. The lines at $1.563 \mathrm{eV}$ and $1.542 \mathrm{eV}$ in Fig. 5.2 are the first- and secondLO phonon replicas of the $\mathrm{W}$ line. The energy separation between the $\mathrm{W}$ line and its first 


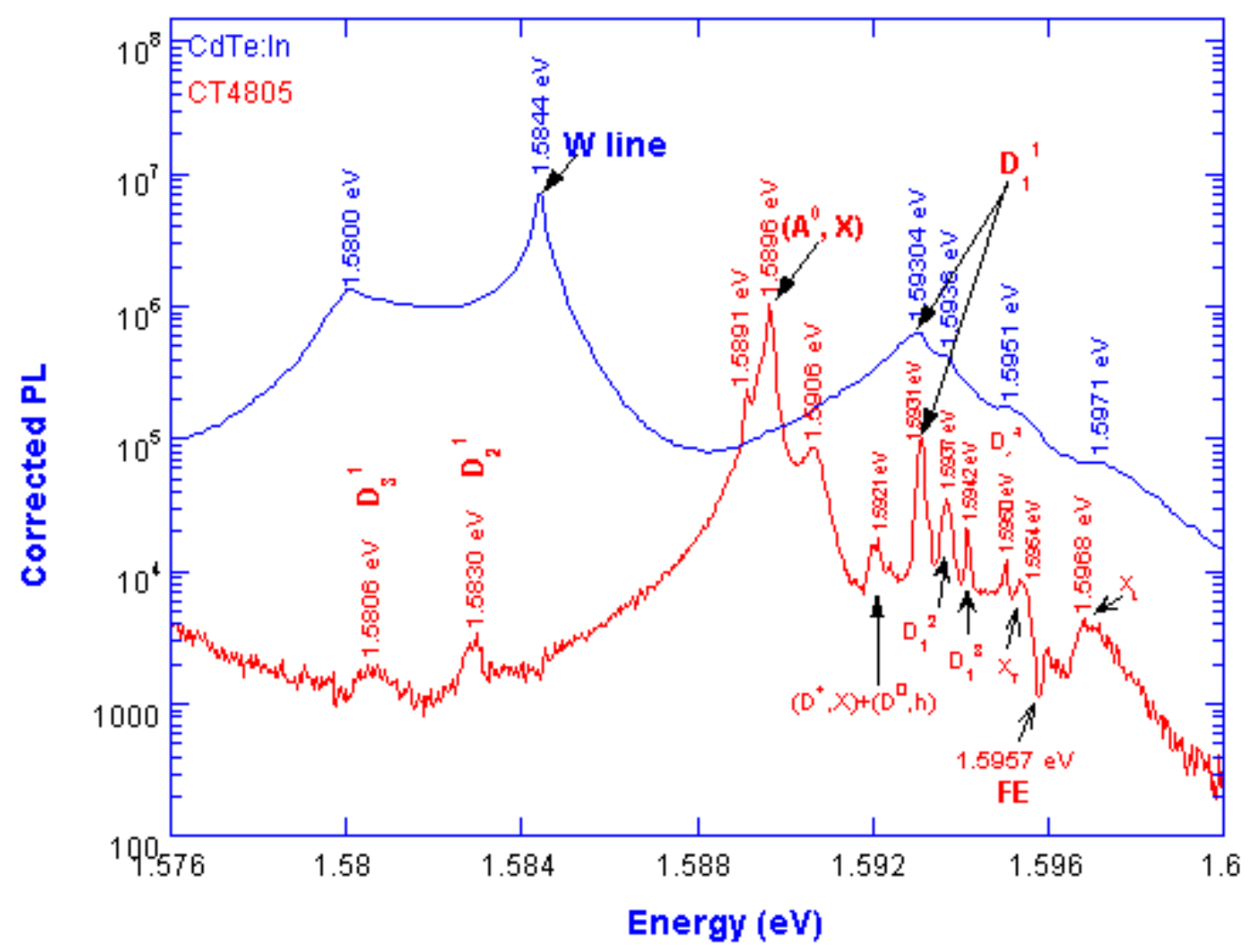

Figure 5.3: PL Spectra of bulk undoped CdTe and bulk doped CdTe:In at $4.5 \mathrm{~K}$, comparing donor features.

phonon replica is $\sim 21 \mathrm{meV}$, and the second LO phonon sideband is displaced an additional $21 \mathrm{meV}$ from the first phonon replica. We can also see the first- and second-LO phonon replicas of the $1.580-\mathrm{eV}$ line at $1.558 \mathrm{eV}$ and $1.538 \mathrm{eV}$. 


\subsection{Temperature-Dependent Photoluminescence Studies}

The behavior of the bound-exciton emission intensity with temperature gives information about defect activation energies and phonon coupling. Figures 5.4.a and 5.4.b show the temperature-dependence data from $10 \mathrm{~K}$ to $125 \mathrm{~K}$ for the $\mathrm{W}$ line. The intensity of the $\mathrm{W}$ line decreases with temperature and after $50 \mathrm{~K}$ is too weak to be detected. The intensity of the phonon sideband at $1.580 \mathrm{eV}$ becomes too weak after $30 \mathrm{~K}$ to observe. We are able to see the upper polariton branch up to $75 \mathrm{~K}$. The broad emission band observed above $75 \mathrm{~K}$ is a superposition of donor-hole and polariton emissions. Fig. 5.4.c, shows a comparison of 125-K PL from undoped CdTe with CdTe:In. In undoped material, which had very few donors, the emission is two bands. The higher energy band is the upper polariton and the other band is the superposition of donor-hole and X-LO phonon replicas (as described in Ch. 4). In CdTe:In, the emission at $125 \mathrm{~K}$ shows a larger relative influence of donor-related emission. The PL peak from the CdTe:In is $7 \mathrm{meV}$ higher than that of the undoped CdTe.

In Figure 5.5, I have plotted the intensity of the W-line vs. 1/T from $4.5 \mathrm{~K}$ to $40 \mathrm{~K}$. I observe a lowering in the $\mathrm{W}$-line intensity for the temperature range between $4.5 \mathrm{~K}$ and $40 \mathrm{~K}$. Worschech et al. (Worschech 1995) have shown a similar behavior of the W-line intensity with temperature. If the vibration energy due to the increase in temperature is in the range of the acoustical-phonon energies, then the coupling of the electronic transition to low-energy acoustic phonons will be the dominating quenching effect of the $\mathrm{W}$-line luminescence. Worschech et al. analyzed the thermal quenching of the W-line intensity using an equation (Bimberg 1971) of the form:

$$
\mathrm{I}(\mathrm{T})=\mathrm{I}_{0} /\left(1+\sum_{\mathrm{i}} \alpha_{\mathrm{i}} \exp \left(-\mathrm{E}_{\mathrm{i}} / \mathrm{KT}\right)\right)
$$


where $E_{\mathrm{i}}$ is the thermal-quenching activation energy. This quenching activation energy can often be related to the energy that is necessary to free an electron from a bound state.

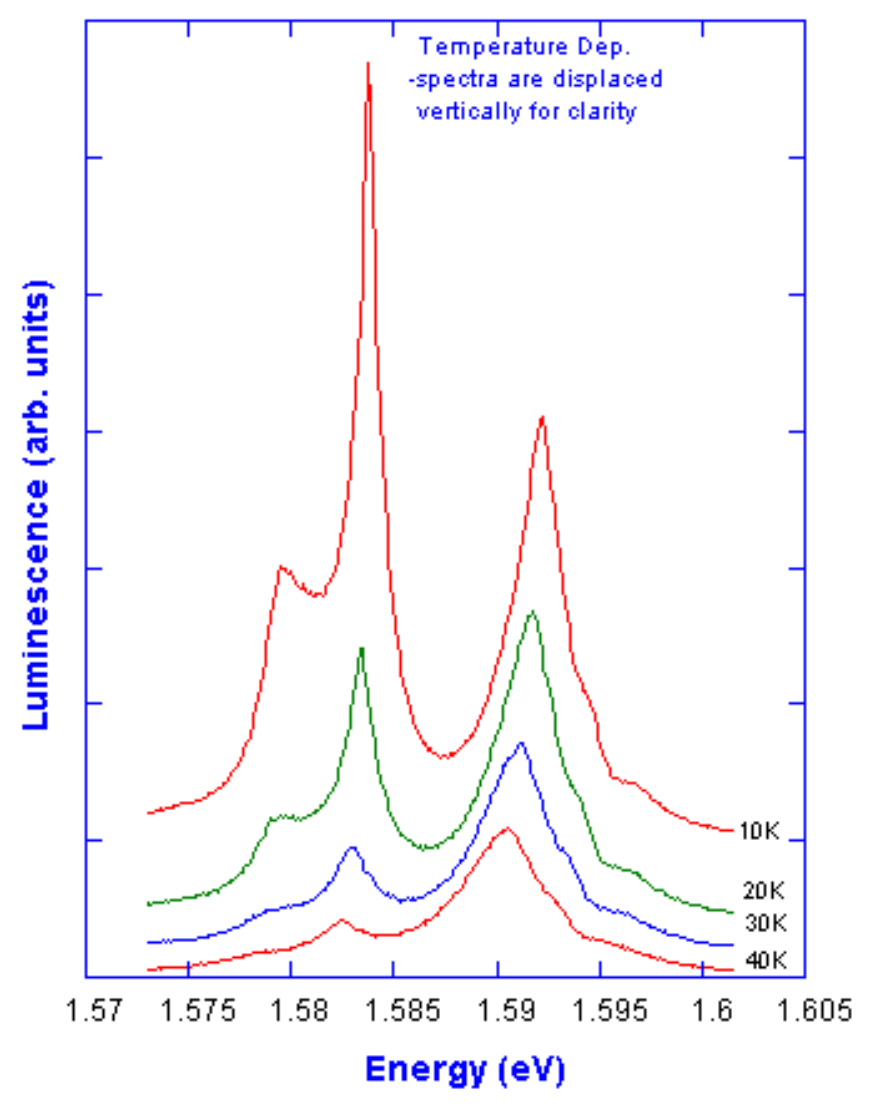

Figure 5.4.a: Plot showing thermal quenching of the $\mathrm{W}$ line in CdTe:In using $514 \mathrm{~nm}, 5 \mathrm{~mW}$ power, 200 micron slits. 


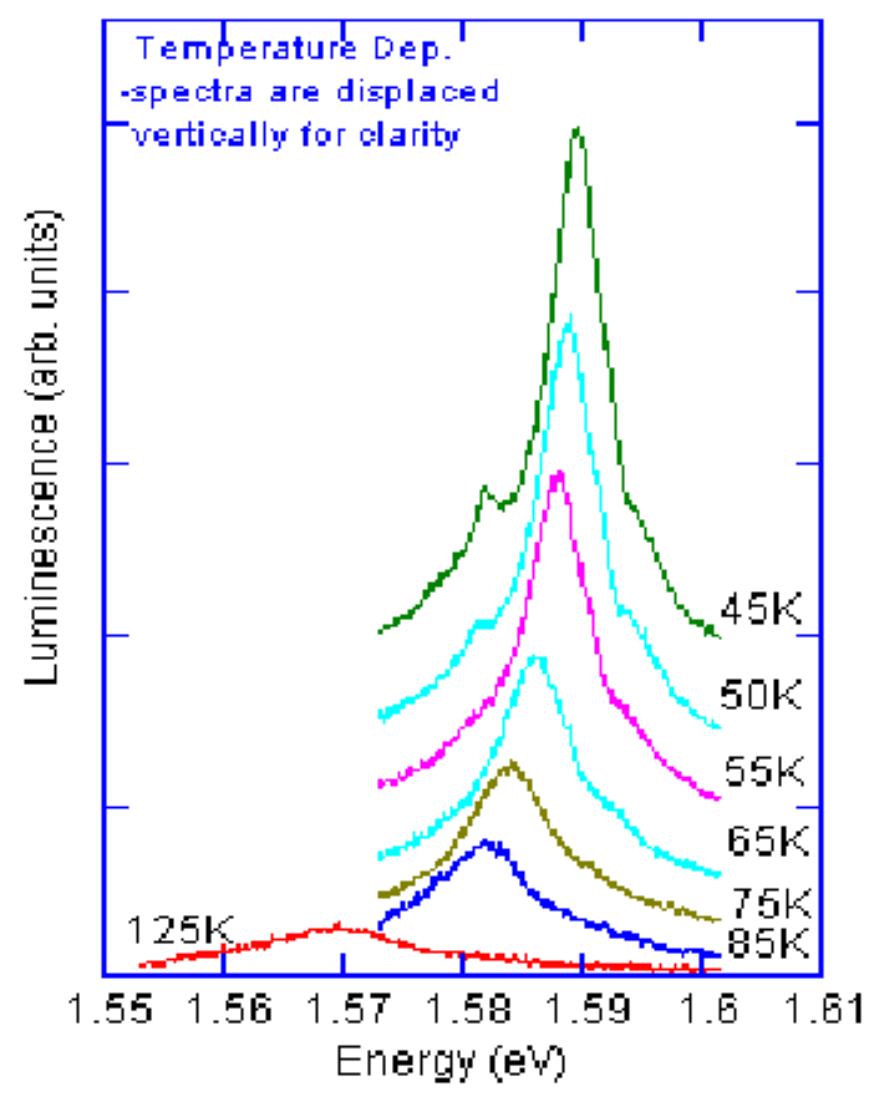

Figure 5.4.b: Temperature dependence spectra taken for CdTe:In using $514 \mathrm{~nm}, 5 \mathrm{~mW}$ power, 200 micron slits, showing the thermal quenching of $\mathrm{W}$-line in the range $45 \mathrm{~K}-125 \mathrm{~K}$. 


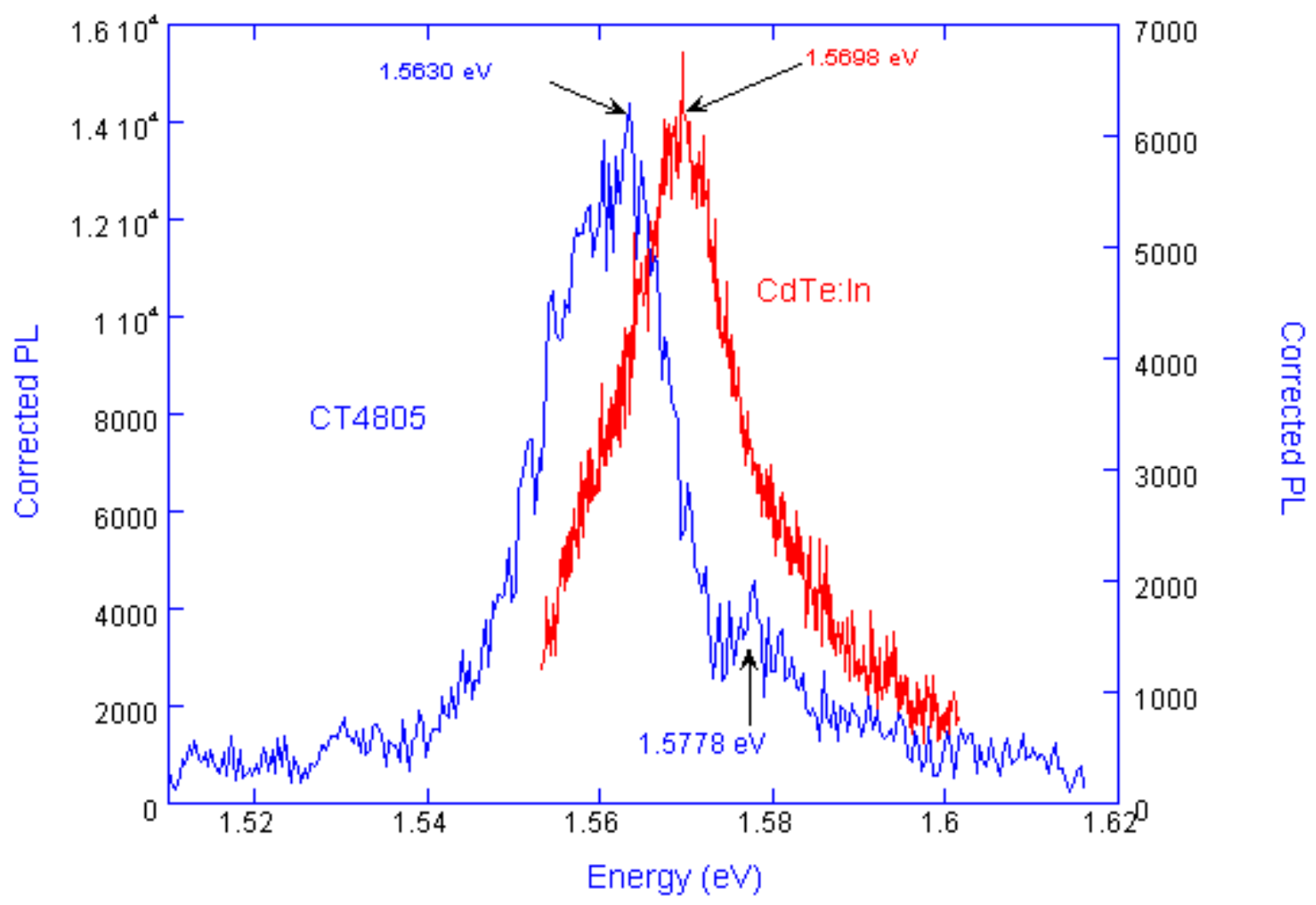

Figure 5.4.c: Temperature dependence data showing PL spectra of undoped CdTe as compared to CdTe:In at $125 \mathrm{~K}$. 


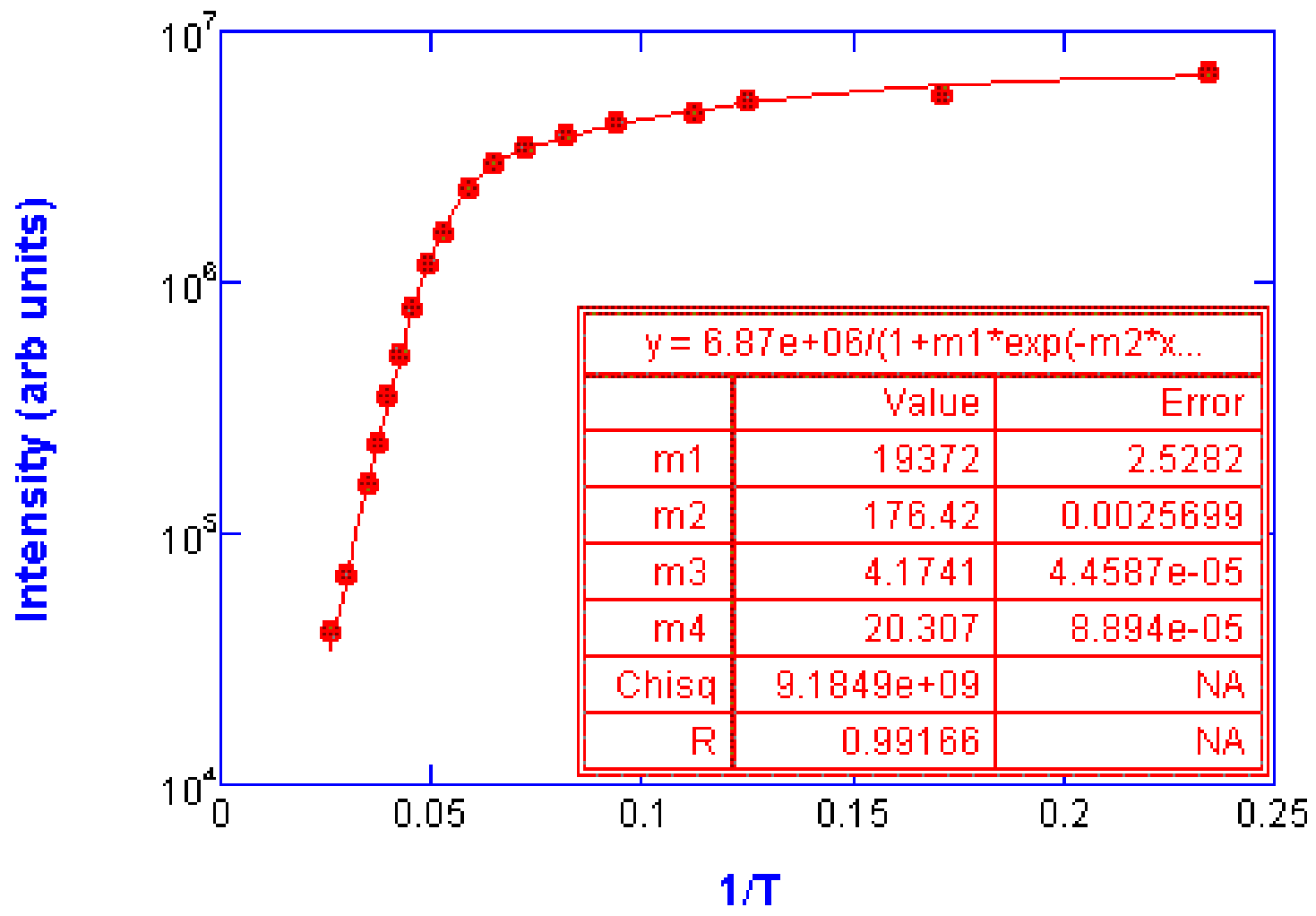

Figure 5.5: Plot showing intensity of $1.584 \mathrm{eV}$ line in bulk CdTe:In vs. 1/T. The closed circles are the data points and the solid line is a curve fit using equation 5.1. The parameters $\mathrm{m} 1$ and $\mathrm{m} 3$ are constants; $\mathrm{m} 2=\mathrm{E}_{\mathrm{T} 1} / \mathrm{k}$ and $\mathrm{m} 4=\mathrm{E}_{\mathrm{T} 2} / \mathrm{k}$ where $\mathrm{E}_{\mathrm{T} 1}$ and $\mathrm{E}_{\mathrm{T} 2}$ are the activation energies.

Worschech et al. applied the form of Eq. 5.1 to their data and obtained two activation energies with values of $7.6 \mathrm{meV}$ and $1.2 \mathrm{meV}$. They attributed the higher activation energy of $7.6 \mathrm{meV}$ to the second excited state of the bound exciton. The 1.2-meV activation energy was interpreted as a phonon energy describing the electron-phonon coupling. I have also used Eq. 5.1 to fit my data for the W-line (see Fig. 5.5). The solid line in Fig. 5.5 is the "best-fit" to 
the data (closed circles) giving two activation energies $\mathrm{E}_{\mathrm{T} 1}=15.2 \mathrm{meV}$ and $\mathrm{E}_{\mathrm{T} 2}=1.75 \mathrm{meV}$. My 15.2-meV activation energy for higher temperatures is very different from the 7.6-meV value reported by Worschech et al. The PL spectra showed by Worschech et al. contains a $\mathrm{Cu}$-related $\left(\mathrm{A}^{0}, \mathrm{X}\right)$ feature that clearly does not exist in my sample and so the value obtained in the prior work may be affected by defect-to-defect interactions. The activation energy of $15.2 \mathrm{meV}$ determined in my work may be a better measure of the thermal quenching of the $\mathrm{W}$-line in the absence of defects.

There are four different general processes proposed for the dissociation of a $\left(\mathrm{A}^{0}, \mathrm{X}\right)$ system (Bimberg 1971). Each of these processes gives a different dissociation energy value $\left(\mathrm{E}_{\mathrm{Ta}}, \mathrm{b}\right.$, c, or d) which can be compared with the measured energies $\mathrm{E}_{\mathrm{T} 1}$ and $\mathrm{E}_{\mathrm{T} 2}$. The four general processes are:

(a) Dissociation resulting in a free exciton

$$
\left(\mathrm{A}^{0}, \mathrm{X}\right) \longrightarrow \mathrm{A}^{0}+\mathrm{X}, \mathrm{E}_{\mathrm{Ta}}=\mathrm{E}\left(\mathrm{A}^{0}, \mathrm{X}\right)=\mathrm{E}_{\mathrm{B}}
$$

(b) Dissociation resulting in one free electron and one free hole:

$$
\left(\mathrm{A}^{0}, \mathrm{X}\right) \longrightarrow \mathrm{A}^{0}+\mathrm{e}+\mathrm{h}, \mathrm{E}_{\mathrm{Tb}}=\mathrm{E}_{\mathrm{B}}+\mathrm{E}_{\mathrm{X}}
$$

(c) Dissociation resulting in one free hole:

$$
\left(\mathrm{A}^{0}, \mathrm{X}\right) \longrightarrow\left(\mathrm{A}^{-}, \mathrm{X}\right)+\mathrm{h}, \mathrm{E}_{\mathrm{Tc}}=\mathrm{E}_{\mathrm{Tb}}-\mathrm{E}\left(\mathrm{A}^{0}, \mathrm{e}\right)<\mathrm{E}_{\mathrm{Tb}}
$$

(d) Dissociation resulting in two free holes and one free electron:

$$
\left(\mathrm{A}^{0}, \mathrm{X}\right) \longrightarrow \mathrm{A}^{-}+\mathrm{h}+\mathrm{h}+\mathrm{e}, \mathrm{E}_{\mathrm{Td}}=\mathrm{E}_{\mathrm{Tb}}+\mathrm{E}_{\mathrm{A}}>\mathrm{E}_{\mathrm{Tb}}
$$

As the W-line in my PL spectra is seen at $1.5844 \mathrm{eV}$, the binding energy of this bound exciton line $\mathrm{E}_{\mathrm{B}}$ is about $11.6 \mathrm{meV}$. Also, we know that the binding energy of the free exciton in CdTe is $E_{X}=10 \mathrm{meV}$. First, I consider the dissociation process (a) given above. This process predicts an activation energy $\mathrm{E}_{\mathrm{T} 1}=\mathrm{E}_{\mathrm{B}}=11.6 \mathrm{meV}$. The thermal quenching of 
the $\mathrm{W}$-line cannot result from this process since the observed value was $\mathrm{E}_{\mathrm{T} 1}=15.2$. Process (b) predicts $\mathrm{E}_{\mathrm{T} 1}=\mathrm{E}_{\mathrm{B}}+\mathrm{E}_{\mathrm{X}}=21.6 \mathrm{meV}$, but this value is much higher than the observed value of $15.2 \mathrm{meV}$. Therefore, process (b) cannot be responsible for the W-line dissociation. Process (c) applied to this case would require $\mathrm{E}_{\mathrm{T} 1}=21.6 \mathrm{meV}-\mathrm{E}\left(\mathrm{A}^{0}, \mathrm{e}\right)$. If this is a valid dissociation process for the $\mathrm{W}$ line, then $\mathrm{E}\left(\mathrm{A}^{0}, \mathrm{e}\right)$ must be equal to $6.4 \mathrm{meV}$ since $\mathrm{E}_{\mathrm{T} 1}=15.2$ meV. Process $(\mathrm{d})$ would give $\mathrm{E}_{\mathrm{T} 1}=22.6+\mathrm{E}_{\mathrm{A}}$ where $\mathrm{E}_{\mathrm{A}}$ is the acceptor ionization energy, but this yields a value which is too high compared to $15.2 \mathrm{meV}$. Thus, process (c) is the only possible explanation for the quenching of the W line in CdTe:In.

The defect model by Worschech et al., i.e. two In atoms on a $\mathrm{Cd}$ site and a cadmium vacancy, further supports that process (c) could be responsible for the quenching of the $\mathrm{W}$ line intensity. A schematic of this neutral defect complex is shown below.

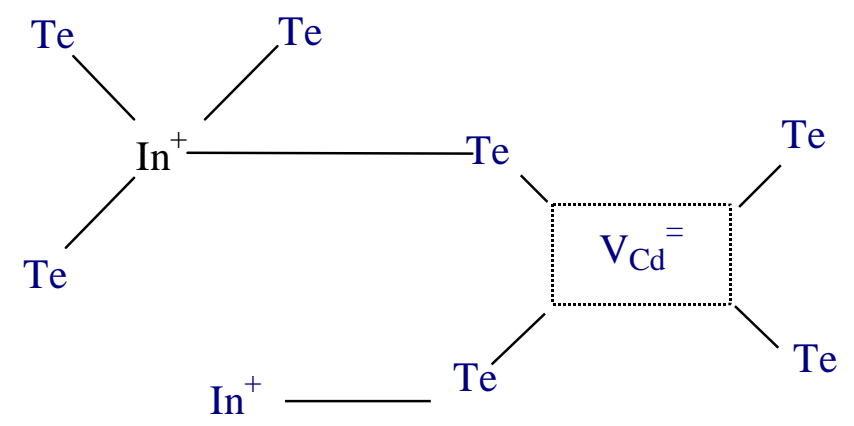

\section{Defect Model}

It is unlikely that a hole would stay localized in the vicinity of this defect. The Cd vacancy is not a hole trap. Also, a singly ionized $\mathrm{In}_{\mathrm{Cd}}$ already represents a net positive charge and would not be expected to trap a hole. On the other hand, because of the polar nature of the charge distribution within this neutral defect complex, it may be possible for an electron to be weakly localized on the $\mathrm{In}^{+}$ions. It is expected that the localization energy would be less than 
the binding energy for an electron at an isolated indium donor (e.g., $14.15 \mathrm{meV}$ ) and the 6.4$\mathrm{meV}$ value agrees with this.

The $1.580-\mathrm{eV}$ lower-energy side band to the $\mathrm{W}$ line (also referred to as a phonon sideband in the literature) exhibits a similar thermal quenching behavior. A plot of intensity vs. 1/T is shown in Fig. 5.6. A curve fitting using Eq. 5.1 gave two activation energies of $\mathrm{E}_{\mathrm{A}}$ $=15.1 \mathrm{meV}$ and $\mathrm{E}_{\mathrm{B}}=1.38 \mathrm{meV}$ respectively.

The second activation energy $\left(\mathrm{E}_{\mathrm{T} 2}\right)$ of $1.75 \mathrm{meV}$ obtained from Fig. 5.5 is interpreted as a phonon energy describing the electron-phonon coupling. Fig. 5.7 shows a plot of fullwidth-at-half-maximum vs. $\mathrm{T}$ of the $1.584-\mathrm{eV}$ line. The FWHM stays fairly constant then increases linearly with temperature above $\sim 20 \mathrm{~K}$. The slope of that linear increase is very close to the value of $\mathrm{k}$ (Boltzman constant, $8.62 \times 10^{-5} \mathrm{eV} / \mathrm{K}$ ). Note that $20 \mathrm{~K}$ corresponds to $\mathrm{kT}=1.72 \mathrm{meV}$ which agrees well with the $\mathrm{E}_{\mathrm{T} 2}$ value obtained from monitoring the thermal quenching of the intensity. Thus, both the intensity decrease and the thermal broadening of the $1.584-\mathrm{eV}$ line are consistent with the $1.7-\mathrm{meV}$ phonon interaction. 


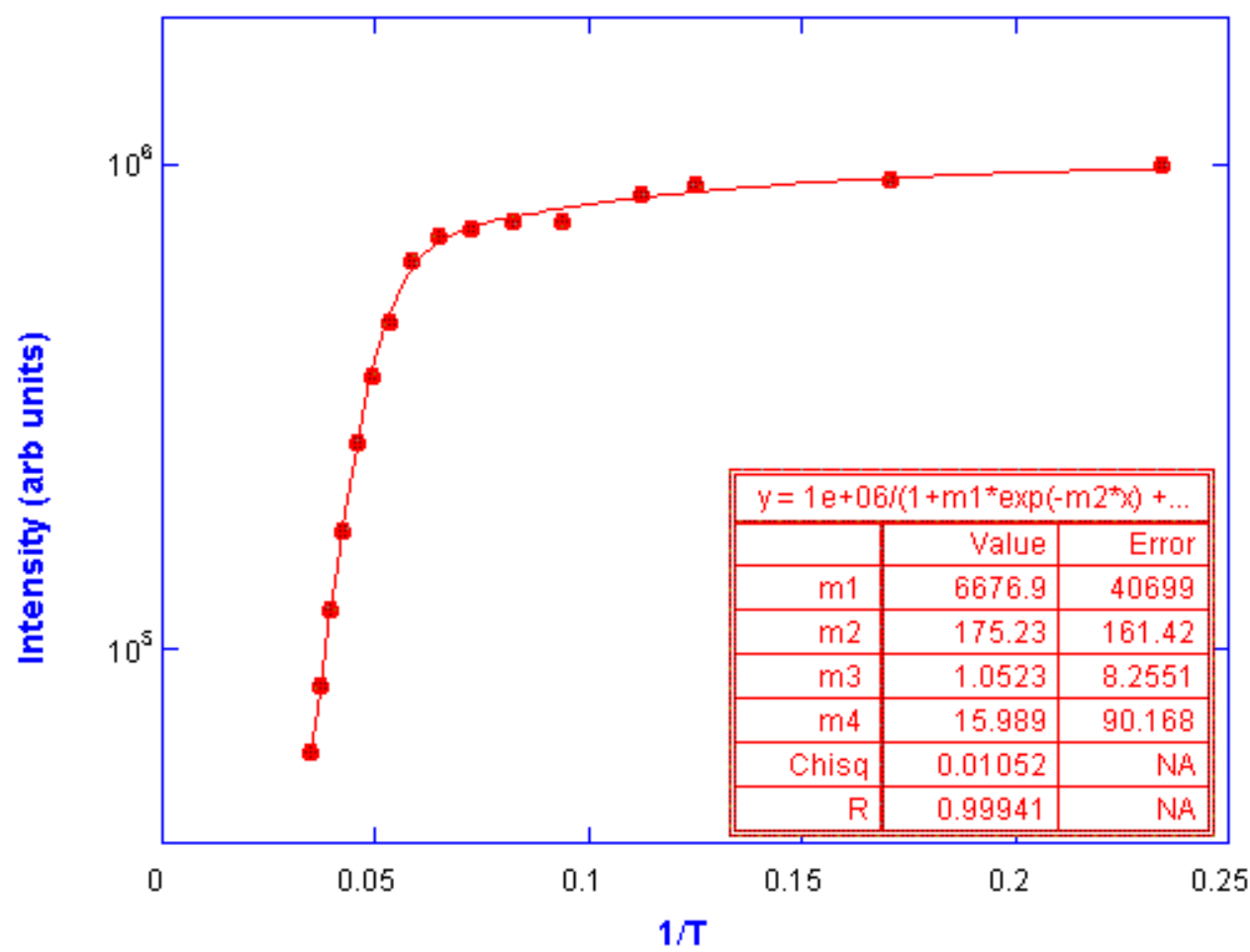

Figure 5.6: Plot showing intensity of $1.580 \mathrm{eV}$ line in bulk CdTe:In vs. 1/T. The closed circles are the data points and the solid line is a curve fit using equation 5.1. The parameters $\mathrm{m} 1$ and $\mathrm{m} 3$ are constants; $\mathrm{m} 2=\mathrm{E}_{\mathrm{T} 1} / \mathrm{k}$ and $\mathrm{m} 4=\mathrm{E}_{\mathrm{T} 2} / \mathrm{k}$ where $\mathrm{E}_{\mathrm{T} 1}$ and $\mathrm{E}_{\mathrm{T} 2}$ are the activation energies. 


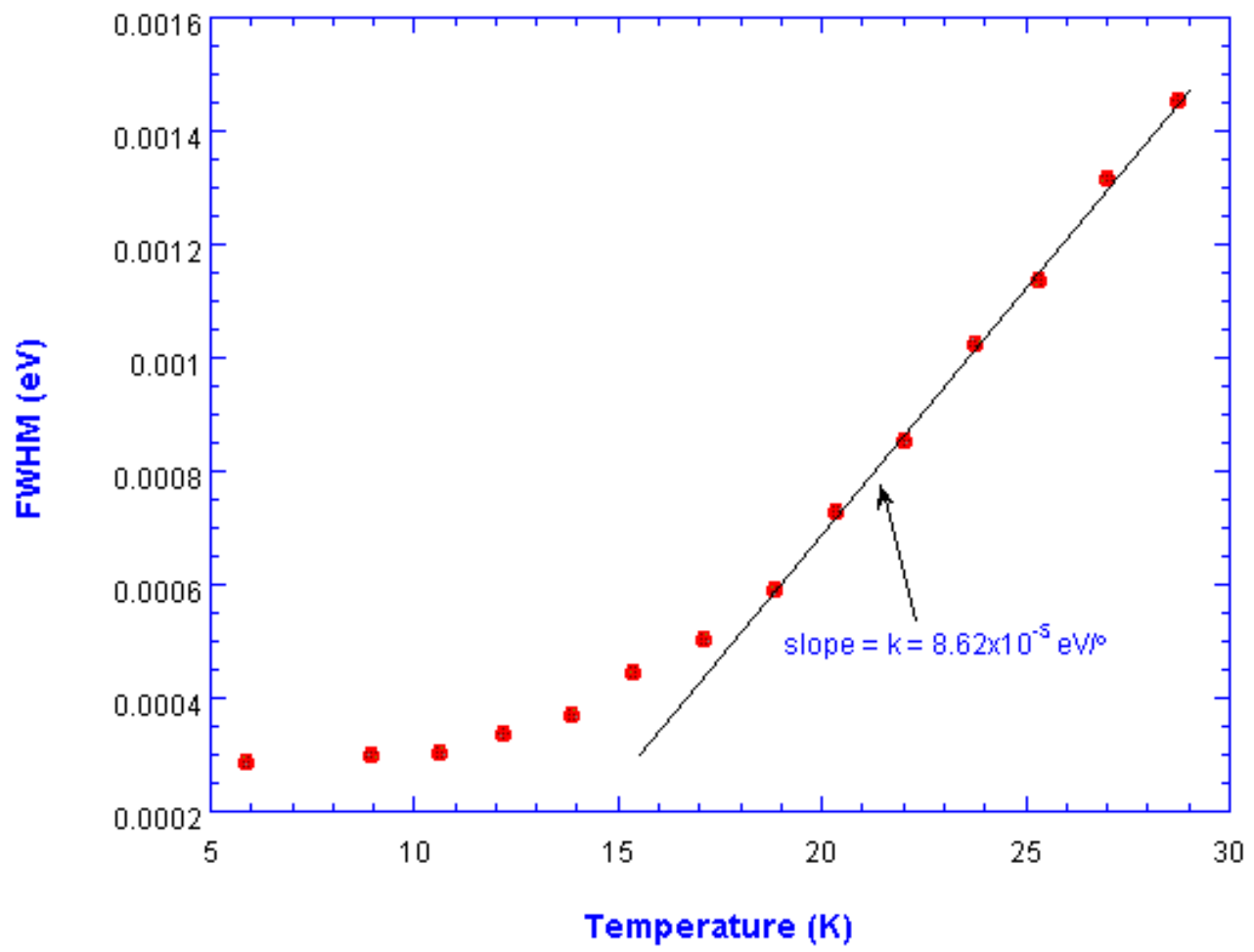

Figure 5.7: Plot showing FWHM of $1.584 \mathrm{eV}$ line in bulk CdTe:In vs. Temp. The closed circles are the data points and the solid line shows that above $\sim 20 \mathrm{~K}$, the increase in FWHM is linear with temperature and is $\sim \mathrm{kT}$. 


\section{CHAPTER 6 \\ CONCLUSIONS}

In this work, photoluminescence spectroscopy was applied to the study of $\mathrm{Cd}_{1-\mathrm{x}} \mathrm{Zn}_{\mathrm{x}} \mathrm{Te}$ alloys $(0<\mathrm{x}<0.14)$. PL data were taken from $5 \mathrm{~K}$ to $300 \mathrm{~K}$ from both doped and undoped CdZnTe bulk crystals. PL spectra at $5 \mathrm{~K}$ were used to determine $\mathrm{E}_{\mathrm{g}}$ values in the crystals. The CdZnTe samples included in this study exhibited both the upper and lower polariton branches and the $X(n=2)$ emission could also be resolved in a few cases. The temperature dependence of the PL emission from these crystals was studied to determine the nature of the PL at room temperature. The upper polariton branch could be resolved upto $125 \mathrm{~K}$. Above $125 \mathrm{~K}$, a single broad band is observed. The origin of this broad PL band is most likely due to a superposition of exciton and phonon-related recombinations. In donor-doped material, the donor-hole recombination is not believed to be dominant at $300 \mathrm{~K}$.

Zinc concentration variations among the samples shifts the emission energies making it difficult to compare features due to point defects. Various low-temperature PL spectra from different samples were compared using the energy shift below $\mathrm{E}_{\mathrm{g}}$ as the common reference. Doping with donor impurities (Al, Cl, In) produced a deep acceptor-bound exciton. The thermal quenching behavior of this line at $1.5844 \mathrm{eV}$ (referred to as $\mathrm{W}$ line or the $\mathrm{C}$ line in literature) in CdTe:In was studied and two activation energies of $15.2 \mathrm{meV}$ and $1.75 \mathrm{meV}$ were determined. 


\section{REFERENCES}

Bimberg, D., Sondergald, M., and Grobe, E., Phys. Rev. B 4, 3451 (1971).

Bebb, H. B. and Williams, E. W, Semiconductors and Semimetals, edited by R. K.

Willardson and A. C. Beer (Academic, New York, 1972), vol 8.

Barnes, C. E., and Zanio, K., J. Appl. Phys. 46, 3959 (1975).

Bassani, F., Tatarenko, S., Saminadayar, K., Bleuse, J., Magnea, N., and Pautrat, J. L., Appl. Phys. Lett. 58, 2651 (1991).

Butler, J.F., Lingren, C.L., and Doty, F.P., IEEE Transactions on Nuclear Science 39, 605 (1992).

Bruder, M., Figgemeier, H., Schmitt, R., and Maier, H., Mater. Sci. Eng. B16, 40 (1993).

Brunett, B.A., Schlesinger, T.E., Toney, J.E., and James, R.B., SPIE Vol. 3768, 348 (1999).

Chamonal, J. P., Molva, E., and Pautrat, J. L., Sol. State Commun. 43, 801 (1982).

Cody, G. D., Hydrogenated Amorphous Silicon, edited by J I. Pankov, Semiconductors and

Semimetals (Academic, New York, 1984), 21(b), Chap. 2, pp. 11-79.

Chen, Y. F., Tsai, C. S., Chang, Y. H., Chang, Y. M.,Chen, T. K., and Pang, Y. M., Appl.

Phys. Lett. 58, 493 (1991).

Chichibu, S., Okumura, H., Nakamura, S., Feuillet, G., Azuhata, T., Sota, T., and Yoshida, S., Jpn. J. Appl. Phys. 36, 1976 (1997).

Dean, P. J. and Herbert, D. C., "Bound Excitons in Semiconductors", Chap. 3 in Excitons, Topics in Current Physics, vol. 14, ed. Cho, K. (Springer-Verlag, Berlin Heidelberg, 1979).

Dean, P.J., Prog. Crystal Growth Charact. 5, 89 (1982).

Dean, P. J., Williams, G. M., and Blackmore, G., J. Phys. D: Appl. Phys. 17, 2291 (1984). 
Duncan, W.M., Koestner, R.J., Tregilgas, J.H., Liu, H.-Y., and Chen, M.-C., Mat. Res. Soc. Symp. Proc. 161, 39 (1990).

Doty, F. P., Butler, F., Schetzina, J. F., and Bowers, K. A., J. Vac. Sci. Technol. B10, 1418 (1992).

Espinosa, J. E., Gracia, J. M., Navarro, H., Zehe, A., and Triboulet, R., J. Lumin. 28, 163 (1983).

Fan, H. Y., Phys. Rev. 82, 900 (1951).

Fong, Z. C., Mascarenhas, A., and Choyke, W. J., J. Lumin. 35, 329 (1986).

Francou, J. M., Saminadayar, K., and Pautrat, J. L., Phys. Rev. B 41, 12035 (1990).

Fonthal, G., Tirado-Mejia, L., Marin-Hurtado, J. I., Ariza-Calderon, H., Mendoza-Alvarez, J. G., J. Phys. Chem. Solids 61, 579 (2000).

Franc, J., Hlidek, P., Moravec, P., Belas, E., Hoschl, P., Turjanska, L., and Varghova, R., Semicond. Sci. Technol. 15, 561 (2000).

Giles, N. C., Bicknell, R. N., and Schetzina, J. F., J. Vac. Sci. Technol. A 5, 3064 (1987).

Giles, N. C., Hwang, S., and Schetzina, J. F., McDevitt, S., and Johnson, C. J., J. Appl. Phys. 64, 2656 (1988).

Haynes, J. R., Phys. Rev. Lett. 4, 361 (1960).

Hopfield, J. J., in Proceedings of the SeventhInternational Conference on the Physics of Semiconductors, Paris, 1964 (Dunod Cie, Paris, 1964), p. 725.

Halstead, R. E. and Aven, M., Phys. Rev. Lett. 14, 64 (1965).

Hastings, J. W., J. Mol. Evol. 19, 309 (1983).

Henderson, B., and Imbusch, G. F., Optical Spectroscopy of Inorganic Solids, Clarendon Press, Oxford (1989). 
Hjelt K., Juvonen, M., Tuomi, T., Nenonen, S., Eissler, E. E., Bavdaz, M., Phys. Status Solidi (a) 162, 747 (1997).

Johnson, S. M., Sen, S., Konkel, W. H., and Kalisher, M. H., J. Vac. Sci. Technol. B 9, 1897 (1991).

Kim, Q. and Langer, D. W., Phys. Stat. Sol. (b) 122, 263 (1984).

Kennedy, J.J., Amritharaj, P.M., Boyd, P. R., Qadri, S. P., Dobbyn, R. C., and Long, G. G., J. Cryst. Growth 86, 93 (1988).

Landsberg, P. T., Recombination in Semiconductors (Cambridge University, Cambridge, 1991).

Lee, J., and Giles, N.C., Rajavel, D., and Summers, C. J., Phys. Rev. B 49, 1668 (1994).

Molva, E., Pautrat, J. L., Saminadayar, K., Milchberg, G., and Magnea, N., Phys. Rev. B 30, 3344 (1984).

Monemar, B., Molva, E., and Dang, L. S., Phys. Rev. B 33, 1134 (1986).

Murphy, J. D., SPIE 2, 659 (1986).

Magnea, N., Dal'bo, F., Pautrat, J. L., Million, A., DiCioccio and Feuillet, G., Mat. Res. Soc. Symp. Proc. 90, 455 (1987).

Madelung, O. and Schulz, M. "Intrinsic Properties of Group IV Elements and III-V, II-VI and I-VII Compounds", Landolt -Bornstein, New Series Vol. III/22a, (Springer - Verlag, New York, 1987).

Moore, C. J. L., and Miner, C. J., J. Crystal Growth 103, 21 (1990).

Mori, Y., Nakamura, M., Sakachi, Y., and Ohkura, H., J. Cryst. Growth 103, 8 (1990).

Magnea, N., and Pautrat, J. L., 1994 Properties of Narrow Gap Semiconductors vol 10, ed P. Capper (London: INSPEC, The Institution of Electrical Engineers), p 399. 
Noblanc, J. P., Loudette, J., and Duraffourg, G., J. Lumin. 1, 2, 528 (1970).

Norris, C. B. and Zanio, K. R., J. Appl. Phys. 53, 6347 (1982).

Olego, D., Cardona, M., Phys. Rev. B 22, 886 (1980).

Olego, D.J., Faurie, J. P., Sivanathan, S., and Raccah, P. M., Appl. Phys. Lett. 47, 1172 (1985).

Oettinger, K., Hofmann, D. M., Efros, A. L., Meyer, B. K., Salk, M., and Bentz, K. W., J. Appl. Phys. 71, 4523 (1992).

Pankove, J. I., "Optical Processes in Semiconductors" (Dover Publications, Inc., New York, 1975).

Reno, J. L., and Jones, E. D., Phys. Rev. B 45, 1440 (1992).

Rablau, C. I., Setzler, S. D., Halliburton, L. E., Giles, N. C., and Doty, F. P., J. Electron. Mater. 27, 813 (1998).

Sharma, R. R. and Rodriguez, Sergio, Phys. Rev. 153, 823 (1967).

Sen, S., Konkel, W. H., Tighe, S. J., Bland, L. G., Sharma, S. R., and Taylor, R. E., J. Cryst. Growth 86, 111 (1988).

Stadler, W., Meyer, B. K., Hoffman, D. M., Kowalski, B., Emanuelsson, P., Omling, P., Weigel, E., Muller-Vogt, C., and Cox, R. T., Mater. Sci. Forum 143-147, 399 (1994).

Schlesinger, T. E., James, R. B., Semiconductors for Room Temperature Nuclear Detector Applications, Semiconductors and Semimetals 43, Academic Press, Inc., 1995.

Sanchez-Almazan, F. G., Navarro-Contreras, H., Ramirez-Flores, G., Vidal, M. A., ZelayaAngel, O., Rodriguez, M. E., and Baquero, R., J. Appl. Phys. 79, 7713 (1996).

Tajima, M., J. Crystal Growth 103, 1 (1990). 
Tobin, S. P., Tower, J. P., and Norton, P. W., Chandler-Horowitz, D., and Amirtharaj, P. M., Lopes, V. C., Duncan, W. M., and Syllaios, A.J., Ard, C. K., Giles, N.C., and Jaesun Lee, Balasubramanian, R., and Bollong, A. B., Steiner, T. W., and Thewalt, M.L.W., Bowen, D.

K., Tanner B. K., J. Electron. Mater. 24, 697 (1995).

Varshni, Y. P., Physica 34, 149 (1967).

Worschech, L., Ossau, W., and Landwehr, G., Phys. Rev. B 52, 13965 (1995).

Zanio, K., "Cadmium Telluride", in Semiconductors and Semimetals, vol 13, eds. Willardson R. K., and Beer, A. C. (Academic Press, New York, 1978), p. 103.

Zimmermann, H., Boyn, R., Lehr, M. U., Schulz, H. -J., Rudolph, P., and Kornack, J. -Th., Semicond. Sci. Technol. 9, 1598 (1994). 


\section{APPENDIX A}

Calculation of Power Density from the Measured Incident Power, for the PL Setup Using U-1000 Spectrometer.

Power density $=\left[(1-\mathrm{R})^{4} \mathrm{I}_{\mathrm{inc}} \cos \theta_{\mathrm{I}}\right] / \mathrm{A}$, Power loss through the suprasil window due to reflectance from one air/dielectric interface is given by the Fresnel coefficients:

$\mathrm{R}=\left[\mathrm{R}_{\text {parallel }+} \mathrm{R}_{\perp}\right] / 2 ; \mathrm{R}_{\text {parallel }}=\mathrm{r}_{\text {parallel }}^{2} ; \mathrm{R}_{\perp}=\mathrm{r}_{\perp}^{2} ;$

$r_{\text {parallel }}=\left[n_{t} \cos \theta_{I}-n_{I} \cos \theta_{t}\right] /\left[n_{I} \cos \theta_{t}+n_{t} \cos \theta_{I}\right]$

$R_{\perp}=\left[n_{I} \cos \theta_{I}-n_{t} \cos \theta_{t}\right]\left[n_{I} \cos \theta_{I}+n_{t} \cos \theta_{t}\right]$

Refractive index, $\mathrm{n}_{\mathrm{I}}$ (air) at $633 \mathrm{~nm}=1.00026325$

[A Physicist's Desk Reference, $2^{\text {nd }}$ edition, editor H. Anderson (AIP, 1989)]

Refractive index, $\mathrm{n}_{\mathrm{t}}$ at $633 \mathrm{~nm}$ for suprasil (synthetic fused silica) window $=1.45702$

[Ref: Melles Griot Catalog, page 4.16]

$\theta_{\mathrm{I}}($ measured $)=13^{\circ}$

$\theta_{\mathrm{t}}=9^{\circ}($ Snell's law)

Diameter of spot $=0.5 \mathrm{~mm}$

[To find the diameter of spot on sample, I moved the dewar and estimated the diameter of laser spot with neutral density filter at O.D $=\log _{10}\left(\mathrm{I}_{0} / \mathrm{I}\right)=2$ on the ruler at the same distance where the sample would be], therefore,

Area $=0.196 \mathrm{~mm}^{2}$

Gives: $\mathrm{R}=0.0346$ and

Power density $=431.8 I_{\text {inc }} / \mathrm{cm}^{2}$. 